\title{
Criteria of distributive justice : an economic inquiry
}

Citation for published version (APA):

Öztürk, Z. E. (2015). Criteria of distributive justice : an economic inquiry. [Doctoral Thesis, Maastricht University]. Maastricht University. https://doi.org/10.26481/dis.20151217zo

Document status and date:

Published: 01/01/2015

DOI:

10.26481/dis.20151217zo

Document Version:

Publisher's PDF, also known as Version of record

\section{Please check the document version of this publication:}

- A submitted manuscript is the version of the article upon submission and before peer-review. There can be important differences between the submitted version and the official published version of record.

People interested in the research are advised to contact the author for the final version of the publication, or visit the DOI to the publisher's website.

- The final author version and the galley proof are versions of the publication after peer review.

- The final published version features the final layout of the paper including the volume, issue and page numbers.

Link to publication

\footnotetext{
General rights rights.

- You may freely distribute the URL identifying the publication in the public portal. please follow below link for the End User Agreement:

www.umlib.nl/taverne-license

Take down policy

If you believe that this document breaches copyright please contact us at:

repository@maastrichtuniversity.nl

providing details and we will investigate your claim.
}

Copyright and moral rights for the publications made accessible in the public portal are retained by the authors and/or other copyright owners and it is a condition of accessing publications that users recognise and abide by the legal requirements associated with these

- Users may download and print one copy of any publication from the public portal for the purpose of private study or research.

- You may not further distribute the material or use it for any profit-making activity or commercial gain

If the publication is distributed under the terms of Article $25 \mathrm{fa}$ of the Dutch Copyright Act, indicated by the "Taverne" license above, 


\title{
Criteria of Distributive Justice
}

\author{
An Economic Inquiry
}

Z. Emel Öztürk 
(C) Zeliha Emel Öztürk, Maastricht 2015

All rights reserved. No part of this publication may be reproduced in any form or by any means without the prior permission in writing from the author.

This book was typeset by the author using LATEX.

ISBN: 978-94-6182-634-3

Printed in The Netherlands by Off Page 


\title{
Criteria of Distributive Justice
}

\section{An Economic Inquiry}

\author{
Dissertation \\ to obtain the degree of Doctor at Maastricht University, \\ on the authority of the Rector Magnificus, \\ Prof. dr. L. L. G. Soete, \\ in accordance with the decision of the Board of Deans, \\ to be defended in public on Thursday 17 December 2015, at \\ $12.00 \mathrm{hrs}$ \\ by

\section{Zeliha Emel Öztürk}


Supervisor

Prof. dr. P. Jean-Jacques Herings

Co-Supervisor

Dr. Kristof Bosmans

\section{Assessment Committee}

Prof. dr. H. Peters (Chairman)

Prof. dr. M. Fleurbaey (Princeton University)

Dr. E. Ooghe (KU Leuven)

Dr. E. Tsakas 
To my parents, Hatice and Mesut. 



\section{ACKNOWLEDGEMENTS}

My deepest gratitude goes to my supervisor Kristof Bosmans. I would like to thank him for the time he spent with me in our weekly meetings and the trust he put in me while I was tutoring his courses. I am immensely grateful to him for being a perfect supervisor, co-author and friend for the last four years.

Second, I would like to thank my supervisor Jean-Jacques Herings. I am very grateful to him for making time for me whenever I needed.

I am grateful to the valuable members of my assessment committee Hans Peters, Marc Fleurbaey, Erwin Ooghe and Elias Tsakas. I would like to thank Marc Fleurbaey also for agreeing to host my research stay at Princeton University. In Princeton, I had the opportunity to discuss earlier drafts of my dissertation with him in addition to following a graduate course he was teaching at the time. The fifth chapter of this study was started when I was in Princeton, and was inspired by his teaching.

I would like to thank Bart Capéau, François Maniquet, Erwin Ooghe, Ronald Peeters, Erik Schokkaert and audiences in Maastricht University, the 11th Meeting of the Society for Social Choice and Welfare, Autonomous University of Barcelona, the 5th ECINEQ meeting and the 15th SAET Conference on Current Trends in Economics for their useful comments on earlier drafts of parts of this dissertation.

During my studies, I've enjoyed the company of many beautiful people. I would like to thank Ayşe Gül Mermer, Gülserim Özcan, Hayrullah Dindar, Selman Erol and Naime Geredeli for their irreplaceable friendship. A special thanks to Selman for his kindness to listen to my endless rants, and read my infinitely long emails and texts. I would also like to thank my aunt Dilek and 
her family Ibrahim, Gamze and Zeliha for their enormous support in my last year in Ankara.

Maastricht has been a wonderful place for me thanks to the company of Burak, Ingrid, Devrim, Özge, Hande, Seher and Birol. A special shout-out to Hande; my time in Maastricht would have been less enjoyable if it wasn't for her. I would also like to thank Aidas, Christine, Çiğdem, Elke, Hande Erkut, Mehmet, Murat, Nicole and Sylvia for making my time in Maastricht enjoyable. I thank Marlies, Wil and Roel Dormans for always being so nice and supportive.

And Dilek, Eda, Fisun, Merve and Zeliha... In our friendship of more than 10 years, they have become my second family; one I know will always be very close to the centre of my life. Being assigned to the same dormitory room with them in my first year at university was one of the best things that ever happened to me. A special thanks to Eda for showing me that life's disappointments are much easier to take when you've got a best friend.

And Bart, from my heart, I thank you for the life you're making me see. I am more grateful than words can explain for every day I get to spend with you.

Finally, my family... I'm grateful to my parents Hatice and Mesut, my brother Mutlu and my nephew Çağrı for their love and support in every stage of my journey.

Maastricht August 2015 


\section{CONTENTS}

List of Figures $\quad$ xi

List of Tables $\quad$ xiii

1 Introduction 1

2 An axiomatic approach to the measurement of envy 7

2.1 Introduction . . . . . . . . . . . . . . 7

2.2 Preliminaries .................. 9

2.3 Envy as the sum of elementary envies . . . . . . . . 13

2.4 Measuring elementary envy ............. 16

2.5 Main result and discussion ... . . . . . . . . . . 21

2.6 Concluding remark ................ 23

3 Laissez-faire versus Pareto $\quad 25$

3.1 Introduction . . . . . . . . . . . . . 25

3.2 Results.................... 26

3.3 Conclusion ................. 30

4 Measurement of equality of opportunity: a normative approach 33

4.1 Introduction . . . . . . . . . . . . . . . . 33

4.2 Preliminaries . . . . . . . . . . . . . . 37

4.3 Compensation and reward principles . . . . . . . . . . 39

4.3.1 Compensation axioms . . . . . . . . . . . . 39

4.3.2 Reward axioms . . . . . . . . . . . . . . . 41 
4.4 Results . . . . . . . . . . . . . . . . . . . . 44

4.4.1 Compensation and liberal reward . . . . . . . . 44

4.4.2 Compensation and utilitarian reward . . . . . . . . . 48

4.5 Inequality measures . . . . . . . . . . . . . . . . 50

4.6 Conclusion . . . . . . . . . . . . . . 55

Appendix 4.A . . . . . . . . . . . . . . . . 57

$5 \quad$ Fair sharing of an international river $\quad 65$

5.1 Introduction . . . . . . . . . . . . . . 65

5.2 Preliminaries . . . . . . . . . . . . . . . 67

5.3 Formalization of the principles . . . . . . . . . . . 69

5.4 Two proposals to rank allocations $\ldots \ldots \ldots$. . . . . 71

5.4.1 Generalized Lorenz preorder . . . . . . . . . . . . 71

5.4.2 Egalitarian equivalent ordering . . . . . . . . 72

5.5 Conclusion . . . . . . . . . . . . . . . 73

Appendix 5.A . . . . . . . . . . . . . 75

$\begin{array}{ll}\text { Bibliography } & 79\end{array}$

$\begin{array}{lr}\text { Nederlandse samenvatting } & 87\end{array}$

$\begin{array}{ll}\text { Valorization } & 91\end{array}$

$\begin{array}{ll}\text { Curriculum Vitae } & 97\end{array}$ 


\section{LIST OF FIGURES}

2.1 Two indifference curves of individual $i \ldots \ldots \ldots$

5.1 Calculation of $d_{i} \mathrm{~s}$. The intersection of $i$ 's indifference curve at $\left(w_{i}, t_{i}\right)$ with the line $w=r_{i}$ is $d_{i}(a) \ldots \ldots \ldots \ldots$ 



\section{LIST OF TABLES}

2.1 Five envy measures . . . . . . . . . . . . . . . 11

4.1 Overview of the results. . . . . . . . . . . . 36 



\title{
INTRODUCTION
}

\author{
"Reasoning is central to the \\ understanding of justice even in a \\ world which contains much \\ 'unreason'; indeed, it may be \\ particularly important in such a \\ world."
}

Amartya Sen

Theories of distributive justice concern the normative evaluation of a society's distribution of income, wealth or other valuable goods among its members. Since A Theory of Justice by Rawls (1971), there has been a flourishing philosophical literature on whether and under what circumstances the allocation of goods in a society can be considered just. ${ }^{1}$

In the early twentieth century, prominent economists (such as Pigou, Dalton, Hicks, Samuelson and Arrow) also focused on normative issues. However, justice is often considered outside the scope of economics nowadays. As noted by Atkinson (2001, p. 195), "Economists do not devote a great deal of time to investigating the values on which their analyses are based" since the 1960s. Yet, "It is a legitimate exercise of economic analysis to examine the consequences of various value judgments" (Samuelson, 1947, p. 220), and there is actually

\footnotetext{
${ }^{1}$ See, among others, Arneson (1989), Cohen (1989), Dworkin (1981a,b), Nozick (1974) and Sen $(1992,2011)$.
} 
an important literature in economics that addresses normative issues, namely, normative economics to which this dissertation seeks to contribute.

The next four chapters study principles of distributive justice in a variety of economic environments. In each chapter, the main goal is to provide criteria - rankings or social welfare functions - for the evaluation of distributions in terms of fairness and efficiency. ${ }^{2}$ Although we draw upon ideas found in the philosophical literature, the current study is primarily an economic inquiry in which we employ an axiomatic approach. ${ }^{3}$ In each chapter, we first postulate axioms representing the relevant principles of distributive justice. The evaluation criteria are obtained as logical consequences of these axioms. Our primary motivation in adopting an axiomatic approach is not the satisfaction we derive from the procedure itself - though the author admits to the satisfaction part - but the fact that such a procedure makes the ethical criteria underlying the welfare statements clear. Hopefully, the results presented here contribute to our knowledge of important principles of distributive justice, and provide tools for their use.

Fairness is a popular but complicated concept. In defining what constitutes a just distribution, one needs to first ask what the relevant outcome of interest (income, well-being, etc.) is and who the recipients of that outcome (individuals, countries, etc.) are. Then comes one of the most important questions, if not the most important question, one must ask when defining distributive justice: "Which individual characteristics are to be considered ethically relevant?" In other words, one must ask which personal characteristics, if any, can justify inequalities in the outcomes obtained by two recipients. Naturally, what is ethically relevant depends on the specific problem at hand. For instance, the number of hours worked might be considered relevant in an income distribution problem, while it might not matter in the problem of seat allocation in a movie theatre.

\footnotetext{
${ }^{2}$ We use "fair" and "just" interchangeably throughout this study.

${ }^{3}$ See Roemer (1998b) for an account of the interplay between contemporary political philosophy and the economic literature on distributive justice.
} 
In Chapter 2, the outcome of interest is a set of $m$ commodities, and the recipients are individuals. The primary notion of fairness adopted is envyfreeness. An allocation is said to be envy-free if no individual prefers someone else's bundle to his own. An inequality in a distribution of the $m$ commodities is considered inoffensive by envy-freeness provided that no individual prefers what another individual has to his own. The criterion thus considers preferences to be the ethically relevant characteristic.

Even though it is one of the most important concepts of the economic literature on distributive justice, envy-freeness does not solve all distributional problems. This is because the set of envy-free and efficient allocations can be quite large, or it might be empty. In the first case, we still have the question of which allocation to choose from the set of envy-free and efficient allocations. In the second case, envy-freeness is completely silent. It is the second problem that Chapter 2 deals with. We propose a method - a class of envy measures - to compare allocations in terms of envy. The characterized class measures the envy of one individual to another by the relative utility difference (using the utility function of the envious) between the bundle of the envied and the bundle of the envious. The particular utility representation to be used is fixed by the axioms. The class measures overall envy by the sum of these (transformed) relative utility differences. In the absence of an envy-free and efficient allocation, the class of envy measures provides a way to compare allocations based on their intensity of envy. For instance, allocations in the Pareto efficient subset that minimize an envy measure constitute interesting options.

In Chapter 3, the outcome of interest is income, and the recipients are a group of $n$ individuals. The principle of distributive justice focused on in this chapter is libertarianism. Libertarianism ascribes ethical significance to laissez-faire outcomes. Redistributive taxation is considered an inherent injustice. We define an axiom, laissez-faire, to capture the libertarian opposition to redistribution. The axiom says that the no-redistribution case (i.e., the allocation in which each individual is given his market income) is better than any other allocation of the same amount of total income. Hence, libertarianism is a criterion of distributive justice that considers market income the ethically significant characteristic. Not 
only are inequalities arising from differences in market incomes considered inoffensive, but also promoted.

Two main lines of justification proposed for libertarianism are individual liberty and efficiency of the free market. It is the second line of arguments that this chapter belongs to. We show that we still encounter problems in achieving efficiency even if redistribution is completely eliminated. Theorem 3.2 shows that it is impossible to combine the laissez-faire principle with Pareto indifference. Weakening Pareto indifference to weak Pareto (which states that an increase in the disposable income of everyone is an improvement) helps us avoid the impossibility, but the possibilities are very limited. We find that a ranking which satisfies weak Pareto and laissez-faire strictly prefers an income allocation with higher total income regardless of the distribution of market incomes. It is only when the sums are equal that the ranking respects market incomes. Thus, the ranking leaves very little room for libertarian values.

Chapter 2 and Chapter 3 both assume that individuals differ only with respect to one relevant personal characteristic: preferences in Chapter 2 and market incomes in Chapter 3. What does distributive justice require if individuals differ with respect to both relevant and irrelevant characteristics? It is this question that Chapter 4 deals with.

In Chapter 4, the outcome of interest is income, and the recipients differ with respect to ethically relevant characteristics (called responsibility characteristics) and irrelevant characteristics (called circumstances). The main ideal of fairness is equality of opportunity.

Equality of opportunity as a criterion of distributive justice consists of two main principles. The first, the principle of compensation, deems inequalities due to differences in circumstances unacceptable. The second, the principle of reward, tackles the question of how to allocate income between individuals who differ only with respect to their responsibility characteristics. We focus on two interpretations of the reward idea. The first, liberal reward, says that market income differences should be respected when distributing income among individuals who share the same circumstances. The second, utilitarian reward, 
says that fairness need not be concerned with the manner in which income is distributed among such individuals.

In Chapter 4, we first present classes of social welfare functions that satisfy compensation and liberal reward, and compensation and utilitarian reward. We also present the optimal distributions suggested by these social welfare functions. In the second part of the chapter, following the procedure proposed by Atkinson (1970) and Kolm (1969), we propose to measure inequality of opportunity in a given income distribution by the per capita income that could be destroyed if incomes are distributed fairly and the resulting income distribution has the same welfare as the given distribution. We show that this is equivalent to measuring inequality of opportunity in a distribution by the difference between the welfare at the actual distribution and welfare at the fair distribution of the same total income. Thus, the characterized welfare function classes serve as the ethical basis for the inequality measures in the sense that the inequality of opportunity registered increases as an income distribution moves further (in terms of welfare difference) from the optimal distribution.

In Chapter 5, the outcome of interest is an international river, and the recipients are sovereign countries located along the river. Sharing water from international rivers has often been a source of conflict between riparian countries mostly because property rights over rivers are not well defined. Several international principles of international law were proposed to solve this problem. We focus on three that attracted most attention from policymakers and researchers. First, the principle of absolute territorial sovereignty (ATS), states that a country has absolute sovereignty over the part of the river that is within its borders. Thus, the principle considers borders ethically relevant. Second, unlimited territorial integrity (UTI), states that one country cannot alter the quantity or quality of water available to another. That is, the principle considers the amount of water available up to a country's border ethically relevant. Third, territorial integration of all basin states (TIBS), considers the entire river a single unit and allows each country an unlimited use of it. That is, the principle considers all countries the same with respect to their relevant characteristics. 
Even though these principles are intuitive, they are difficult to formulate in applications. Moreover, there is an ongoing debate on which one to use in practical applications. It is these two questions that Chapter 5 tackles. First, we propose a way to formalize the principles. To do so, we take a reference vector $r$ that defines the property rights over the river. That is, $r_{i}$ shows the amount of river water $i$ has a right to consume without having to compensate any other country. Our main axiom, Pigou-Dalton for $r$, says that, given that each country consumes its reference level of water, equalizing monetary compensations received by countries is an improvement. We argue that the axiom provides a reasonable way to formalize the aforementioned principles via the choice of the reference vector. Theorem 5.1 shows that anonymity and Pigou-Dalton for $r$ imply that TIBS must be chosen over ATS and UTI (Theorem 5.1).

Taking territorial integration of all basin states as the primary criterion of distributive justice, we show that a ranking that satisfies Pigou-Dalton for $r$, Pareto, anonymity and an independence axiom applies the Lorenz dominance criterion to equivalent income vectors. The equivalent income of a country is the amount of the hypothetical monetary compensation that, if combined with the reference level of water consumption, would give the country the same utility as its initial situation. The Hammond equity version of Pigou-Dalton for $r$ combined with weak Pareto, on the other hand, characterizes the class of egalitarian equivalent orderings that apply the maximin criterion to vectors of equivalent income. 


\section{AN AXIOMATIC APPROACH TO THE MEASUREMENT OF ENVY ${ }^{1}$}

\subsection{Introduction}

An allocation is envy-free if no individual prefers another individual's commodity bundle to his own. ${ }^{2}$ Envy-freeness is a crude criterion of distributive justice. It distinguishes only two classes of allocations, those that are envy-free and those that are not.

There are good reasons to consider envy measures that provide more discriminatory envy rankings of allocations. Envy-freeness generalizes the idea of equality to the setting of ordinal non-comparable preferences. ${ }^{3}$ The study of envy measures is therefore a natural extension of the theory of inequality measurement. Further, allocations that are both envy-free and Pareto efficient are not guaranteed to exist in non-transferable-commodities or production settings. ${ }^{4}$

\footnotetext{
${ }^{1}$ This chapter is based on collaborative work with Kristof Bosmans.

${ }^{2}$ The seminal references are Tinbergen (1946), Foley (1967), Kolm (1972) and Varian (1974). See Arnsperger (1994) and Thomson (2010) for surveys.

${ }^{3}$ See Arnsperger (1994, pp.157-158) and Fleurbaey (2008, pp.22-24). For example, if there is only one commodity, say income, then the equal income distribution is the unique envy-free allocation. See Temkin $(1986,1993)$ and Cowell and Ebert (2004) for approaches to income inequality measurement that explicitly refer to envy-freeness.

${ }^{4}$ See Tadenuma (2002) for a discussion of the clash between Pareto efficiency and envyfreeness in a formal setting similar to ours.
} 


\section{CHAPTER 2. AN AXIOMATIC APPROACH TO THE MEASUREMENT OF ENVY}

Hence, allocations in the Pareto efficient subset that minimize an envy measure constitute interesting compromises.

We introduce a new class of envy measures. Throughout, we discuss the connections with envy measures proposed by Feldman and Kirman (1974), Chaudhuri (1986), Diamantaras and Thomson (1990) and Fleurbaey (2008). Whereas these previous envy measures were proposed on the basis of their direct appeal, we use an axiomatic approach in order to make intuitions explicit. We develop our class in two steps.

First, we examine the consequences of imposing decomposability. This axiom requires that, for each partitioning of the population in two subgroups, envy in the total population can be written as the sum of the envy within subgroups and the envy between subgroups. In combination with a standard normalization axiom, decomposability implies that envy is measured by $\sum_{i} \sum_{j} E_{i j}$, where $E_{i j}$ represents the envy of individual $i$ towards individual $j$ and depends only on the bundles of $i$ and $j$ and the preferences of $i$. The value of $E_{i j}$ is zero if $i$ does not envy $j$, and positive otherwise.

Second, we formulate two axioms, betweenness and proportionality, that deal with envy comparisons in the simple two-individual setting. Assume that the two individuals are $i$ and $j$, and that $i$ envies $j$ but not vice versa. Betweenness demands that envy decreases if $i$ 's bundle improves or if $j$ 's bundle worsens according to $i$ 's preferences. Proportionality requires that, for cases where the bundles of individuals $i$ and $j$ are proportional to each other, envy is smaller if the radial distance between the bundles is smaller. We show that betweenness and proportionality are incompatible. We weaken the latter axiom to $r$-proportionality, which applies the idea of proportionality only if the bundles of $i$ and $j$ are proportional to a predetermined reference bundle $r$. Given anonymity, betweenness and $r$-proportionality imply that $E_{i j}$ is an increasing function of the ratio $u_{i}\left(x_{j}\right) / u_{i}\left(x_{i}\right)$, where $x_{i}$ and $x_{j}$ are the bundles of individuals $i$ and $j$ and $u_{i}$ is a utility representation of $i$ 's preferences. The utility representation $u_{i}$ is not arbitrary, but rather is determined by the axioms and depends on the chosen reference bundle $r$. 


\subsection{Preliminaries}

The set of individuals is $\mathscr{N}$, a finite subset of the set of positive integers. There are $m$ commodities. The set of commodity bundles is $X=\mathbb{R}_{++}^{m}$. Each individual $i$ in $\mathscr{N}$ has a preference relation $R_{i}$, a complete and transitive binary relation on $X$. The strict preference and indifference relations corresponding to $R_{i}$ are denoted by $P_{i}$ and $I_{i}$, respectively. Let $\bar{R}$ be a preference relation such that $x \bar{R} y$ for all bundles $x$ and $y$ in $X$. The preference relation $\bar{R}$ is indifferent between all bundles in $X$ and will play the role of a dummy preference relation. Let $\mathscr{R}$ be the union of $\{\bar{R}\}$ and the set of all continuous and strictly monotonic preference relations. Each individual $i$ in $\mathscr{N}$ has a preference relation in $\mathscr{R}$. For a set of individuals $N \subseteq \mathscr{N}$, we let $x_{N}=\left(x_{i}\right)_{i \in N}$ and $R_{N}=\left(R_{i}\right)_{i \in N}$. We refer to $\left(x_{N}, R_{N}\right)$ as a social state. We do not distinguish between two social states that differ only with respect to the order in which the individuals are listed (e.g., $\left(x_{i}, x_{j}, R_{i}, R_{j}\right)$ and $\left(x_{j}, x_{i}, R_{j}, R_{i}\right)$ are treated as the same social state). The set $S$ collects all social states for all finite population sizes. That is, $S=\bigcup_{N \subset \mathscr{N}} X^{|N|} \times \mathscr{R}^{|N|}$.

Consider a social state $s=\left(x_{N}, R_{N}\right)$. Individual $i$ is said to envy individual $j$ if $x_{j} P_{i} x_{i}$. The social state $s$ is said to be envy-free if $x_{i} R_{i} x_{j}$ for all individuals $i$ and $j$ in $N$. We use an envy measure to rank all social states in $S$ on the basis of envy. An envy measure is a function $E: S \rightarrow \mathbb{R}$ that associates with each social state $s$ in $S$ a level of envy $E(s)$.

We define two basic axioms. More axioms will be introduced in the subsequent sections. Normalization requires the envy measure to attain the value of zero in envy-free social states and positive values in other social states.

Normalization. For each social state $\left(x_{N}, R_{N}\right)$ in $S$, we have $E\left(x_{N}, R_{N}\right) \geq 0$ with equality holding if and only if $x_{i} R_{i} x_{j}$ for all individuals $i$ and $j$ in $N$.

Anonymity demands that two social states with identical bundle-preference pairs have the same level of envy. These two states may distribute these identical preference-bundle pairs differently over the same population or over altogether different populations (of the same size). For a bijection $\pi: N \rightarrow M$, and a social state $\left(x_{N}, R_{N}\right)$, we write $\pi\left(x_{N}\right)$ for $\left(x_{\pi(i)}\right)_{i \in N}$ and $\pi\left(R_{N}\right)$ for $\left(R_{\pi(i)}\right)_{i \in N}$. 


\section{CHAPTER 2. AN AXIOMATIC APPROACH TO THE MEASUREMENT OF ENVY}

Anonymity. For each social state $\left(x_{N}, R_{N}\right)$ in $S$ and each bijection $\pi: N \rightarrow M$, we have $E\left(x_{N}, R_{N}\right)=E\left(\pi\left(x_{N}\right), \pi\left(R_{N}\right)\right)$.

It will be useful to single out two social states induced by a social state $s=\left(x_{N}, R_{N}\right)$ in $S$. First, let $s_{i}$ denote the social state in which the preference relation of each individual $j \neq i$ is replaced by $\bar{R}$. That is, we set $s_{i}=\left(x_{1}, \ldots, x_{n}, \bar{R}, \ldots, \bar{R}, R_{i}, \bar{R}, \ldots, \bar{R}\right)$. Second, let $s_{i j}$ denote the social state for the two-individual population $\{i, j\} \subseteq N$ in which the preference relation of individual $j$ is replaced by $\bar{R}$. That is, $s_{i j}=\left(x_{i}, x_{j}, R_{i}, \bar{R}\right)$. In the social state $s_{i}$, the only envy that occurs is that of individual $i$ towards all other individuals in $N$. Likewise, in the social state $s_{i j}$, the only envy that occurs is that of individual $i$ towards individual $j$. We may therefore interpret $E\left(s_{i}\right)$ as the envy of individual $i$ in social state $s$ and $E\left(s_{i j}\right)$ as the envy of individual $i$ towards individual $j$ in social state $s$. We will refer to $E\left(s_{i}\right)$ as the individual envy of $i$ and to $E\left(s_{i j}\right)$ as the elementary envy of $i$ to $j$. Note that $E\left(s_{i}\right)$ and $E\left(s_{i j}\right)$ are well defined for each envy measure $E$ and each social state $s$ in $S$.

To put the analysis of the subsequent sections into perspective, we consider several envy measures that have been proposed in the literature. None of these measures has received axiomatic foundations. Each measure has been motivated instead by its immediate intuitive appeal. Table 2.1 presents the envy measures proposed by Feldman and Kirman (1974), Chaudhuri (1986), Diamantaras and Thomson (1990). ${ }^{5}$ The table also shows how the measures fare with respect to the axioms defined in this section and subsequent sections.

All five measures rely on elementary envy as a basic building block. For the first four measures in Table 2.1, overall envy $E(s)$ equals the sum of all elementary envies $\sum_{i \in N} \sum_{j \in N} E\left(s_{i j}\right)$. For the final measure in the table, overall

\footnotetext{
${ }^{5}$ Our formulation of the Diamantaras-Thomson measure follows Arnsperger (1994, Definition 5.4).
} 
Table 2.1 Five envy measures

\begin{tabular}{|c|c|c|c|c|c|c|c|}
\hline Measure & $E(s)$ & $\mathrm{N}$ & A & $\mathrm{D}$ & B & $\mathrm{P}$ & $r-\mathrm{P}$ \\
\hline First Feldman-Kirman & $\left|\left\{\{i, j\} \subseteq N: x_{j} P_{i} x_{i}\right\}\right|$ & $\checkmark$ & $x$ & $\checkmark$ & $x$ & $x$ & $x$ \\
\hline Second Feldman-Kirman* & $\sum_{i \in N} \sum_{j \in N}\left[u_{i}\left(x_{j}\right)-u_{i}\left(x_{i}\right)\right]$ & $x$ & $\checkmark$ & $\checkmark$ & $\checkmark$ & $\sqrt{\$}$ & $\mathbb{S}^{\ddagger}$ \\
\hline Third Feldman-Kirman* & $\sum_{i \in N} \sum_{j \in N} \max \left\{u_{i}\left(x_{j}\right)-u_{i}\left(x_{i}\right), 0\right\}$ & $\checkmark$ & $\checkmark$ & $\sqrt{ }$ & $\checkmark$ & $\mathcal{J}^{\ddagger}$ & $\mathfrak{S}^{\ddagger}$ \\
\hline Chaudhuri ${ }^{\dagger}$ & $\sum_{i \in N} \sum_{j \in N} \max \left\{\frac{1}{\lambda_{i j}}-1,0\right\}$ & $\checkmark$ & $\checkmark$ & $\checkmark$ & $x$ & $\checkmark$ & $\sqrt{ }$ \\
\hline Diamantaras-Thomson $^{\dagger}$ & $\max _{i, j \in N}\left\{\frac{1}{\lambda_{i j}}-1\right\}$ & $x$ & $\checkmark$ & $x$ & $x$ & $\checkmark$ & $\checkmark$ \\
\hline
\end{tabular}

Abbreviations: $\mathrm{N}$ (ormalization), $\mathrm{A}$ (nonymity), $\mathrm{D}$ (ecomposability), $\mathrm{B}$ (etweenness), $\mathrm{P}$ (roportionality), $r$ - $\mathrm{P}$ (roportionality).

${ }^{*}$ The function $u_{i}: \mathbb{R}_{+}^{m} \rightarrow \mathbb{R}$ is a utility representation of $R_{i}$.

${ }^{\dagger}$ The real number $\lambda_{i j}$ is such that $x_{i} I_{i} \lambda_{i j} x_{j}$.

${ }^{\ddagger}$ The axiom is satisfied only for specific utility representations.

envy $E(s)$ equals the maximum elementary envy $\max _{i, j \in N} E\left(s_{i j}\right) .{ }^{6}$ Let us focus now on how each of the measures defines elementary envy.

For the first Feldman-Kirman measure, which is a simple count of the instances of envy, the elementary envy $E\left(s_{i j}\right)$ equals 1 if individual $i$ envies individual $j$ and 0 if not. The measure clearly neglects the intensity of elementary envy, contrary to the next four measures in the table.

The second and third Feldman-Kirman measures assume each individual $i$ has a utility representation $u_{i}$ with cardinal significance, and compute the intensity of elementary envy using utility differences. The elementary envy $E\left(s_{i j}\right)$ equals $u_{i}\left(x_{j}\right)-u_{i}\left(x_{i}\right)$ for the second Feldman-Kirman measure, and the same truncated at zero for the third Feldman-Kirman measure. Hence, the former measure takes into account 'negative' elementary envies, i.e., the extent to which individuals prefer their own bundles to those of others, whereas the latter

\footnotetext{
${ }^{6}$ Hence, the five measures in Table 2.1 depend only indirectly on the individual envies. The individual envy of $i$ to all other individuals in $N$ equals $E\left(s_{i}\right)=\sum_{j \in N} E\left(s_{i j}\right)$ for the first four measures in the table and $E\left(s_{i}\right)=\max _{j \in N} E\left(s_{i j}\right)$ for the final measure. In Section 2.5, we discuss a measure by Fleurbaey (2008, Chapter 2$)$ that gives a more substantial role to the individual envies.
} 


\section{CHAPTER 2. AN AXIOMATIC APPROACH TO THE MEASUREMENT OF ENVY}

measure does not. ${ }^{7}$ A shortcoming of these two measures is the dependence on the arbitrary choice of a utility representation $u_{i}$ for each individual $i$.

The Chaudhuri and Diamantaras-Thomson measures do not rely on cardinal utility information. Instead, these measures focus on the fraction $\lambda_{i j}$ by which the bundle of $j$ has to be shrunk in order for $i$ to stop envying $j$. For the Diamantaras-Thomson measure, elementary envy $E\left(s_{i j}\right)$ equals $\left(1 / \lambda_{i j}\right)-1$, where $\lambda_{i j}$ is such that $x_{i} I_{i} \lambda_{i j} x_{j}$. For the Chaudhuri measure, elementary envy is the same value truncated at zero. Again, the Diamantaras-Thomson measure takes into account 'negative' elementary envies, whereas the Chaudhuri measure does not. A shortcoming of these two measures is their arbitrary dependence on the particular procedure of shrinking the bundle of the envied. An a priori equally appealing procedure would be to focus on the factor by which the bundle of the envious has to be blown up in order for him to stop envying, but this procedure yields different results (see Section 2.4).

We proceed as follows. In Section 2.3 we characterize an envy measure that equates overall envy to the sum of all elementary envies. The measure takes the form of the first four measures in Table 2.1. But measures that equate overall envy to the maximum elementary envy, as the DiamantarasThomson measure, or to the minimum elementary envy may be obtained as limiting cases (see Section 2.5). In Section 2.4 we consider axioms that only impose properties on an envy measure for the two-individual case. Using these axioms we characterize a measure of elementary envy that combines the utility difference approach of the second and third Feldman-Kirman measures and the radial distance approach of the Chaudhuri and Diamantaras-Thomson measures. But at the same time it avoids the shortcomings of these approaches. Section 2.5 combines the results of the two preceding sections into a single class of envy measures and discusses its properties.

\footnotetext{
${ }^{7}$ Feldman and Kirman (1974, p. 997) introduce their third measure with the explicit objective of measuring envy without taking into account 'negative' elementary envies. It may indeed be argued that such 'negative' elementary envies should be considered as irrelevant in equity evaluations. Our axioms also neutralize their role (see Section 2.3).
} 


\subsection{Envy as the sum of elementary envies}

To define decomposability, imagine a partitioning of the population into two subgroups, e.g., on the basis of region, ethnicity or gender. Decomposability conveniently allows to write overall envy in the population as a sum of the envy within subgroups and the envy between subgroups. ${ }^{8}$

Decomposability. For each social state $\left(x_{N}, R_{N}\right)$ in $S$ and each partition $\left\{N_{1}, N_{2}\right\}$ of $N$ with non-empty $N_{1}$ and $N_{2}$, we have

$$
\begin{aligned}
& E\left(x_{N}, R_{N}\right)=E\left(x_{N_{1}}, R_{N_{1}}\right)+E\left(x_{N_{2}}, R_{N_{2}}\right) \\
& +\sum_{i \in N_{1}} E\left(x_{i}, x_{N_{2}}, R_{i}, \bar{R}, \ldots, \bar{R}\right)+\sum_{i \in N_{2}} E\left(x_{i}, x_{N_{1}}, R_{i}, \bar{R}, \ldots, \bar{R}\right) .
\end{aligned}
$$

The first two terms in equation (2.1) constitute the within subgroup component, the final two terms the between subgroup component. Within subgroup envy is the sum of the envy levels in the two subgroups. Between subgroup envy is the sum of the individual envy of each individual toward the other subgroup.

The following lemma says that if an envy measure satisfies normalization and decomposability, then it measures individual envy by the sum of the individual's elementary envies.

Lemma 2.1. If E satisfies normalization and decomposability, then, for each social state $\left(x_{N}, R_{N}\right)$ in $S$ and each individual $i$ in $N$, we have

$$
E\left(s_{i}\right)=\sum_{j \in N} E\left(x_{i}, x_{j}, R_{i}, \bar{R}\right)
$$

Proof. The proof is by induction on the number of individuals.

\footnotetext{
${ }^{8}$ Similar decomposability requirements have been studied in the context of inequality measurement (e.g., Bourguignon, 1979, Cowell, 1980 and Shorrocks, 1980, 1984). The decomposability axiom used here most resembles that of Ebert (2010). While we, as is customary, state the axiom in terms of two subgroups, repeated application of equation (2.1) allows a decomposition in any number of subgroups.
} 
Step 1. Let $N$ be such that $|N|=2$. Without loss of generality, let $N=\left\{i_{1}, i_{2}\right\}$.

Let $s=\left(x_{i_{1}}, x_{i_{2}}, R_{i_{1}}, R_{i_{2}}\right)$ be a social state. By decomposability,

$$
\begin{aligned}
& E\left(s_{i_{1}}\right)=E\left(x_{i_{1}}, R_{i_{1}}\right)+E\left(x_{i_{2}}, \bar{R}\right) \\
& +E\left(x_{i_{1}}, x_{i_{2}}, R_{i_{1}}, \bar{R}\right)+E\left(x_{i_{2}}, x_{i_{1}}, \bar{R}, \bar{R}\right) .
\end{aligned}
$$

The first, second and final terms are equal to zero by normalization. Hence,

$$
E\left(s_{i_{1}}\right)=E\left(x_{i_{1}}, x_{i_{2}}, R_{i_{1}}, \bar{R}\right) .
$$

Step 2. Suppose the hypothesis holds for all $N$ such that $|N|=n$ with $n \geq 2$. We have to show that it holds for all social states with $n+1$ individuals.

Let $N^{\prime}$ be such that $\left|N^{\prime}\right|=n+1$ and let $s=\left(x_{N^{\prime}}, R_{N^{\prime}}\right)$ be a social state. Without loss of generality, let $N^{\prime}=\left\{i_{1}, i_{2}, \ldots, i_{n+1}\right\}$. Consider the partitioning of $N^{\prime}$ into $N_{1}^{\prime}=\left\{i_{1}, i_{2}, \ldots, i_{n}\right\}$ and $N_{2}^{\prime}=\left\{i_{n+1}\right\}$. By decomposability,

$$
\begin{aligned}
& E\left(s_{i_{1}}\right)=E\left(x_{N_{1}^{\prime}}, R_{i_{1}}, \bar{R}, \ldots, \bar{R}\right)+E\left(x_{i_{n+1}}, \bar{R}\right) \\
& +E\left(x_{i_{1}}, x_{i_{n+1}}, R_{i_{1}}, \bar{R}\right)+\sum_{k=2}^{n} E\left(x_{i_{k}}, x_{i_{n+1}}, \bar{R}, \bar{R}\right)+E\left(x_{i_{n+1}}, x_{N_{1}^{\prime}}, \bar{R}, \ldots, \bar{R}\right) .
\end{aligned}
$$

The second, fourth and final terms are equal to zero by normalization. Hence,

$$
E\left(s_{i_{1}}\right)=E\left(x_{N_{1}^{\prime}}, R_{i_{1}}, \bar{R}, \ldots, \bar{R}\right)+E\left(x_{i_{1}}, x_{i_{n+1}}, R_{i_{1}}, \bar{R}\right) .
$$

By the induction hypothesis,

$$
E\left(x_{N_{1}^{\prime}}, R_{i_{1}}, \bar{R}, \ldots, \bar{R}\right)=\sum_{k=1}^{n} E\left(x_{i_{1}}, x_{i_{k}}, R_{i_{1}}, \bar{R}\right) .
$$

Hence,

$$
E\left(s_{i_{1}}\right)=\sum_{k=1}^{n+1} E\left(x_{i_{1}}, x_{i_{k}}, R_{i_{1}}, \bar{R}\right) .
$$


The following proposition says that an envy measure satisfies normalization and decomposability if and only if overall envy equals the sum of all elementary envies.

Proposition 2.1. An envy measure E satisfies normalization and decomposability if and only if, for each social state $\left(x_{N}, R_{N}\right)$ in $S$, we have

$$
E\left(x_{N}, R_{N}\right)=\sum_{i \in N} \sum_{j \in N} E\left(x_{i}, x_{j}, R_{i}, \bar{R}\right)
$$

where $E\left(x_{i}, x_{j}, R_{i}, \bar{R}\right)=0$ for all individuals $i$ and $j$ in $N$ such that $x_{i} R_{i} x_{j}$.

Proof. It is easy to see that the stated envy measure satisfies normalization and decomposability. We focus on the reverse implication. The proof is by induction on the number of individuals.

Step 1. Let $N$ be such that $|N|=2$. Without loss of generality, let $N=\left\{i_{1}, i_{2}\right\}$. Let $s=\left(x_{i_{1}}, x_{i_{2}}, R_{i_{1}}, R_{i_{2}}\right)$ be a social state. By decomposability,

$$
\begin{aligned}
E(s) & =E\left(x_{i_{1}}, R_{i_{1}}\right)+E\left(x_{i_{2}}, R_{i_{2}}\right) \\
& +E\left(x_{i_{1}}, x_{i_{2}}, R_{i_{1}}, \bar{R}\right)+E\left(x_{i_{2}}, x_{i_{1}}, R_{i_{2}}, \bar{R}\right) .
\end{aligned}
$$

The first and second terms are equal to zero by normalization. Hence,

$$
E(s)=E\left(x_{i_{1}}, x_{i_{2}}, R_{i_{1}}, \bar{R}\right)+E\left(x_{i_{2}}, x_{i_{1}}, R_{i_{2}}, \bar{R}\right) .
$$

Step 2. Suppose the hypothesis holds for all $N$ such that $|N|=n$ with $n \geq 2$. We have to show that it holds for all social states with $n+1$ individuals.

Let $N^{\prime}$ be such that $\left|N^{\prime}\right|=n+1$ and let $s=\left(x_{N^{\prime}}, R_{N^{\prime}}\right)$ be a social state. Without loss of generality, let $N^{\prime}=\left\{i_{1}, i_{2}, \ldots, i_{n+1}\right\}$. Consider the partitioning of $N^{\prime}$ into $N_{1}^{\prime}=\left\{i_{1}, i_{2}, \ldots, i_{n}\right\}$ and $N_{2}^{\prime}=\left\{i_{n+1}\right\}$. By decomposability,

$$
\begin{aligned}
E(s) & =E\left(x_{N_{1}^{\prime}}, R_{N_{1}^{\prime}}\right)+E\left(x_{i_{n+1}}, R_{i_{n+1}}\right) \\
& +\sum_{k=1}^{n} E\left(x_{i_{k}}, x_{i_{n+1}}, R_{i_{k}}, \bar{R}\right)+E\left(x_{i_{n+1}}, x_{N_{1}^{\prime}}, R_{i_{n+1}}, \bar{R}, \ldots, \bar{R}\right) .
\end{aligned}
$$


The second term is equal to zero by normalization. Using, in addition, the induction hypothesis,

$$
\begin{aligned}
E(s) & =\sum_{k=1}^{n} \sum_{\ell=1}^{n} E\left(x_{i_{k}}, x_{i_{\ell}}, R_{i_{k}}, \bar{R}\right) \\
& +\sum_{k=1}^{n} E\left(x_{i_{k}}, x_{i_{n+1}}, R_{i_{k}}, \bar{R}\right)+E\left(x_{i_{n+1}}, x_{N_{1}^{\prime}}, R_{i_{n+1}}, \bar{R}, \ldots, \bar{R}\right) .
\end{aligned}
$$

By Lemma 2.1,

$$
E\left(x_{i_{n+1}}, x_{N_{1}^{\prime}}, R_{i_{n+1}}, \bar{R}, \ldots, \bar{R}\right)=\sum_{k=1}^{n+1} E\left(x_{i_{n+1}}, x_{i_{k}}, R_{i_{n+1}}, \bar{R}\right)
$$

Hence,

$$
E(s)=\sum_{k=1}^{n+1} \sum_{\ell=1}^{n+1} E\left(x_{i_{k}}, x_{i_{\ell}}, R_{i_{k}}, \bar{R}\right)
$$

Proposition 2.1 says that overall envy equals the sum of all elementary envies, but largely leaves open how to measure elementary envy. All it imposes in this respect is that 'negative' elementary envies, i.e., the extent to which individuals prefer their own bundles to those of others, are not taken into account. In the next section, we will consider axioms that give more content to the concept of elementary envy.

\subsection{Measuring elementary envy}

Consider a setting with two individuals, only one of whom is envious. We propose axioms that require the envy measure to react to simple changes in the bundles of the two individuals. The axioms bear on the envy measure $E$, but only directly impose properties on the elementary envy measure corresponding to $E$.

Betweenness requires the elementary envy of individual $i$ to individual $j$ to decrease if $i$ 's bundle improves or $j$ 's bundle worsens according to $i$ 's 
preferences. In terms of $i$ 's preferences, the new bundles lie 'in between' the original bundles.

Betweenness. For all individuals $i$ and $j$ in $\mathscr{N}$, all bundles $x_{i}, x_{j}, x_{i}^{\prime}$ and $x_{j}^{\prime}$ in $X$ and each preference relation $R_{i}$ in $\mathscr{R}$ such that $x_{j} P_{i} x_{i}$, we have that $x_{j} R_{i} x_{j}^{\prime}, x_{j}^{\prime} R_{i} x_{i}^{\prime}$ and $x_{i}^{\prime} R_{i} x_{i}$ imply $E\left(x_{i}, x_{j}, R_{i}, \bar{R}\right) \geq E\left(x_{i}^{\prime}, x_{j}^{\prime}, R_{i}, \bar{R}\right)$ with strict inequality holding whenever $x_{j} P_{i} x_{j}^{\prime}$ or $x_{i}^{\prime} P_{i} x_{i}$.

We emphasize an implication of betweenness. Let $u_{i}$ be a utility representation of the preference relation $R_{i}$. Betweenness implies that the elementary envy $E\left(x_{i}, x_{j}, R_{i}, \bar{R}\right)$ of individual $i$ to $j$ is a function only of the utility levels $u_{i}\left(x_{i}\right)$ and $u_{i}\left(x_{j}\right)$. That is, if $u_{i}\left(x_{i}\right)=u_{i}\left(x_{i}^{\prime}\right)$ and $u_{i}\left(x_{j}\right)=u_{i}\left(x_{j}^{\prime}\right)$ (as depicted in Figure 2.1), then $E\left(x_{i}, x_{j}, R_{i}, \bar{R}\right)=E\left(x_{i}^{\prime}, x_{j}^{\prime}, R_{i}, \bar{R}\right)$. Note that the second and third Feldman-Kirman measures are in this functional form and satisfy betweenness.

The next axiom captures the idea of gauging elementary envy by the radial distance between bundles. Consider two approaches. The first approach, as adopted in the Chaudhuri and Diamantaras-Thomson measures, measures the elementary envy of $i$ to $j$ using the fraction $\lambda_{i j}$ by which $j$ 's bundle has to be shrunk in order for $i$ to stop envying $j$. That is, $\lambda_{i j}$ is such that $x_{i} I_{i} \lambda_{i j} x_{j}$, and the higher $\lambda_{i j}$, the lower the elementary envy of $i$ to $j$. The second approach measures the elementary envy of $i$ to $j$ using the factor $\kappa_{i j}$ by which $i$ 's bundle has to be blown up in order for $i$ to stop envying $j$. That is, $\kappa_{i j}$ is such that $\kappa_{i j} x_{i} I_{i} x_{j}$, and the higher $\kappa_{i j}$, the higher the elementary envy of $i$ to $j$. The two approaches are a priori equally appealing, but yield conflicting results. To see this, consider the social states $s^{1}=\left(x_{i}, x_{j}^{\prime}, R_{i}, \bar{R}\right)$ and $s^{2}=\left(x_{i}^{\prime}, x_{j}, R_{i}, \bar{R}\right)$ in Figure 2.1. The first approach implies $E\left(s^{1}\right)>E\left(s^{2}\right)$ because $\lambda_{i j}^{\prime}<\lambda_{i j}$, whereas the second approach implies $E\left(s^{1}\right)<E\left(s^{2}\right)$ because $\kappa_{i j}<\kappa_{i j}^{\prime}$. ${ }^{9}$

We do not make a choice among the two conflicting approaches. Instead, we formulate an axiom that is sufficiently weak to be consistent with both. The axiom only considers the cases where the bundles of the envied and envious are proportional to each other (in which case the two above approaches coincide)

\footnotetext{
${ }^{9}$ The two approaches do give the same result if the preference relation is homothetic.
} 


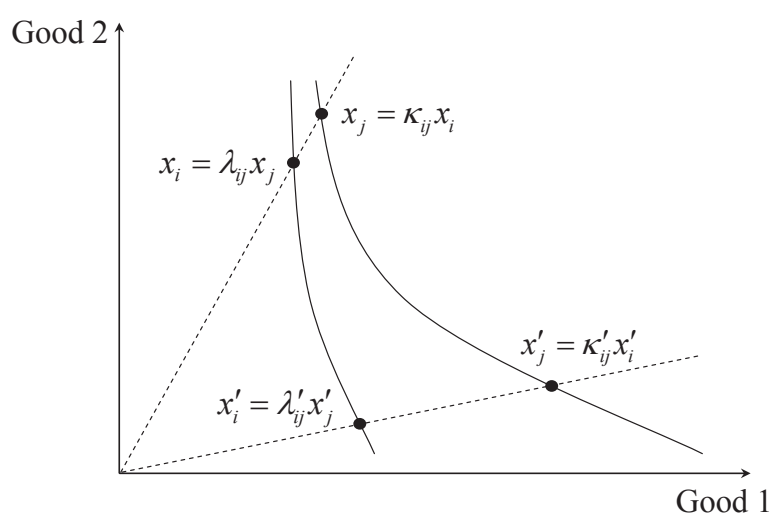

Figure 2.1 Two indifference curves of individual $i$.

and says that a decrease of the radial distance between these two bundles reduces elementary envy.

Proportionality. For all individuals $i$ and $j$ in $\mathscr{N}$, all bundles $x_{i}, x_{j}, x_{i}^{\prime}$ and $x_{j}^{\prime}$ in $X$ such that $\kappa x_{i}=x_{j}$ and $\kappa^{\prime} x_{i}^{\prime}=x_{j}^{\prime}$ and all preference relations $R_{i}$ and $R_{i}^{\prime}$ in $\mathscr{R}$ such that $x_{j} P_{i} x_{i}$ and $x_{j}^{\prime} P_{i}^{\prime} x_{i}^{\prime}$, we have that $\kappa \geq \kappa^{\prime}$ implies $E\left(x_{i}, x_{j}, R_{i}, \bar{R}\right) \geq$ $E\left(x_{i}^{\prime}, x_{j}^{\prime}, R_{i}^{\prime}, \bar{R}\right)$ with strict inequality holding if and only if $\kappa>\kappa^{\prime}$.

However, betweenness and proportionality are incompatible: there is no envy measure that satisfies both axioms. Consider the social states $s=\left(x_{i}, x_{j}, R_{i}, \bar{R}\right)$ and $s^{\prime}=\left(x_{i}^{\prime}, x_{j}^{\prime}, R_{i}, \bar{R}\right)$ in Figure 2.1. Betweenness implies $E(s)=E\left(s^{\prime}\right)$, whereas proportionality implies $E(s)<E\left(s^{\prime}\right)$ because $\kappa_{i j}<\kappa_{i j}^{\prime} .{ }^{10}$ Note that a stronger clash, with betweenness implying $E(s)>E\left(s^{\prime}\right)$, can easily be constructed as well.

We treat betweenness as essential and therefore weaken proportionality. The following axiom requires all bundles to be proportional to a predetermined reference bundle $r$. Later we will argue that the axiom may be regarded as a minimal weakening of proportionality that is compatible with betweenness.

\footnotetext{
${ }^{10}$ If the domain of preference relations is restricted to homothetic preferences relations, then the two axioms are compatible.
} 
$\boldsymbol{r}$-Proportionality. There is a bundle $r$ in $X$ such that the following holds. For all individuals $i$ and $j$ in $\mathscr{N}$, all bundles $x_{i}, x_{j}, x_{i}^{\prime}$ and $x_{j}^{\prime}$ in $X$ proportional to $r$ and such that $\kappa x_{i}=x_{j}$ and $\kappa^{\prime} x_{i}^{\prime}=x_{j}^{\prime}$ and all preference relations $R_{i}$ and $R_{i}^{\prime}$ in $\mathscr{R}$ such that $x_{j} P_{i} x_{i}$ and $x_{j}^{\prime} P_{i}^{\prime} x_{i}^{\prime}$, we have that $\kappa \geq \kappa^{\prime}$ implies $E\left(x_{i}, x_{j}, R_{i}, \bar{R}\right) \geq$ $E\left(x_{i}^{\prime}, x_{j}^{\prime}, R_{i}^{\prime}, \bar{R}\right)$ with strict inequality holding if and only if $\kappa>\kappa^{\prime}$.

Before proceeding, we need to define the $\rho$-utility representation. Let $\rho$ be a reference bundle in $X$. Let $u_{\rho}\left(x_{i}, R_{i}\right)$ be the real number such that individual $i$ is indifferent between the fraction $u_{\rho}\left(x_{i}, R_{i}\right)$ of the bundle $\rho$ and his own bundle $x_{i}$. That is, for a preference relation $R_{i}$ in $\mathscr{R} \backslash\{\bar{R}\}$, we have that $u_{\rho}\left(x_{i}, R_{i}\right)$ is the real number such that $x_{i} I_{i} u_{\rho}\left(x_{i}, R_{i}\right) \rho$. For the preference relation $R_{i}=\bar{R}$, we let $u_{\rho}\left(x_{i}, R_{i}\right)$ equal a positive constant. The function $u_{\rho}\left(\cdot, R_{i}\right)$ is a utility representation of the preference relation $R_{i}{ }^{11}$

The following proposition says that an envy measure satisfies betweenness and $r$-proportionality if and only if it measures the elementary envy of individual $i$ to $j$ by the ratio of $i$ 's $\rho$-utility levels associated with $j$ 's and $i$ 's bundles. Moreover, the reference bundle $\rho$ that determines the utility representation has to be chosen such that $\rho=r$.

Proposition 2.2. Let $E$ be an envy measure that satisfies anonymity. Then $E$ satisfies betweenness and r-proportionality if and only if there exists a strictly increasing function $f: \mathbb{R} \rightarrow \mathbb{R}$ such that for all individuals $i$ and $j$ in $\mathscr{N}$, all bundles $x_{i}$ and $x_{j}$ in $X$ and each preference relation $R_{i}$ in $\mathscr{R}$ such that $x_{j} P_{i} x_{i}$, we have

$$
E\left(x_{i}, x_{j}, R_{i}, \bar{R}\right)=f\left(\frac{u_{r}\left(x_{j}, R_{i}\right)}{u_{r}\left(x_{i}, R_{i}\right)}\right) .
$$

Proof. It is easy to see that the stated envy measure satisfies betweenness and $r$-proportionality. We focus on the reverse implication.

Let $r$ be a given bundle in $X$. Let $i$ and $j$ be individuals in $\mathscr{N}$, let $x_{i}, x_{i}^{\prime}, x_{j}$ and $x_{j}^{\prime}$ be bundles in $X$ and let $R_{i}$ and $R_{i}^{\prime}$ be preference relations in $\mathscr{R}$ such that $x_{j} P_{i} x_{i}$ and $x_{j}^{\prime} P_{i}^{\prime} x_{i}^{\prime}$. We have to show that

$$
E\left(x_{i}, x_{j}, R_{i}, \bar{R}\right) \geq E\left(x_{i}^{\prime}, x_{j}^{\prime}, R_{i}^{\prime}, \bar{R}\right)
$$

${ }^{11}$ See Fleurbaey and Maniquet (2011, p. 7) for a discussion of the $\rho$-utility representation. 


\section{CHAPTER 2. AN AXIOMATIC APPROACH TO THE MEASUREMENT OF ENVY}

if and only if

$$
\frac{u_{r}\left(x_{j}, R_{i}\right)}{u_{r}\left(x_{i}, R_{i}\right)} \geq \frac{u_{r}\left(x_{j}^{\prime}, R_{i}^{\prime}\right)}{u_{r}\left(x_{i}^{\prime}, R_{i}^{\prime}\right)} .
$$

Then there exists a strictly increasing function $f$ as stated. Note that $f$ does not depend on $i$ and $j$ by anonymity.

Let $y_{i}, y_{i}^{\prime}, y_{j}$ and $y_{j}^{\prime}$ be bundles in $X$ proportional to $r$ and such that $y_{i} I_{i} x_{i}$, $y_{i}^{\prime} I_{i}^{\prime} x_{i}^{\prime}, y_{j} I_{i} x_{j}$ and $y_{j}^{\prime} I_{i}^{\prime} x_{j}^{\prime}$. Such bundles exist since $R_{i}$ and $R_{i}^{\prime}$ are continuous and strictly monotonic. Let $\kappa$ and $\kappa^{\prime}$ be such that $\kappa y_{i}=y_{j}$ and $\kappa^{\prime} y_{i}^{\prime}=y_{j}^{\prime}$.

Suppose that equation (2.2) holds. We have to show that equation (2.3) holds as well. By betweenness, we have $E\left(x_{i}, x_{j}, R_{i}, \bar{R}\right)=E\left(y_{i}, y_{j}, R_{i}, \bar{R}\right)$ and $E\left(x_{i}^{\prime}, x_{j}^{\prime}, R_{i}^{\prime}, \bar{R}\right)=E\left(y_{i}^{\prime}, y_{j}^{\prime}, R_{i}^{\prime}, \bar{R}\right)$. Hence, $E\left(y_{i}, y_{j}, R_{i}, \bar{R}\right) \geq E\left(y_{i}^{\prime}, y_{j}^{\prime}, R_{i}^{\prime}, \bar{R}\right)$. If $\kappa<$ $\kappa^{\prime}$, then we have $E\left(y_{i}, y_{j}, R_{i}, \bar{R}\right)<E\left(y_{i}^{\prime}, y_{j}^{\prime}, R_{i}^{\prime}, \bar{R}\right)$ by $r$-proportionality. Hence, it must be that $\kappa \geq \kappa^{\prime}$. From the definition of $u_{r}, \kappa=u_{r}\left(y_{j}, R_{i}\right) / u_{r}\left(y_{i}, R_{i}\right)$ and $\kappa^{\prime}=u_{r}\left(y_{j}^{\prime}, R_{i}^{\prime}\right) / u_{r}\left(y_{i}^{\prime}, R_{i}^{\prime}\right)$. Since $u_{r}\left(x_{j}, R_{i}\right) / u_{r}\left(x_{i}, R_{i}\right)=u_{r}\left(y_{j}, R_{i}\right) / u_{r}\left(y_{i}, R_{i}\right)$ and $u_{r}\left(x_{j}^{\prime}, R_{i}^{\prime}\right) / u_{r}\left(x_{i}^{\prime}, R_{i}^{\prime}\right)=u_{r}\left(y_{j}^{\prime}, R_{i}^{\prime}\right) / u_{r}\left(y_{i}^{\prime}, R_{i}^{\prime}\right)$, we obtain equation (2.3).

Now, suppose that equation (2.3) holds. We have to show that equation (2.2) holds as well. Equation (2.3) implies that $\kappa=u_{r}\left(y_{j}, R_{i}\right) / u_{r}\left(y_{i}, R_{i}\right)$ which is greater than or equal to $\kappa^{\prime}=u_{r}\left(y_{j}^{\prime}, R_{i}^{\prime}\right) / u_{r}\left(y_{i}^{\prime}, R_{i}^{\prime}\right)$. Since $\kappa \geq \kappa^{\prime}$, $E\left(y_{i}, y_{j}, R_{i}, \bar{R}\right) \geq E\left(y_{i}^{\prime}, y_{j}^{\prime}, R_{i}^{\prime}, \bar{R}\right)$ by $r$-proportionality. Using betweenness, we obtain equation (2.2).

The measure of elementary envy in Proposition 2.2 shares with the second and third Feldman-Kirman measures that it depends on the utility distance between the bundles of the envious and the envied. However, the utility representation used is not an arbitrary choice as in those measures. Rather, the $\rho$-utility representation is singled out by the radial distance idea inherent in the Chaudhuri and Diamantaras-Thomson measures.

Note that, for a given individual $i$, the criterion in Proposition 2.2 provides a complete ranking of all social states of the form $\left(x_{i}, x_{j}, R_{i}, \bar{R}\right)$. This means that any further strengthening of $r$-proportionality in the direction of proportionality will either lead to conflicts or is already implied by the combination of $r$ - 
proportionality and betweenness. In this sense, the axiom $r$-proportionality is the minimal weakening of proportionality that is compatible with betweenness.

\subsection{Main result and discussion}

Our main result characterizes the class of envy measures that satisfy normalization, anonymity, decomposability, betweenness and $r$-proportionality. The theorem is a straightforward combination of Propositions 2.1 and 2.2.

Theorem 2.1. An envy measure E satisfies normalization, anonymity, decomposability, betweenness and r-proportionality if and only if there exists a function $f: \mathbb{R}_{++} \rightarrow \mathbb{R}_{+}$with $f$ strictly increasing on the interval $(1,+\infty)$ and $f(t)=0$ for each $t \leq 1$ such that, for each social state $\left(x_{N}, R_{N}\right)$ in $S$, we have

$$
E\left(x_{N}, R_{N}\right)=\sum_{i \in N} \sum_{j \in N} f\left(\frac{u_{r}\left(x_{j}, R_{i}\right)}{u_{r}\left(x_{i}, R_{i}\right)}\right) .
$$

To understand the role of the function $f$, it is useful to treat the utility ratio $u_{r}\left(x_{j}, R_{i}\right) / u_{r}\left(x_{i}, R_{i}\right)$ as a natural cardinalization of the measure of elementary envy of individual $i$ to individual $j$. The more convex is $f$, the more sensitive is the envy measure $E$ to changes in larger elementary envies (as measured by the utility ratio) relative to changes in smaller elementary envies. Given a sufficiently convex $f$, the measure that equates overall envy to the largest elementary envy, as in the Diamantaras-Thomson measure, can be approximated arbitrarily closely. Similarly, choosing $f$ sufficiently concave delivers the other extreme that identifies overall envy with the minimal elementary envy.

We discuss two variants of Theorem 2.1. The first concerns the aggregation of elementary envies into overall envy, the second the definition of elementary envy.

First, not all envy measures that have been proposed take the form of a sum over the elementary envies. Fleurbaey (2008, Chapter 2)'s measure equates the individual envy of $i$ to his maximal elementary envy $E\left(s_{i}\right)=\max _{j \in N} E\left(s_{i j}\right)$ 


\section{CHAPTER 2. AN AXIOMATIC APPROACH TO THE MEASUREMENT OF ENVY}

and overall envy to the sum of all individual envies $E(s)=\sum_{i \in N} E\left(s_{i}\right) .{ }^{12}$ This measure, contrary to the measures in Theorem 2.1, does not depend only on the values of the elementary envies, but also on their distribution over the individuals. Such a genuine role for the individual envies can be allowed by replacing decomposability by two simple positive responsiveness axioms. The first axiom requires individual envy to increase if at least one individual's elementary envy increases, other things equal. The second axiom requires overall envy to increase if at least one individual envy increases, other things equal. These axioms lead to a general approach that allows different aggregations for the elementary envies into individual envy and for the individual envies into overall envy. We omit the straightforward formal treatment.

Second, we examine how the measure of elementary envy changes if we focus on the absolute distance between bundles instead of on the relative distance. The only change to the assumptions in Section 2.2 is that commodities can take negative or zero values in addition to positive values. We use $1_{m}$ to denote the $m$-vector with a one at each entry. Consider the following absolute version of $r$-proportionality. Let $x_{i}, x_{j}, x_{i}^{\prime}$ and $x_{j}^{\prime}$ be bundles that are translations of the reference bundle $r$, and $x_{i}+\mu 1_{m}=x_{j}$ and $x_{i}^{\prime}+\mu^{\prime} 1_{m}=x_{j}^{\prime}$. Let $x_{j} P_{i} x_{i}$ and $x_{j}^{\prime} P_{i} x_{i}^{\prime}$. Then, according to the alternative axiom, $\mu \geq \mu^{\prime}$ implies $E\left(x_{i}, x_{j}, R_{i}, \bar{R}\right) \geq E\left(x_{i}^{\prime}, x_{j}^{\prime}, R_{i}^{\prime}, \bar{R}\right)$ with strict inequality holding if and only if $\mu>\mu^{\prime}$. Replacing $r$-proportionality by this alternative axiom in Theorem 2.1 yields the following class of measures: for each social state $\left(x_{N}, R_{N}\right)$ in $S$, we have

$$
E\left(x_{N}, R_{N}\right)=\sum_{i \in N} \sum_{j \in N} g\left(v_{r}\left(x_{j}, R_{i}\right)-v_{r}\left(x_{i}, R_{i}\right)\right),
$$

where $v_{r}\left(x_{i}, R_{i}\right)$ is the real number such that $x_{i} I_{i}\left(r+v_{r}\left(x_{i}, R_{i}\right) 1_{m}\right)$, and $g: \mathbb{R} \rightarrow \mathbb{R}$ is a function with $g$ strictly increasing on the interval $(0,+\infty)$ and $g(t)=0$ for each $t \leq 0$. The proof involves a simple adaptation of the proof of Proposition 2.2 and is therefore omitted.

\footnotetext{
${ }^{12}$ Fleurbaey's approach to measure elementary envy is similar to that used in the Chaudhuri and Diamantaras-Thomson measures.
} 


\subsection{Concluding remark}

We conclude with a remark on the connection between envy measures and inequality measures. The literature on multidimensional inequality measurement focuses on the setting with multiple commodities but homogenous preferences. ${ }^{13}$ If $R_{i}=R$ for each individual $i$, then the envy measures in equations (2.4) and (2.5) correspond to so-called two-stage inequality measures. ${ }^{14}$ The utility vectors, $\left(u_{r}\left(x_{i}, R\right)\right)_{i \in N}$ for (2.4) and $\left(v_{r}\left(x_{i}, R\right)\right)_{i \in N}$ for (2.5), are computed in the first stage. The second stage applies a unidimensional (income) inequality measure to these utility vectors. For the second stage, it is easy to obtain well-known unidimensional inequality measures such as the absolute Gini index, the variance and the variance of logarithms as special cases of equations (2.4) or (2.5). ${ }^{15}$ This connection suggests envy measurement as a generalization of the two-stage approach to the setting of heterogenous preferences.

\footnotetext{
${ }^{13}$ See Weymark (2006) and Chakravarty (2009) for surveys. While contributions to this literature do not always explicitly define preferences, an interpretation in terms of (homogenous) preferences is usually valid (see e.g., Tsui (1995, pp. 252-253).

${ }^{14}$ Maasoumi (1986) introduced the two-stage approach. See Dardanoni (1995), Weymark (2006) and Bosmans et al. (2015) for further discussions.

${ }^{15}$ See Ebert (2010) for definitions of these and other measures covered by equations (2.4) and (2.5). In a fixed-population setting, the envy measures and inequality measures correspond exactly. In a variable-population setting, division by $2|N|^{2}$ is required to obtain the inequality measures.
} 



\section{LAISSEZ-FAIRE VERSUS PARETO ${ }^{1}$}

\subsection{Introduction}

Libertarianism ascribes intrinsic value to laissez-faire outcomes. Proponents of this political philosophy accordingly regard redistributive taxation as an inherent injustice. For example, Nozick (1974, p. 169) states that "Taxation of earnings from labor is on a par with forced labor. ... taking the earnings of $n$ hours labor is like taking $n$ hours from the person; it is like forcing the person to work $n$ hours for another's purpose." The respect for laissez-faire outcomes is not restricted to the "rightward" extreme of the liberal spectrum. It is also a component of egalitarian liberalism, which disapproves redistribution to redress inequalities resulting from the exercise of personal responsibility. ${ }^{2}$

We introduce a "laissez-faire" principle to capture the above ethical role for laissez-faire outcomes. To do so, we distinguish between an individual's market income (without government intervention) and her disposable income (after government intervention). Consider a social state in which disposable incomes coincide with market incomes. The laissez-faire principle simply says

\footnotetext{
${ }^{1}$ This chapter is based on collaborative work with Kristof Bosmans.

${ }^{2}$ As Arneson (1990, p. 176) puts it, "distributive justice does not recommend any intervention by society to correct inequalities that arise through the voluntary choice or fault of those who end up with less, so long as it is proper to hold the individuals responsible for the voluntary choice or faulty behavior that gives rise to the inequalities." Inequalities arising from other sources do call for redistribution according to egalitarian liberalism. See also Dworkin (1981b), Rawls (1982) and Cohen (1989).
} 
that redistribution that moves disposable incomes away from market incomes (while preserving total income) results in a socially worse social state.

We show that the laissez-faire principle, when combined with the Pareto principle, puts strong demands on the social ranking. According to the weak Pareto principle, an increase in the disposable income (which we assume to measure utility) of every individual is a social improvement. Our main result says that a social ranking satisfies laissez-faire and weak Pareto only if it maximizes total disposable income (Theorem 3.1). That is, with the exception of comparisons involving equal total disposable incomes, the social ranking must ignore distributional considerations altogether. The result is striking, as it is counter to treating the relationship between disposable incomes and market incomes as intrinsically important. We further show that there is no social ranking that satisfies the laissez-faire principle and the Pareto indifference principle (Theorem 3.2).

Our results reveal a strong tension between the laissez-faire principle and the Pareto principle. This poses a clear challenge for the important task of incorporating liberal political philosophies into the standard 'Paretian' economic framework for social evaluation.

\subsection{Results}

The set of individuals is $N=\{1, \ldots, n\}$. For each individual $i$ in $N$, the real number $x_{i}$ denotes her disposable income (after government intervention) and the real number $m_{i}$ denotes her market income (without government intervention). ${ }^{3}$ Let $x=\left(x_{1}, \ldots, x_{n}\right)$ and $m=\left(m_{1}, \ldots, m_{n}\right)$. We refer to a pair $(x, m)$ as a social state. ${ }^{4}$ The set $S=\mathbb{R}^{n} \times \mathbb{R}^{n}$ collects all social states. We assume that each individual ranks the social states in $S$ in accordance with her own disposable

\footnotetext{
${ }^{3}$ Because of individual responses to government intervention, incomes "before" intervention need not coincide with incomes "without" intervention. The latter are the ones relevant for our purpose.

${ }^{4}$ For a social state $(x, m)$, we allow total disposable income $\sum_{i} x_{i}$ to be greater than, equal to or smaller than total market income $\sum_{i} m_{i}$. Note that the proofs of Theorems 3.1 and 3.2 still work if we impose, for each social state $(x, m)$, that $\sum_{i} x_{i}=\sum_{i} m_{i}$.
} 
income. That is, individual $i$ in $N$ weakly prefers social state $(x, m)$ to social state $\left(x^{\prime}, m^{\prime}\right)$ if and only if $x_{i} \geq x_{i}^{\prime}$.

The aim is to compare social states on the basis of social welfare. A social ranking $R$ is a reflexive and transitive binary relation in $S$. The asymmetric and symmetric parts of $R$ ('is at least as good as') are denoted by $P$ ('is better than') and $I$ ('is equally good as').

We impose two principles on the social ranking. The first principle expresses respect for laissez-faire outcomes. Consider a social state that gives each individual a disposable income equal to her market income. Laissez-faire demands that any redistribution (that preserves total disposable income) is regarded as a social worsening.

Laissez-faire. For all social states $(x, m)$ and $\left(x^{\prime}, m\right)$ in $S$ such that $\sum_{i} x_{i}=$ $\sum_{i} x_{i}^{\prime}=\sum_{i} m_{i}$, if $x=m$ and $x^{\prime} \neq m$, then $(x, m) P\left(x^{\prime}, m\right)$.

The second principle is a weak form of the Pareto principle. Weak Pareto requires that an increase in the disposable income of every individual is regarded as a social improvement.

Weak Pareto. For all social states $(x, m)$ and $\left(x^{\prime}, m^{\prime}\right)$ in $S$, if $x_{i}>x_{i}^{\prime}$ for each $i$ in $N$, then $(x, m) P\left(x^{\prime}, m^{\prime}\right)$.

Our main result says that the combination of laissez-faire and weak Pareto forces the social ranking to maximize total disposable income.

Theorem 3.1. If a social ranking $R$ satisfies laissez-faire and weak Pareto, then, for all social states $(x, m)$ and $\left(x^{\prime}, m^{\prime}\right)$ in $S$,

$$
\sum_{i} x_{i}>\sum_{i} x_{i}^{\prime} \text { implies }(x, m) P\left(x^{\prime}, m^{\prime}\right) .
$$

Proof. Let $R$ satisfy laissez-faire and weak Pareto. Let $(x, m)$ and $\left(x^{\prime}, m^{\prime}\right)$ be social states in $S$ such that $\sum_{i} x_{i}>\sum_{i} x_{i}^{\prime}$. We will show that $(x, m) P\left(x^{\prime}, m^{\prime}\right)$. Let $1_{n}$ be the $n$-vector with a one at each entry.

First, assume that there is a positive real number $\mu$ such that $x=\left(x^{\prime}+\mu 1_{n}\right)$. Then we have $(x, m) P\left(x^{\prime}, m^{\prime}\right)$ by weak Pareto. 
Next, assume that there is no positive real number $\mu$ such that $x=\left(x^{\prime}+\mu 1_{n}\right)$. Let $\delta$ be the positive real number for which $\sum_{i} x_{i}-\sum_{i} x_{i}^{\prime}=2 \delta n$.

By weak Pareto, we have

$$
(x, m) P\left(x-\delta 1_{n}, x-\delta 1_{n}\right)
$$

Note that $\sum_{i}\left(x_{i}-\delta\right)=\sum_{i}\left(x_{i}^{\prime}+\delta\right)$ and, by the above assumption, we have $\left(x-\delta 1_{n}\right) \neq\left(x^{\prime}+\delta 1_{n}\right)$. Hence, by laissez-faire, we have

$$
\left(x-\delta 1_{n}, x-\delta 1_{n}\right) P\left(x^{\prime}+\delta 1_{n}, x-\delta 1_{n}\right) .
$$

By weak Pareto, we have

$$
\left(x^{\prime}+\delta 1_{n}, x-\delta 1_{n}\right) P\left(x^{\prime}, m^{\prime}\right) .
$$

Using transitivity, we obtain $(x, m) P\left(x^{\prime}, m^{\prime}\right)$.

Laissez-faire and weak Pareto are surprisingly demanding if imposed jointly on a social ranking. ${ }^{5}$ Comparisons of social states with different total disposable incomes must be made solely on the basis of total disposable income. In all such comparisons, the social ranking must therefore ignore the relationship between disposable incomes and market incomes. Proponents of liberal political philosophies may find this implication hard to swallow. They may reject, for example, a policy that only marginally increases total disposable income, but at the cost of a major shift of disposable incomes away from market incomes. ${ }^{6}$

\footnotetext{
${ }^{5}$ The following example shows that there exist social rankings that satisfy laissez-faire and weak Pareto. For each social state $(x, m)$ in $S$, let $v(x-m)$ denote the variance of the vector $x-m=\left(x_{1}-m_{1}, \ldots, x_{n}-m_{n}\right)$. Let $R$ be the social ranking such that, for all social states $(x, m)$ and $\left(x^{\prime}, m^{\prime}\right)$ in $S$, we have that (i) if $\sum_{i} x_{i}>\sum_{i} x_{i}^{\prime}$, then $(x, m) P\left(x^{\prime}, m^{\prime}\right)$ and (ii) if $\sum_{i} x_{i}=\sum_{i} x_{i}^{\prime}$, then $(x, m) R\left(x^{\prime}, m^{\prime}\right)$ if and only if $v(x-m) \leq v\left(x^{\prime}-m^{\prime}\right)$. The (complete) social ranking $R$ satisfies laissez-faire and weak Pareto.

${ }^{6}$ Consider an example with two individuals. Let $(x, m)$ be such that $x=m=(0,100)$ and let $\left(x^{\prime}, m\right)$ be such that $x^{\prime}=(100+\varepsilon, 0)$ with $\varepsilon>0$. It is clear that in social state $\left(x^{\prime}, m\right)$ the disposable incomes and market incomes are far apart. A mild extension of laissez-faire would be that $(x, m)$ should be socially preferred to $\left(x^{\prime}, m\right)$ for some small $\varepsilon>0$. But Theorem 3.1 says that $\left(x^{\prime}, m\right) P(x, m)$ for each $\varepsilon>0$.
} 
Next, we consider the implications of strengthening weak Pareto. The 'full' Pareto principle is usually defined as the combination of strong Pareto and Pareto indifference. Strong Pareto demands that if the disposable income of at least one individual increases and the disposable income of no individual decreases, then this is deemed a social improvement.

Strong Pareto. For all social states $(x, m)$ and $\left(x^{\prime}, m^{\prime}\right)$ in $S$, if $x_{i} \geq x_{i}^{\prime}$ for each $i$ in $N$ with at least one strict inequality, then $(x, m) P\left(x^{\prime}, m^{\prime}\right)$.

Pareto indifference requires that if each individual is indifferent between two social states, i.e., has the same disposable income in both, then these two social states are regarded as socially equally good.

Pareto indifference. For all social states $(x, m)$ and $\left(x^{\prime}, m^{\prime}\right)$ in $S$, if $x_{i}=x_{i}^{\prime}$ for each $i$ in $N$, then $(x, m) I\left(x^{\prime}, m^{\prime}\right)$.

A direct implication of Theorem 3.1 is that the combination of laissez-faire and weak Pareto implies strong Pareto.

Corollary 1. If a social ranking $R$ satisfies laissez-faire and weak Pareto, then $R$ satisfies strong Pareto.

Pareto indifference cannot, however, be combined with laissez-faire. Hence, a social ranking that satisfies laissez-faire must violate the full Pareto principle.

Theorem 3.2. There is no social ranking that satisfies laissez-faire and Pareto indifference.

Proof. Assume that $R$ is a social ranking that satisfies laissez-faire and Pareto indifference.

Let $x$ and $x^{\prime}$ in $\mathbb{R}^{n}$ be such that $\sum_{i} x_{i}=\sum_{i} x_{i}^{\prime}$ and $x \neq x^{\prime}$. We have $\left(x, x^{\prime}\right) I(x, x)$ by Pareto indifference, $(x, x) P\left(x^{\prime}, x\right)$ by laissez-faire. Pareto indifference implies $\left(x^{\prime}, x\right) I\left(x^{\prime}, x^{\prime}\right)$. Thus, by transitivity, $\left(x, x^{\prime}\right) P\left(x^{\prime}, x^{\prime}\right)$. But we have $\left(x^{\prime}, x^{\prime}\right) P\left(x, x^{\prime}\right)$ by laissez-faire. 
To end this section, we discuss the relation between our results and a result by Kaplow and Shavell (2001, p. 284), which states that a social ranking "that is not purely welfarist violates the Pareto principle". Laissez-faire makes the social ranking non-welfarist, as it makes it dependent on non-preference information, viz., the market incomes. Nevertheless, it would be a mistake to regard Theorem 3.2 as a mere implication of the result by Kaplow and Shavell (2001). What their result in fact shows is that a complete and continuous ${ }^{7}$ social ranking that satisfies weak Pareto (which they identify with the Pareto principle) must satisfy Pareto indifference (which they identify with welfarism). ${ }^{8}$ Therefore, the result of Kaplow and Shavell concerns a relationship between two components of the full Pareto principle, whereas our results in Theorems 3.1 and 3.2 concern relationships between a component of the full Pareto principle on the one hand and the (non-welfarist) laissez-faire principle on the other hand.

\subsection{Conclusion}

The economic literature has traditionally stressed the role of laissez-faire as an instrument for welfare maximization. Our results show the difficulties in treating the respect for laissez-faire outcomes as an end in itself. If the full Pareto principle is required, then no social ranking can satisfy the laissez-faire principle. If only weak Pareto is required, then there are possibilities, but these are very restricted. In cases where the social states differ in total disposable income, market incomes must be ignored and the social state with greater total disposable income must be chosen, leaving little room for liberal values.

We end with a digression on two taxation principles, viz., equal sacrifice and liberal reward. Interpret $m$ as the pre-tax income distribution and $x$ as the post-tax income distribution. The question is how to divide the total tax burden $\sum_{i} m_{i}-\sum_{i} x_{i}$ among the individuals. The equal sacrifice principle says that taxes

\footnotetext{
${ }^{7}$ A social ranking $R$ satisfies continuity if, for all social states $(x, m)$ and $(y, m)$ in $S$, if a sequence of vectors $\left\{y^{k}\right\}_{k \in \mathbb{N}}$ converges to $y$ and $(x, m) R\left(y^{k}, m\right)$ (respectively, $\left(y^{k}, m\right) R(x, m)$ ) for each $k$ in $\mathbb{N}$, then $(x, m) R(y, m)$ (respectively, $(y, m) R(x, m)$ ).

${ }^{8}$ See also the exchange between Fleurbaey et al. (2003) and Kaplow and Shavell (2004).
} 
should be such that each individual incurs the same utility loss. ${ }^{9}$ Let $u: \mathbb{R} \rightarrow \mathbb{R}$ be an increasing function, to be interpreted as the common utility function. The equal sacrifice principle demands that, for all social states $(x, m)$ and $\left(x^{\prime}, m\right)$ in $S$ such that $\sum_{i} x_{i}=\sum_{i} x_{i}^{\prime}$, if $u\left(x_{1}\right)-u\left(m_{1}\right)=u\left(x_{2}\right)-u\left(m_{2}\right)=\cdots=u\left(x_{n}\right)-u\left(m_{n}\right)$ and $x \neq x^{\prime}$, then $(x, m) P\left(x^{\prime}, m\right)$. It is immediate that equal sacrifice implies laissez-faire. Indeed, equal sacrifice implies that if the tax burden $\sum_{i} m_{i}-\sum_{i} x_{i}$ is zero (the case laissez-faire deals with), then pre-tax income and post-tax income should coincide.

The liberal reward principle says that, if individuals differ only with respect to responsibility characteristics, then taxes should be such that each individual incurs the same income loss. ${ }^{10}$ The liberal reward principle is obtained from the equal sacrifice principle by setting $u$ equal to the identity function. Again, provided we regard all individuals as equals with respect to non-responsibility characteristics, liberal reward implies laissez-faire.

Both equal sacrifice and liberal reward extend laissez-faire. By consequence, our results are also relevant for the study of these principles. The principles are difficult to incorporate into a social ranking together with the natural requirement of the Pareto principle. ${ }^{11}$

\footnotetext{
${ }^{9}$ The equal sacrifice principle was proposed by, among others, Mill (1865). See Musgrave (1959) for a historical account. For modern uses of the principle, see, e.g., Young (1987, 1990) and Weinzierl (2014).

${ }^{10}$ The principle is one of the two components of the equality of opportunity idea of egalitarian liberalism (see Section 3.1), the other being the compensation principle, which says that taxes should be such that post-tax incomes of individuals who differ only with respect to non-responsibility characteristics are equal. On this literature, Fleurbaey and Maniquet (2004), Fleurbaey (2008) and Roemer and Trannoy (2013).

${ }^{11}$ Theorem 3.1 is particularly interesting in the context of the liberal reward principle. The result says that in many comparisons we must follow instead what is known as the utilitarian reward principle, which advocates maximization of incomes rather than, as liberal reward, minimizing deviations from the market incomes. See Roemer (1993) and Van de gaer (1993).
} 



\section{MEASUREMENT OF EQUALITY OF OPPORTUNITY: A NORMATIVE APPROACH ${ }^{1}$}

\subsection{Introduction}

The theory of equality opportunity distinguishes between two types of individual characteristics: circumstances and responsibility characteristics. ${ }^{2}$ The former are characteristics for which individuals cannot be held responsible such as gender, race, sexual orientation, parental background and parents' education. The latter are those we can hold individuals accountable for such as effort. In the classical approach to inequality measurement, on the other hand, it is assumed that individuals are homogeneous in all dimensions except for the outcome in question, and hence any inequality is unfair. However, we know from social and political debate, surveys (Schokkaert and Devooght, 2003) and economic experiments (Cappelen et al., 2007) that the conception of fairness adopted by the theory of equality of opportunity might reflect fairness ideals upheld by people better. More importantly, a society in which people are not discriminated against on the basis of race, ethnicity, religion, gender and sexual orientation is desirable in itself (Arneson, 2015). Moreover, as argued by the The World Bank (2005), equality of opportunity rather than equality of outcomes can be instrumental for economic growth. Indeed, Marrero and

\footnotetext{
${ }^{1}$ This chapter is based on collaborative work with Kristof Bosmans.

${ }^{2}$ See Dworkin (1981a,b), Arneson (1989) and Cohen (1989).
} 
Rodríguez (2013) find a negative relationship between inequality of opportunity and growth using Panel Study of Income Dynamics data for the U.S. Equality of opportunity is thus an important concept normatively and practically.

Two principles are at the heart of equality of opportunity as an ideal: the principle of compensation and the principle of reward. Compensation says that circumstances should not have an impact on individuals' achievements. Two interpretations of the principle of compensation, ex post compensation and ex ante compensation, can be found in the literature. This distinction is due to Ooghe et al. (2007) and Fleurbaey and Peragine (2013). ${ }^{3}$

The ex post approach to compensation focuses on the income levels of individuals who share the same responsibility characteristics. ${ }^{4}$ We propose two axioms that capture the ex post approach to compensation: ex post PigouDalton compensation and ex post compensation symmetry. Ex post PigouDalton compensation says that an income transfer widening the income gap between two individuals with the same responsibility characteristics reduces social welfare. Ex post compensation symmetry says that two individuals in the same responsibility group must be treated in a symmetric way, that is, permuting their incomes leaves social welfare unchanged.

The ex ante approach to compensation focuses on income distributions of circumstance groups which are considered to represent opportunity sets of circumstance groups. ${ }^{5}$ We use two axioms to capture the ex ante approach to compensation: ex ante Pigou-Dalton compensation and ex ante compensation symmetry. Ex ante Pigou-Dalton compensation says that equalizing opportunity sets of circumstance groups increases social welfare. Ex ante compensation symmetry says that two circumstance groups should be treated in a symmetric way, that is, permuting their opportunity sets leaves social welfare unchanged.

\footnotetext{
${ }^{3}$ Ooghe et al. (2007) call the ex post approach "the compensating outcomes approach", and the ex ante approach "the compensating sets approach". See also Ramos and Van de gaer (2012) for discussions of the ex ante ex post distinction.

${ }^{4}$ For uses of the ex post approach, see Bossert (1995), Bossert and Fleurbaey (1996), Fleurbaey (1994) and Roemer (1993, 1998a, 2002).

${ }^{5}$ See, for instance, Kranich (1996), Ok and Kranich (1998) and Van de gaer (1993).
} 
The second conception of equality of opportunity is the principle of reward. The principle is concerned with the appropriate amount of inequality due to differences in responsibility characteristics. Naturally, what is appropriate is subject to interpretation. We focus on two interpretations of the idea of reward: liberal reward and utilitarian reward. Utilitarian reward is indifferent to the manner in which a certain amount of income is distributed within a circumstance group. Liberal reward, on the other hand, says that laissez-faire outcomes must be respected within a circumstance group. That is, two individuals with the same circumstance characteristics must be subjected to the same government transfer.

In Section 4.4, we investigate the existence of social welfare functions that satisfy various combinations of compensation and reward. However, we find that market incomes must be additively separable if we are to combine liberal PigouDalton reward with ex post Pigou-Dalton compensation or ex ante compensation symmetry (Propositions 4.1 and 4.2). That is, the change in the market income of an individual caused by a change in his responsibility characteristics must be independent of his circumstances. Consequently, we characterize the class of welfare functions that combine liberal reward with the compensation principles in the case of additively separable market incomes only (Theorems 4.1 and 4.2). Moreover, we find that it is impossible to combine ex post compensation with utilitarian reward (Proposition 4.3). A domain restriction does not make sense in this case since utilitarian reward is independent of market incomes, so we present a class of welfare functions that satisfy a weaker version of utilitarian reward, called uniform utilitarian reward, and ex post Pigou-Dalton compensation (Theorem 4.4). Table 4.1 summarizes our results.

We also provide the optimal distribution of a given amount of income for each class of welfare functions. In the classical approach to inequality measurement, the optimal allocation assigns each individual the mean income in the society since individuals are assumed to be homogeneous. In our responsibility sensitive framework, on the other hand, fair income of an individual depends on his individual characteristics and the fairness principles used. Surprisingly, we find that, if one is only interested in the first-best allocations, the choice 
Table 4.1 Overview of the results.

\begin{tabular}{lcc}
\hline Axioms & Ex post compensation & Ex ante compensation \\
\hline Liberal reward & Theorem 4.1 & Theorem 4.2 \\
& (with AS $^{*}$ market incomes) & (with AS market incomes) \\
\hline Utilitarian reward & Incompatible & Theorem 4.3 \\
Uniform utilitarian reward & Theorem 4.4 & Not combined $^{\dagger}$ \\
\hline
\end{tabular}

* AS: additively separable. $\dagger$ We do not attempt to combine the two axioms since utilitarian reward is compatible with ex ante Pigou-Dalton compensation.

between ex ante and ex post compensation becomes irrelevant if combined with liberal reward. In this case, both approaches lead to the same allocation rule (Proposition 4.4).

In Section 4.5, we present our measures of inequality of opportunity. Following the procedure proposed by Atkinson (1970) and Kolm (1969), we propose to measure the inequality of opportunity in an income distribution by the per capita income that could be destroyed if incomes are distributed fairly and the resulting income distribution has the same welfare as the original distribution. Each of our indices is therefore a measure of welfare waste due to unfairness. We show that this is equivalent to measuring inequality of opportunity in a distribution by the difference between the welfare at the actual distribution and welfare at the fair distribution of the same total income (Proposition 4.5). Thus, the welfare function classes characterized serve as the ethical basis for the inequality measures in the sense that the inequality of opportunity registered increases as an income distribution moves further (in terms of welfare difference) from the optimal distribution.

The axioms defined here can be found in the literature on equality of opportunity. The main contribution of this paper is in providing a complete picture of the relationship between compensation and reward axioms. We present social welfare functions, allocation rules, and inequality measures for each possible combination of the two principles. Each of these tools interrelates with all 
the others. For instance, for the researcher who wishes to use the inequality measures here, which social welfare function to use is clear. Similarly, if one wants to focus only on the first-best allocations, the optimal distribution to choose is clear depending on one's fairness perceptions.

\subsection{Preliminaries}

Each individual is characterized by his circumstance and responsibility characteristics. The set of all circumstance characteristics is $C=\{1, \ldots, c\}$ and the set of all responsibility characteristics is $R=\{1, \ldots, r\}$. For simplicity, we assume that every combination $(i, j)$ in $C \times R$ is represented by exactly one individual. Thus, we refer to each $(i, j)$ as an individual.

We use a $c \times r$ real-valued matrix $X$ to represent an income distribution. The $i j$ th entry of $X$, denoted by $x_{i j}$, is the income of individual $(i, j)$. The $i$ th row of $X$ is denoted by $x_{i}$. and the $j$ th column is denoted by $x_{\text {. }}$. The vector $x_{i}$. can be interpreted as the income prospect of group $i$.

We distinguish between an individual's income with and without government intervention. We refer to the latter as his market income. The market income distribution is a matrix $M$ in $\mathbb{R}^{c \times r}$. The distinction between the income and market income of an individual is needed since the market income distribution is ethically significant according to the liberal reward principles (Section 4.3.2).

We do not restrict ourselves to income distributions where the sum of market incomes is equal to the sum of incomes. These two might differ due to individual responses to government intervention. Additionally, different sums of income in $X$ and $M$ might be observed due to government policies such as a welfare program.

We denote by $1_{n}$ and $1_{c \times r}$ the $n$-dimensional vector and the $c \times r$ matrix with 1 at each entry, respectively.

We use a social welfare function to compare income distributions. A social welfare function $W: \mathbb{R}^{c \times r} \rightarrow \mathbb{R}$ assigns a real number to each income distribution in $\mathbb{R}^{c \times r}$. The value $W$ assigns to an income distribution depends on $M$. We suppress this in the notation since $M$ is fixed. 
A social welfare function should satisfy a number of basic properties if it is to serve as the basis of value judgements. We formulate these properties as axioms.

The first group of axioms is not concerned with the distributional aspects of the social welfare function.

The first axiom says that increasing the income of an individual is socially desirable provided that nobody's income is decreased.

Monotonicity. For all income distributions $X$ and $X^{\prime}$ in $\mathbb{R}^{c \times r}$, if $x_{i j} \geq x_{i j}^{\prime}$ for each individual $(i, j)$ in $C \times R$ and $x_{k s}>x_{k s}^{\prime}$ for some individual $(k, s)$ in $C \times R$, then $W(X)>W\left(X^{\prime}\right)$.

Continuity ensures that the analysis is not sensitive to small changes in the distributions of income.

Continuity. The function $W$ is continuous.

The next axiom, translation invariance, says that adding a constant to the income of each individual does not change the ranking of two income distributions. Translation invariance ensures that the inequality indices we derive later are absolute. That is, adding the same constant to each income does not change the level of inequality of opportunity in a distribution. Thus, translation invariance guarantees that the ethically significant information is the income difference. $^{6}$

Translation invariance. For all income distributions $X$ and $X^{\prime}$ in $\mathbb{R}^{c \times r}$ and for each real number $\lambda$, we have $W(X) \geq W\left(X^{\prime}\right)$ if and only if $W\left(X+\lambda 1_{c \times r}\right) \geq$ $W\left(X^{\prime}+\lambda 1_{c \times r}\right)$.

The next two axioms are reasonable for a welfare function that takes the ex ante or ex post approach specifically. Ex ante aggregation says that the

\footnotetext{
${ }^{6} \mathrm{We}$ do not impose scale invariance (an axiom which says that multiplying each income with the same constant does not change the ranking of two income distributions) since it is not compatible with liberal Pigou-Dalton reward and liberal symmetry defined in Section 4.3.2. See the Appendix.
} 
social welfare function first aggregates across responsibility groups for each circumstance group. The obtained values are aggregated across circumstance groups in the second stage.

Ex ante aggregation. There exist a function $\phi: \mathbb{R}^{c} \rightarrow \mathbb{R}$ and functions $\gamma_{1}, \ldots, \gamma_{c}$ : $\mathbb{R}^{r} \rightarrow \mathbb{R}$ such that, for each income distribution $X$ in $\mathbb{R}^{c \times r}$, we have $W(X)=$ $\phi\left(\gamma_{1}\left(x_{1}.\right), \ldots, \gamma_{c}\left(x_{c}\right)\right)$.

Ex post aggregation says that the social welfare function first aggregates across circumstance groups for each responsibility group. The obtained values are aggregated across responsibility groups in the second stage.

Ex post aggregation. There exist a function $\phi: \mathbb{R}^{r} \rightarrow \mathbb{R}$ and functions $\gamma_{1}, \ldots, \gamma_{r}$ : $\mathbb{R}^{c} \rightarrow \mathbb{R}$ such that, for each income distribution $X$ in $\mathbb{R}^{c \times r}$, we have $W(X)=$ $\phi\left(\gamma_{1}\left(x_{\cdot 1}\right), \ldots, \gamma_{r}\left(x_{\cdot r}\right)\right)$.

Next, we present the principles of fairness.

\subsection{Compensation and reward principles}

\subsubsection{Compensation axioms}

Ex post compensation axioms focus on individuals with the same responsibility characteristics. The first, ex post Pigou-Dalton compensation, states that an income transfer widening the income gap between two members of the same responsibility group reduces social welfare.

Ex post Pigou-Dalton compensation. For all income distributions $X$ and $X^{\prime}$ in $\mathbb{R}^{c \times r}$, if there exist two individuals $(i, j)$ and $(k, j)$ in $C \times R$ such that $x_{i j} \geq x_{k j}$ and a positive real number $\delta$ such that $x_{i j}^{\prime}=x_{i j}+\delta$ and $x_{k j}^{\prime}=x_{k j}-\delta$ with $X$ and $X^{\prime}$ coinciding everywhere else, then $W(X)>W\left(X^{\prime}\right)$.

A complementary idea to ex post Pigou-Dalton compensation is that if one individual has more income than another member of the same responsibility group, the social welfare function should be indifferent to which circumstance group the richer individual belongs to. Ex post compensation symmetry captures 
this idea. The axiom says that permuting the incomes of two individuals in the same responsibility group does not change social welfare.

Ex post compensation symmetry. For all income distributions $X$ and $X^{\prime}$ in $\mathbb{R}^{c \times r}$, if there exist two individuals $(i, j)$ and $(k, j)$ in $C \times R$ such that $x_{i j}=x_{k j}^{\prime}$ and $x_{k j}=x_{i j}^{\prime}$ with $X$ and $X^{\prime}$ coinciding everywhere else, then $W(X)=W\left(X^{\prime}\right)$.

With the exception of Ooghe et al. (2007), ex post compensation symmetry is not an axiom commonly used in the literature. However, we believe that it is an important part of the ex post approach to compensation as the principle says that circumstances should not have an impact on individual achievements. Now imagine a social welfare function which does not satisfy ex post compensation symmetry. Suppose that there exist two income distributions $X$ and $X^{\prime}$ such that $x_{i j}>x_{k j}$, and $X^{\prime}$ is obtained via a permutation of income levels of $(i, j)$ and $(k, j)$ with $X$ and $X^{\prime}$ coinciding everywhere else. Now, having $W(X)>W\left(X^{\prime}\right)$ means that $(i, j)$ is favoured since the distribution he has a higher income in is valued more by the social welfare function. This is not justifiable from the point of view of compensation.

The next axiom, ex ante Pigou-Dalton compensation, is implied by ex post Pigou-Dalton compensation. Assume that, in an income distribution, the minimum income in a circumstance group $i$ is higher than the maximum income in another circumstance group $k$. In such a situation, we can unambiguously conclude that group $i$ is better off than group $k$. Imagine we take away an amount $\delta$ from every individual in the worse-off group, and give $\delta$ to each individual in the better-off group. Ex ante Pigou-Dalton compensation says that such a transfer reduces welfare.

Ex ante Pigou-Dalton compensation. For all income distributions $X$ and $X^{\prime}$ in $\mathbb{R}^{c \times r}$, if there exist two circumstance groups $i$ and $k$ in $C$ such that $\min _{j \in R} x_{i j} \geq$ $\max _{j \in R} x_{k j}$ and a positive real number $\delta$ such that $x_{i}^{\prime}=x_{i}+\delta 1_{r}$ and $x_{k}^{\prime}$. $x_{k}-\delta 1_{r}$ with $X$ and $X^{\prime}$ coinciding everywhere else, then $W(X)>W\left(X^{\prime}\right)$.

Ex ante Pigou-Dalton compensation is based on the idea that equality of opportunity needs to focus only on the income prospects (i.e., the vectors $x_{i}$.) 
of different circumstance groups. In this interpretation, equal prospects mean equal opportunities and hence, ex ante Pigou-Dalton compensation requires equalizing the opportunities of circumstance groups. ${ }^{7}$ Additionally, unlike its ex post counterpart, ex ante Pigou-Dalton compensation demands no information on responsibility characteristics. This can be an empirical advantage since responsibility characteristics are not always observable. ${ }^{8}$ Fleurbaey and Peragine (2013) find an incompatibility between what is called ex ante and ex post compensation in their context. This, however, is not the case in our setting. In fact, ex ante Pigou-Dalton compensation is implied by ex post Pigou-Dalton compensation.

A complementary idea to ex ante Pigou-Dalton compensation is that the different circumstance groups should be treated in a symmetric way. That is, their income distribution vectors can be permuted without influencing the social welfare level. This idea is captured by ex ante compensation symmetry. The axiom says that permuting two rows of an income distribution $X$ does not change social welfare. Note that, ex post compensation symmetry implies ex ante compensation symmetry. This is not surprising given the fact that ex post Pigou-Dalton compensation implies ex ante Pigou-Dalton compensation.

Ex ante compensation symmetry. For all income distributions $X$ and $X^{\prime}$ in $\mathbb{R}^{c \times r}$, if there exist two circumstance groups $i$ and $k$ such that $x_{i}=x_{k}^{\prime}$. and $x_{k}=x_{i}^{\prime}$. with $X$ and $X^{\prime}$ coinciding everywhere else, then $W(X)=W\left(X^{\prime}\right)$.

\subsubsection{Reward axioms}

Reward principles set the appropriate income distribution within a circumstance group based on responsibility characteristics. The two main principles of reward defined in the literature are liberal reward and utilitarian reward. Liberal reward and utilitarian reward differ in terms of their attitude towards responsibility. The former says that redistribution should stop once every difference

\footnotetext{
${ }^{7}$ See Kranich (1996), Ok and Kranich (1998) and Ooghe et al. (2007) for such an interpretation.

${ }^{8}$ Effort exerted is an example of a commonly used, unobservable responsibility characteristic.
} 
between individuals can be attributed to responsibility, whereas the latter is indifferent between any two distributions of the same total income within a circumstance group. ${ }^{9}$

First, we define liberal Pigou-Dalton reward. Liberal Pigou-Dalton reward demands that differences in market incomes due to responsibility characteristics be respected. That is, two individuals in the same circumstance group should be subjected to the same government transfer.

Consider two individuals $(i, j)$ and $(i, s)$ who are members of the same circumstance group. The government transfers received by $(i, j)$ and $(i, s)$ are $x_{i j}-m_{i j}$ and $x_{i s}-m_{i s}$. Assume that the government transfer received by $(i, j)$ is larger than the government transfer received by $(i, s)$. Liberal reward says that transferring income from $(i, s)$ to $(i, j)$ reduces welfare since such an income transfer further widens the gap between the government transfers received by $(i, s)$ and $(i, j)$.

Liberal Pigou-Dalton reward. For all income distributions $X$ and $X^{\prime}$ in $\mathbb{R}^{c \times r}$, if there exist two individuals $(i, j)$ and $(i, s)$ in $C \times R$ such that $x_{i j}-m_{i j} \geq$ $x_{i s}-m_{i s}$ and a positive real number $\delta$ such that $x_{i j}^{\prime}=x_{i j}+\delta$ and $x_{i s}^{\prime}=x_{i s}-\delta$ with $X$ and $X^{\prime}$ coinciding everywhere else, then $W(X)>W\left(X^{\prime}\right)$.

Let us illustrate the axiom with a simple example. Imagine a society with one circumstance group and three responsibility groups. Let $X$ and $X^{\prime}$ be such that $X=(7,7,13)$ and $X^{\prime}=(8,6,13)$. Assume $M=(7,9,14)$. Note that the distributions of government transfers in $X$ and $X^{\prime}$ are $X-M=(0,-2,-1)$ and $X^{\prime}-M=(1,-3,-1)$, respectively. The government transfers received by the individuals in the first and second responsibility groups are closer to each other in $X$ than in $X^{\prime}$. Thus, liberal Pigou-Dalton reward considers $X$ better than $X^{\prime}$. The best distribution of the total income in $X$ and $X^{\prime}$ with respect to liberal Pigou-Dalton reward is $(6,8,13)$ since each individual receives a transfer of -1 in this case.

Liberal symmetry, similar to ex post and ex ante compensation symmetry, presents a complementary idea to liberal Pigou-Dalton reward. It says that

\footnotetext{
${ }^{9}$ See Fleurbaey (2008) for a detailed discussion of these two principles.
} 
permuting the government transfers received by two individuals in the same circumstance group leaves social welfare unchanged. Note that such a permutation does not alter the total income of the circumstance group.

Liberal symmetry. For all income distributions $X$ and $X^{\prime}$ in $\mathbb{R}^{c \times r}$, if there exist two individuals $(i, j)$ and $(i, s)$ in $C \times R$ such that $x_{i j}-m_{i j}=x_{i s}^{\prime}-m_{i s}$ and $x_{i s}-m_{i s}=x_{i j}^{\prime}-m_{i j}$ with $X$ and $X^{\prime}$ coinciding everywhere else, then $W(X)=$ $W\left(X^{\prime}\right)$.

To explain liberal symmetry, let $M=(7,9,14)$ and $X^{\prime \prime}=(5,9,13)$. Note that we have $X^{\prime \prime}-M=(-2,0,-1)$. Liberal symmetry says that $W$ should be indifferent between $X^{\prime \prime}$ and $X=(7,7,13)$ since $X^{\prime \prime}-M=(-2,0,-1)$ is obtained from $X-M=(0,-2,-1)$ by a permutation.

The second reward principle we define is utilitarian reward. Utilitarian reward requires the social welfare function to be neutral to the specific way that a given amount of income is distributed among members of a circumstance group. ${ }^{10}$

Utilitarian reward. For all income distributions $X$ and $X^{\prime}$ in $\mathbb{R}^{c \times r}$, if there exist two individuals $(i, j)$ and $(i, s)$ in $C \times R$ and a positive real number $\delta$ such that $x_{i j}^{\prime}=x_{i j}+\delta$ and $x_{i s}^{\prime}=x_{i s}-\delta$ with $X$ and $X^{\prime}$ coinciding everywhere else, then $W(X)=W\left(X^{\prime}\right)$.

Utilitarian reward is based on the idea that fairness need not be concerned with inequalities due to responsibility. Utilitarian reward is indifferent between $X=(7,7,13)$ and $X^{\prime}=(8,6,13)$ in the example above, unlike liberal PigouDalton reward which considers $X$ better than $X^{\prime}$.

Proposition 4.3 in the next section shows that utilitarian reward is incompatible with ex post Pigou-Dalton compensation. Uniform utilitarian reward is a weaker version of utilitarian reward that is compatible with ex post PigouDalton compensation. The axiom says that transferring the same amount $\delta$ from everyone in a responsibility group to everyone in another responsibility group does not alter social welfare.

\footnotetext{
${ }^{10}$ A slightly different version of utilitarian reward has been used by, for example, Checchi and Peragine (2010), Ferreira and Gignoux (2011) and Ooghe et al. (2007).
} 
Uniform utilitarian reward. For all income distributions $X$ and $X^{\prime}$ in $\mathbb{R}^{c \times r}$, if there exist two responsibility groups $j$ and $s$ in $R$ and a positive real number $\delta$ such that $x_{\cdot j}^{\prime}=x_{\cdot j}+\delta 1_{c}, x_{\cdot s}^{\prime}=x_{\cdot s}-\delta 1_{c}$ with $X$ and $X^{\prime}$ coinciding everywhere else, then $W(X)=W\left(X^{\prime}\right)$.

We present the characterization results in the next section.

\subsection{Results}

\subsubsection{Compensation and liberal reward}

In this section, we present the classes of social welfare functions that combine liberal reward with compensation.

In Theorems 4.1 and 4.2, we assume that market incomes are additively separable. We say that market incomes are additively separable if $m_{i j}-m_{i s}=$ $m_{k j}-m_{k s}$ for all circumstance groups $i$ and $k$ and all responsibility groups $j$ and $s .{ }^{11}$ That is, a change in the responsibility characteristics of an individual leads to the same change in his market income regardless of his circumstances.

This restriction is necessary to combine liberal reward with ex post PigouDalton compensation. ${ }^{12}$

Proposition 4.1. If a social welfare function $W$ satisfies ex post Pigou-Dalton compensation and liberal Pigou-Dalton reward, then market incomes must be additively separable.

Let us illustrate this impossibility with a simple example. Assume that $c=2$ and $r=2$. Consider

\footnotetext{
${ }^{11}$ The literature uses an income function $f$ where $f(i, j)$ is the market income of $(i, j)$. Market incomes are said to be additively separable if there exist functions $g$ and $h$ such that for each $(i, j)$, we have $f(i, j)=g(i)+h(j)$. An equivalent condition for the additive separability of $f$ is that we have $f(i, j)-f(i, s)=f(k, j)-f(k, s)$. Thus, our definition of additive separability is the same as the one used in the literature.

${ }^{12}$ Necessity of additively separable market incomes in order to combine ex post Pigou-Dalton compensation and liberal Pigou-Dalton reward has been shown by Bossert (1995), Bossert and Fleurbaey (1996) and Fleurbaey $(1994,1995)$ in the context of allocation rules and by Fleurbaey (2008) and Fleurbaey and Peragine (2013) in a context of social rankings.
} 


$$
X=\left[\begin{array}{ll}
5 & 6 \\
5 & 6
\end{array}\right] \text { and } M=\left[\begin{array}{ll}
0 & 3 \\
1 & 0
\end{array}\right]
$$

Note that market incomes are not additively separable. Liberal Pigou-Dalton reward considers it an improvement to transfer 1 unit of income from individual $(1,1)$ to individual $(1,2)$ since this equalizes the government transfers received by these two individuals. Similarly, transferring 1 unit of income from individual $(2,2)$ to individual $(2,1)$ is an improvement. We therefore reach the distribution

$$
X^{\prime}=\left[\begin{array}{ll}
4 & 7 \\
6 & 5
\end{array}\right] \text {. }
$$

By liberal Pigou-Dalton reward, $W\left(X^{\prime}\right)>W(X)$. By ex post Pigou-Dalton compensation, on the other hand, $W(X)>W\left(X^{\prime}\right)$ since the equality of incomes within responsibility groups is distorted in $X^{\prime}$.

We find that the same restriction is needed for a welfare function to satisfy liberal Pigou-Dalton reward and ex ante compensation symmetry.

Proposition 4.2. If a social welfare function $W$ satisfies liberal Pigou-Dalton reward and ex ante compensation symmetry, then market incomes must be additively separable.

To see the incompatibility, consider

$$
M=\left[\begin{array}{cc}
2 & 4 \\
10 & 14
\end{array}\right], X=\left[\begin{array}{cc}
11 & 13 \\
10 & 14
\end{array}\right] \text { and } X^{\prime}=\left[\begin{array}{cc}
10 & 14 \\
11 & 13
\end{array}\right]
$$

Note that market incomes are not additively separable. By ex ante compensation symmetry, $W(X)=W\left(X^{\prime}\right)$. By liberal Pigou-Dalton reward, however, we have $W(X)>W\left(X^{\prime}\right)$

Before presenting the characterization results, we need to introduce new notation. For each $i$ in $C$, let $\mu^{i}$ be the $r$-dimensional vector obtained by subtracting the minimum income in the vector $m_{i}$. from each component of $m_{i}$. That is, $\mu^{i}=\left(m_{i 1}-\min \left\{m_{i 1}, \ldots, m_{i r}\right\}, \ldots, m_{i r}-\min \left\{m_{i 1}, \ldots, m_{i r}\right\}\right)$. Note that market incomes are additively separable if and only if there exists a vector $\mu$ in $\mathbb{R}^{r}$ such that $\mu^{i}=\mu$ for each circumstance group $i$ in $C$. We call the vector 
$\mu$ the summary vector since it describes the manner in which market income changes across responsibility groups. In the next two theorems, we make use of a vector $\mu$ defined this way.

Theorem 4.1 presents the class of social welfare functions that combine ex post compensation with liberal reward when market incomes are additively separable. The social welfare function in (4.1) first subtracts the vector $\mu$ from each income at $X$. The resulting vectors are evaluated by a translatable ${ }^{13}$ and Schur-concave ${ }^{14}$ function $f$. Subtracting $\mu$ ensures that the welfare function satisfies liberal Pigou-Dalton reward and its symmetry counterpart.

We denote by $\mathbb{R}^{c r}$ the set of $c \times r$-dimensional real valued vectors.

Theorem 4.1. Suppose that market incomes are additively separable with summary vector $\mu$ in $\mathbb{R}^{r}$. A social welfare function $W$ satisfies monotonicity, continuity, translation invariance, liberal symmetry, ex post compensation symmetry, liberal Pigou-Dalton reward and ex post Pigou-Dalton compensation if and only if there exists a strictly increasing, continuous, translatable and Schur-concave function $f: \mathbb{R}^{c r} \rightarrow \mathbb{R}$ such that, for each $X$ in $\mathbb{R}^{c \times r}$,

$$
W(X)=f\left(x_{1 .}-\mu, x_{2 \cdot}-\mu, \ldots, x_{c}-\mu\right) .
$$

Theorem 4.2 presents the class of ex ante social welfare functions that combine compensation with liberal reward when market incomes are additively separable. The social welfare function in (4.2) aggregates in two steps. In the first step, the welfare function focuses on the income distributions of circumstance groups. The vector $\mu$ is subtracted from each row of $X$. The resulting vectors are evaluated by a unit-translatable and Schur-concave function $g$. Note that a difference between two elements of the vector $x_{i}$. $-\mu$ is the difference between the government transfers received by the corresponding individuals.

\footnotetext{
${ }^{13}$ A function $f: \mathbb{R}^{n} \rightarrow \mathbb{R}$ is unit-translatable if $f\left(x+\delta 1_{n}\right)=f(x)+\delta$ for every real number $\delta$. The function is translatable if there exist a strictly increasing function $\phi$ and a unit-translatable function $g$ such that, for each $x$ in $\mathbb{R}^{n}$, we have $f(x)=\phi(g(x))$.

${ }^{14}$ A function $f: \mathbb{R}^{n} \rightarrow \mathbb{R}$ is Schur concave if $f(B x) \geq f(x)$ for all $x$ in $\mathbb{R}^{n}$ and all $n \times n$ bistochastic matrices $B$. A bistochastic matrix is a nonnegative square matrix of which each row sum and each column sum is equal to 1 . Note that Schur-concavity implies symmetry of $f$.
} 
Hence, this step ensures that social welfare increases if the government transfers received by two individuals in the same circumstance group are equalized.

In the second step, the values assigned by $g$ are aggregated via a Schurconcave and translatable function $f$. Note that, since $g$ is unit-translatable and $f$ is S-concave, transferring the same $\delta$ from each individual in a better-off circumstance group to each individual in a worse-off one increases welfare. Hence, the second step ensures that equalizing income prospects of circumstance groups is considered an improvement by the function $W$.

Theorem 4.2. Suppose that market incomes are additively separable with summary vector $\mu$ in $\mathbb{R}^{r}$. A social welfare function $W$ satisfies monotonicity, continuity, translation invariance, ex ante aggregation, liberal symmetry, ex ante compensation symmetry, liberal Pigou-Dalton reward and ex ante PigouDalton compensation if and only if there exists a strictly increasing, continuous, translatable and Schur-concave function $f: \mathbb{R}^{c} \rightarrow \mathbb{R}$ and a strictly increasing, continuous, unit-translatable and Schur-concave function $g: \mathbb{R}^{r} \rightarrow \mathbb{R}$ such that, for each $X$ in $\mathbb{R}^{c \times r}$,

$$
W(X)=f\left(g\left(x_{1 .}-\mu\right), \ldots, g\left(x_{c}-\mu\right)\right) .
$$

The welfare function class characterized above is large in the sense that one can choose the functions $f$ and $g$ in many different ways. This, in turn, implies that very simple choices for $f$ and $g$ are available. For instance, one can choose $f$ and $g$ in (4.2) such that $W(X)=\sum_{i \in C} \omega_{i} \sum_{j \in R} \theta_{j}\left(x_{i j}-\mu\right)$, where $\sum_{i \in C} \omega_{i}=1$, $\sum_{j \in R} \theta_{j}=1$ and the weight assigned decreases as the value of the corresponding element increases. That is, both $f$ and $g$ are weighted sums of their arguments where the weights are chosen to ensure that the functions are Schur-concave. Weighted sums can also be used for the three classes characterized below. 


\subsubsection{Compensation and utilitarian reward}

The next theorem presents the class of social welfare functions that combine utilitarian reward with ex ante compensation. ${ }^{15}$ The social welfare function in (4.3) focuses on the sums of incomes received by circumstance groups. Since $f$ is Schur-concave, equalizing the total incomes of two circumstance groups is considered an improvement by a social welfare function in this class. The functions are indifferent to how that sum is allocated within a circumstance group due to utilitarian reward.

Theorem 4.3. A social welfare function $W$ satisfies monotonicity, continuity, translation invariance, ex ante compensation symmetry, utilitarian reward and ex ante Pigou-Dalton compensation if and only if there exists a strictly increasing, continuous, translatable and Schur-concave function $f: \mathbb{R}^{c} \rightarrow \mathbb{R}$ such that, for each $X$ in $\mathbb{R}^{c \times r}$,

$$
W(X)=f\left(\sum_{j=1}^{r} x_{1 j}, \ldots, \sum_{j=1}^{r} x_{c j}\right) .
$$

Van de gaer (1993) proposed a well-known method to compare distributions on the basis of equality of opportunity. The Van de gaer rule considers an income distribution $X$ better than a distribution $X^{\prime}$ if the lowest sum of incomes of circumstance groups in $X$ is higher than that in $X^{\prime}$. That is, the Van de gaer rule can be represented by a social welfare function $W_{V}: \mathbb{R}^{c \times r} \rightarrow \mathbb{R}$ such that, for each $X$ in $\mathbb{R}^{c \times r}$, we have $W_{V}(X)=\min _{i \in C} \sum_{j \in R} x_{i j}$. Although it is not strictly increasing, the Van de gaer rule can be approached arbitrarily closely by a function in (4.3) if $f$ is chosen to be concave enough.

We run into an impossibility in combining ex post Pigou-Dalton compensation with utilitarian reward. ${ }^{16}$ We present the proposition without a proof since the counterexample below suffices.

\footnotetext{
${ }^{15}$ Monotonicity and utilitarian reward imply ex ante aggregation, so we do not include the latter in the theorem.

${ }^{16}$ Fleurbaey and Peragine (2013) show a similar incompatibility.
} 
Proposition 4.3. There exists no social welfare function $W: \mathbb{R}^{c \times r} \rightarrow \mathbb{R}$ that satisfies ex post Pigou-Dalton compensation and utilitarian reward.

To see the clash, consider

$$
X=\left[\begin{array}{ll}
8 & 7 \\
6 & 9
\end{array}\right] \text { and } X^{\prime}=\left[\begin{array}{ll}
7 & 8 \\
7 & 8
\end{array}\right]
$$

Ex post Pigou-Dalton compensation implies $W\left(X^{\prime}\right)>W(X)$. Utilitarian reward, on the other hand, implies $W(X)=W\left(X^{\prime}\right)$.

Clearly, a domain restriction is not possible in this case since utilitarian reward does not take market incomes into account. We therefore weaken utilitarian reward to uniform utilitarian reward so as to make it compatible with ex post Pigou-Dalton compensation. Theorem 4.4 presents the social welfare functions that combine uniform utilitarian reward with ex post compensation. The function $g$ in (4.4) ensures that equalizing the incomes of two individuals in the same responsibility group is registered as an improvement by the social welfare function.

Theorem 4.4. A social welfare function $W$ satisfies monotonicity, continuity, translation invariance, ex post aggregation, ex post compensation symmetry, ex post Pigou-Dalton compensation and uniform utilitarian reward if and only if there exists a strictly increasing and continuous function $\phi: \mathbb{R} \rightarrow \mathbb{R}$, and a strictly increasing, continuous, unit-translatable and Schur-concave function $g: \mathbb{R}^{c} \rightarrow \mathbb{R}$ such that, for each $X$ in $\mathbb{R}^{c \times r}$,

$$
W(X)=\phi\left(\sum_{j=1}^{r} g(x \cdot j)\right)
$$

Another well-known criterion of equality of opportunity is the Roemer rule (Roemer, 1993, 1998a, 2002). A social welfare function that represents the Roemer rule is a function $W_{R}: \mathbb{R}^{c \times r} \rightarrow \mathbb{R}$ such that, for each $X$ in $\mathbb{R}^{c \times r}$, we have $W_{R}(X)=\sum_{j \in R} \min _{i \in C} x_{i j}$. A function in (4.4) approximates the Roemer rule if $g$ is chosen to be concave enough. 
A modification to the proposals of Roemer and Van de gaer was proposed by Ooghe et al. (2007). The so-called flexible Van de gaer and Roemer rules they define belong to the classes characterized in (4.3) and (4.4).

\subsection{Inequality measures}

We follow the procedure proposed by Atkinson (1970) and Kolm (1969) to define our measure of inequality of opportunity. Let $W: \mathbb{R}^{c \times r} \rightarrow \mathbb{R}$ be a social welfare function and $X$ an income distribution in $\mathbb{R}^{c \times r}$. Let $\hat{X}$ be an income distribution such that the total income in $\hat{X}$ is optimally distributed according to $W$ and $\hat{X}$ has the same welfare as $X$. The inequality of opportunity measure is a function $I: \mathbb{R}^{c \times r} \rightarrow \mathbb{R}$ that measures the inequality of opportunity in $X$ by the difference between the average income in $X$ and the average income in $\hat{X} .{ }^{17}$ That is,

$$
I(X)=\frac{1}{c r}\left(\sum_{i \in C} \sum_{j \in R} x_{i j}-\sum_{i \in C} \sum_{j \in R} \hat{x}_{i j}\right) .
$$

Note that $I(X)$ is the maximum amount of income that could be taken away from each individual without sacrificing any welfare. Hence, $I$ is a measure of waste due to the suboptimal allocation of income.

To be able to measure inequality of opportunity, we need to know how income is distributed in $\hat{X}$. That is, we need to know what the optimal distribution is for a given social welfare function. ${ }^{18}$ In the classical approach to unidimensional inequality measurement, this step is straightforward. The optimum is unique: it is the distribution in which each individual is given the same income. This is however not the case in our context. The optimal distribution of a certain amount of income depends on which of the four classes (characterized in the previous section) the social welfare function belongs to.

Proposition 4.4 shows the set of optimal distributions for these four cases. Part 1 of the proposition shows the optimal distribution for a social welfare function that combines liberal reward with compensation. Surprisingly, we find

\footnotetext{
${ }^{17}$ Note that the average income in $\hat{X}$ is typically less than the average income in $X$.

${ }^{18} \mathrm{~A}$ distribution $Y$ is the optimal distribution of a given amount of total income if $W(Y) \geq$ $W\left(Y^{\prime}\right)$ for every $Y^{\prime}$ with the same total income.
} 
that the optimal income distributions for the ex ante and ex post approaches coincide in this case. Thus, the choice of ex ante and ex post becomes irrelevant if one focuses only on the fair allocation for liberal reward and compensation. At the optimal distribution, every individual $(i, j)$ is given his summary income $\mu_{j}$ plus $\alpha$, where $\alpha$ is a constant that ensures that the income in $X$ is fully distributed. Part 2 (a) presents the optimal distribution chosen by a function that combines utilitarian reward and compensation with an ex ante approach. In this case, the optimal distribution gives each circumstance group the same total income. Due to utilitarian reward, the manner in which this total income is distributed within a circumstance group is irrelevant. For the ex post counterpart, in part 2 (b), the optimum is obtained by equalizing incomes of individuals within responsibility groups. Members of one responsibility group might receive a higher income than the members of another group in this case. 


\section{Proposition 4.4.}

1. Let $W$ be a social welfare function that belongs to the class characterized in Theorem 4.1 or 4.2. For each income distribution $X$ in $\mathbb{R}^{c \times r}$, the unique optimal distribution of the total income in $X$, denoted by $X^{*}$, is such that, for all $i$ in $C, x_{i}^{*}=\mu+\alpha(X) 1_{r}$, where $\alpha(X)=\left(\sum_{i \in C} \sum_{j \in R} x_{i j}-\right.$ $\left.c \sum_{i \in R} \mu_{i}\right) / c r$.

2. (a) Let $W$ be a social welfare function that belongs to the class characterized in Theorem 4.3. For each income distribution $X$ in $\mathbb{R}^{c \times r}, a$ distribution $X^{*}$ is an optimal distribution of the total income in $X$ if and only if we have $\sum_{j \in R} x_{i j}^{*}=\sum_{j \in R} x_{k j}^{*}$ for all circumstance groups $i$ and $k$ in $C$.

(b) Let $W$ be a social welfare function that belongs to the class characterized in Theorem 4.4. For each income distribution $X$ in $\mathbb{R}^{c \times r}$, a distribution $X^{*}$ is an optimal distribution of the total income in $X$ if and only if we have $x_{i j}^{*}=x_{k j}^{*}$ for all circumstance groups $i$ and $k$ in $C$, and each responsibility group $j$ in $R$.

The optimal distributions given above define allocation rules. In fact, the optimal distribution chosen by a social welfare function that combines liberal reward with compensation coincides with the well-known egalitarian-equivalent allocation rule (Bossert and Fleurbaey, 1996). The rule first chooses a reference circumstance group, $\tilde{c}$, and then assigns to each $(i, j)$ an income $x_{i j}^{E E}=m_{\tilde{c} j}+\beta$, where $\beta$ is a constant to ensure that the income in $X$ is fully distributed. The egalitarian-equivalent allocation coincides with the allocation presented in the first part of Proposition 4.4 if $\tilde{c}$ is chosen from the set $C .{ }^{19}$ Additionally, the income distributions presented in 2 (a) and 2 (b) above coincide with the optimal allocations with respect to the the Van de gaer rule and the Roemer rule, respectively.

\footnotetext{
${ }^{19}$ Which circumstance group is chosen as the reference does not matter since market incomes must be additively separable for a $W$ to satisfy liberal reward and compensation in our context.
} 
Finally, Proposition 4.5 shows that the inequality measure defined as above has the intuitive property that the inequality of opportunity in $X$ is a function of the difference between $W(X)$ and $W\left(X^{*}\right)$ where $X^{*}$ is an optimal distribution of the income in $X$. That is, the inequality of opportunity assigned to $X$ increases as it moves further (in terms of welfare) from the optimum. This property makes the measure very easy to compute since the optima are given in Proposition $4.4 .^{20}$

Proposition 4.5. For each income distribution $X$ below, let $X^{*}$ be an optimal distribution of the total income in $X$ according to the social welfare function $W$.

1. Let $W$ be a social welfare function that belongs to the class characterized in Theorem 4.1 or 4.2 such that $f$ is unit-translatable and $f(0,0, \ldots, 0)=$ 0 and $g(0,0, \ldots, 0)=0$. For each income distribution $X$ in $\mathbb{R}^{c \times r}$, we have $I(X)=W\left(X^{*}\right)-W(X)$.

2. Let $W$ be a social welfare function that belongs to the class characterized in Theorem 4.3 or 4.4 such that $f$ is unit-translatable and $f(0,0, \ldots, 0)=$ 0 and $g(0,0, \ldots, 0)=0$. For each income distribution $X$ in $\mathbb{R}^{c \times r}$, we have $I(X)=\frac{1}{r}\left(W\left(X^{*}\right)-W(X)\right)$.

We conclude this section with a discussion of how the current study relates to the literature on equality of opportunity measurement. We do not attempt to review the vast literature here, but one can say that most measures proposed so far rely on a counterfactual income distribution obtained from the actual income distribution. ${ }^{21}$ The constructed distribution reflects either an income distribution in which all unacceptable inequalities are removed, or one in which all unacceptable inequalities due to differences in effort are eliminated, and

\footnotetext{
${ }^{20}$ In Proposition 4.5, we take $f$ and $g$ such that each $f$ is unit-translatable, $f(0,0, \ldots, 0)=0$ and $g(0,0, \ldots, 0)=0$. This is not restrictive. Any social welfare function characterized in the previous section can be represented by such a choice of $f$ and $g$ without changing its ordinal properties. The particular choice of $f$ and $g$ therefore does not change $\hat{X}$, and hence the inequality level.

${ }^{21}$ See Ferreira and Peragine (2015), Ramos and Van de gaer (2012) and Roemer and Trannoy (2013) for reviews.
} 
hence we are left with a distribution that violates compensation only. In the first case, inequality of opportunity is measured by the distance between the actual income distribution and the counterfactual distribution. In the second case, an inequality index is applied to the counterfactual distribution. Naturally, the counterfactual distribution depends on the choice of compensation and reward principles.

Bourguignon et al. (2007), Checchi and Peragine (2010), Ferreira and Gignoux (2011) and Peragine (2002) use a counterfactual distribution in which all inequalities due to differences in effort are eliminated. At this counterfactual distribution, each individual is given the average income of his circumstance group. Such a formulation clearly follows utilitarian reward and ex ante compensation. Our measures that combine ex ante compensation with utilitarian reward (derived through Theorem 4.3, part 2 (a) of Proposition 4.4 and part 2 of Proposition 4.5) can be interpreted as measuring the inequality in the same counterfactual distribution. Additionally, we allow for alternative counterfactual distributions in which other combinations of compensation and reward are employed.

Almås et al. (2011) and Devooght (2008) define counterfactual distributions in which all inequality of opportunity is removed. In their case, the counterfactual distribution represents the fair income distribution in the society. Both studies propose to measure inequality of opportunity at a given income distribution by the distance between the actual income distribution and the fair income distribution. Almås et al. (2011) use the generalized proportionality principle developed by Cappelen and Tungodden (2010) as their norm. Their counterfactual distribution thus employs ex post Pigou-Dalton compensation and a weaker version of liberal Pigou-Dalton reward (if all individuals have the same circumstance characteristics, each individual's fair income is equal to his pre-tax income). They define the "unfair treatment of an individual" as the absolute value of the difference between his income and his fair income, and propose an (unfairness) Gini applied to these differences as their measure of deviation from the norm. Devooght (2008) proposes to use the measure of distributional change developed by Cowell (1985) as the distance function. He 
takes the egalitarian-equivalent allocation as the fair distribution. We differ from Almås et al. (2011) and Devooght (2008) in two important aspects. First, we do not only focus on combinations of compensation with liberal reward. Our measures allow for the use of utilitarian reward as well. Second, the norms (given in Proposition 4.4) and the distance functions (Proposition 4.5) in this paper are axiomatically derived from the same principles.

The main contribution and the difference of the current study lies in the fact that we provide a complete and consistent picture: we explicitly derive underlying welfare criteria, fair distributions and the inequality measures from the same combinations of principles.

\subsection{Conclusion}

We conclude by a discussion of three potential directions for future research. A natural first extension of this paper would be to study the empirical applications of our measures. The classes of welfare functions and inequality measures presented here are large in the sense that many possibilities are available for use in empirical research. A potential difficulty in empirical applications is due to the necessity of additively separable market functions in case one wants the evaluation criterion to satisfy compensation and liberal reward. Devooght (2008) proposes one possible way to tackle this issue. To obtain additively separable market incomes, Devooght (2008) regresses the market income variable (annual pre-tax income) on individual characteristics, and chooses to include the error term in the circumstance set. ${ }^{22}$ One can then use the estimated equation to determine market incomes and deduce the vector $\mu$ needed for the measurement of inequality of opportunity in this case.

This paper considers comparisons of income distributions with a fixed set of circumstance and responsibility characteristics, a weakness we share with most of the literature. A second natural extension would be to develop measures

\footnotetext{
${ }^{22}$ Clearly, one can include the error term in the responsibility set as well. See Devooght (2008) for more details.
} 
CHAPTER 4. MEASUREMENT OF EQUALITY OF OPPORTUNITY: A NORMATIVE APPROACH

for comparisons of income distributions with different profiles of individual characteristics.

A third possible extension would be to focus on multidimensional inequality of opportunity. That is, developing criteria for the evaluation of distributions of $m$ commodities - as opposed to just income - among individuals who are characterized by their responsibility and circumstance characteristics. 


\section{Appendix 4.A}

We first show the impossibility mentioned in footnote 5 of this chapter. Let $M=(2,8), X=(3,13)$ and $X^{\prime}=(7,9)$. By liberal symmetry $W(X)=$ $W\left(X^{\prime}\right)$ since $X-M=(1,5), X^{\prime}-M=(5,1)$. Now consider $2 X=(6,26)$ and $2 X^{\prime}=(14,18)$. By liberal Pigou-Dalton reward, $W\left(2 X^{\prime}\right)>W(2 X)$ while $W\left(2 X^{\prime}\right)=W(2 X)$ by scale invariance, a contradiction.

We distinguish between two types of income transfers between individuals. First, a Pigou-Dalton transfer is a transfer of income from a richer to a poorer individual that results in the initially poorer person ending up with an income that is less than or equal to the income the initially richer person starts with. Note that for two income levels $x>y$, a Pigou-Dalton transfer is at most equal to $x-y$. Second, a progressive transfer is a transfer of income from a richer to a poorer individual such that the one that starts out with less money does not end up with more than the other. Hence, a progressive transfer is at most equal to $(x-y) / 2$. Clearly, any progressive transfer is a Pigou-Dalton transfer. We say that a function is inequality averse if its value increases as a result of a progressive transfer.

The following two lemmas are used throughout the proofs. The first lemma can be found in Olkin and Marshall (1979, pp.10-12). See Dasgupta et al. (1973) and Sen (1973) for the second lemma.

Lemma 4.1. For all vectors $a$ and $b$ in $\mathbb{R}^{n}, a$ is obtained from $b$ by a finite sequence of Pigou-Dalton transfers if and only if $a=b B$ for some $n \times n$ bistochastic matrix $B$.

Lemma 4.2. Any symmetric, inequality averse function $f: \mathbb{R}^{n} \rightarrow \mathbb{R}$ is Schurconcave.

In light of Lemma 4.2, it is enough to show that a symmetric function is inequality averse in order to show it is Schur-concave. That is what we do in the proofs of the theorems.

Proof of Proposition 4.1. Suppose the social welfare function $W$ satisfies liberal Pigou-Dalton reward and ex post Pigou-Dalton compensation. 
Assume $M$ is not additively separable. That is, there exist $i, k$ in $C$ and $j, s$ in $R$ such that $m_{i j}-m_{i s} \neq m_{k j}-m_{k s}$. Let $X$ be an income distribution such that $x_{i j}=x_{k j}=\left(m_{i j}+m_{k j}\right) / 2, x_{i s}=x_{k s}=\left(m_{i s}+m_{k s}\right) / 2$ with $X$ and $M$ coinciding everywhere else. Next, let $X^{\prime}$ be an income distribution such that $x_{i j}^{\prime}+x_{i s}^{\prime}=x_{i j}+x_{i s}$ with $x_{i j}^{\prime}-x_{i s}^{\prime}=m_{i j}-m_{i s}$ and $x_{k j}^{\prime}+x_{k s}^{\prime}=x_{k j}+x_{k s}$ with $x_{k j}^{\prime}-x_{k s}^{\prime}=m_{k j}-m_{k s}$ with $X^{\prime}$ and $M$ coinciding everywhere else. By liberal Pigou-Dalton reward, $W\left(X^{\prime}\right)>W(X)$. By ex post Pigou-Dalton compensation, on the other hand, $W(X)>W\left(X^{\prime}\right)$, a contradiction.

Proof of Proposition 4.2. Suppose the social welfare function $W$ satisfies liberal Pigou-Dalton reward and ex ante compensation symmetry.

Let $X$ be an income distribution such that there exist two positive real numbers $\lambda, \lambda^{\prime}$ such that $x_{i}=m_{i} .+\lambda 1_{r}$, and $x_{k} .=m_{k} .+\lambda^{\prime} 1_{r}$ with $\sum_{j \in R} x_{i j}=$ $\sum_{j \in R} x_{k j}$ with $X$ and $M$ coinciding everywhere else. Let $X^{\prime}$ be an income distribution obtained from $X$ by permuting the $i$ th and $k$ th rows of $X$. That is, $x_{i}=x_{k}^{\prime}$ and $x_{k}=x_{i}^{\prime}$. with $X$ and $X^{\prime}$ coinciding everywhere else.

Note that, at $x_{i}$. and $x_{k}$, each individual receives the same government transfer $\left(\lambda\right.$ and $\left.\lambda^{\prime}\right)$. Moreover, $\sum_{j \in R} x_{i j}=\sum_{j \in R} x_{k j}$. Thus, by liberal PigouDalton reward, $W(X) \geq W\left(X^{\prime}\right)$ with equality holding only if $m_{i j}-m_{i s}=m_{k j}-$ $m_{k s}$ for all $j, s$ in $R$. But, by ex ante compensation symmetry, we have $W(X)=$ $W\left(X^{\prime}\right)$. So, we must have $m_{i j}-m_{i s}=m_{k j}-m_{k s}$ for all $j, s$ in $R$. Thus, market incomes must be additively separable.

Proof of Theorem 4.1. Suppose that market incomes are additively separable with summary vector $\mu$ in $\mathbb{R}^{r}$. Let $W$ be a social welfare function that satisfies all axioms.

By monotonicity and continuity, there exists a strictly increasing, continuous function $\hat{f}: \mathbb{R}^{c r} \rightarrow \mathbb{R}$ such that, for each distribution $X$ in $R^{c \times r}, W(X)=$ $\hat{f}\left(x_{1}, x_{2}, \ldots, x_{c}\right)$.

Next, let us define a new function $f: \mathbb{R}^{c r} \rightarrow \mathbb{R}$ such that, for each $X$ in $R^{c \times r}, \hat{f}\left(x_{1}, x_{2} \ldots, x_{c}.\right)=f\left(x_{1}-\mu, x_{2}-\mu \ldots, x_{c}-\mu\right)$. Such a function can be defined since the $c$-vector $(\mu, \mu, \ldots, \mu)$ is the same for every $c \times r$ dimensional 
vector $\left(x_{11}, \ldots, x_{1 r}, x_{21}, \ldots, x_{2 r}, \ldots, x_{c 1}, \ldots, x_{c r}\right)$. The function $f$ inherits strict increasingness and continuity from $\hat{f}$. It is translatable by translation variance.

Next, we show that $f$ is symmetric. Let $X, X^{\prime}$ be income distributions such that the vector $\left(x_{1}^{\prime}-\mu, x_{2}^{\prime}-\mu, \ldots, x_{c}^{\prime}-\mu\right)$ is obtained from the vector $\left(x_{1} .-\mu, x_{2} .-\mu \ldots, x_{c} .-\mu\right)$ by a single permutation.

Assume the permutation is applied to $(i, j)$ to $(k, j)$ who are in the same responsibility group. A permutation of $x_{i j}-\mu_{j}$ and $x_{k j}-\mu_{j}$ is equivalent to a permutation of $x_{i j}$ and $x_{k j}$. Thus, by ex post Pigou-Dalton compensation symmetry, $W(X)=W\left(X^{\prime}\right)$. Similarly, if the permutation is applied to $(i, j)$ to $(i, s)$ who are in the same circumstance group, we have $W(X)=W\left(X^{\prime}\right)$ by liberal symmetry.

Now, assume the permutation is applied to $(i, j)$ to $(k, s)$. Let $Y$ and $X^{\prime \prime}$ be income distributions such that $y_{k s}=x_{i s}$ and $x_{k s}=y_{i s}$ with $Y$ and $X$ coinciding everywhere else, and $x_{k s}^{\prime}=x_{i s}^{\prime \prime}$ and $x_{k s}^{\prime}=x_{i s}^{\prime \prime}$ with $X^{\prime \prime}$ and $X^{\prime}$ coinciding everywhere else. By ex post compensation symmetry, we have $W(X)=W(Y)$ and $W\left(X^{\prime}\right)=W\left(X^{\prime \prime}\right)$. By liberal symmetry, we have $W(Y)=\left(X^{\prime \prime}\right)$. Thus, $W(X)=\left(X^{\prime}\right)$.

Finally, we show that $f$ is Schur-concave. Since $f$ is symmetric, it suffices to show that $f$ is inequality averse. Let $X, X^{\prime}$ be income distributions such that the vector $\left(x_{1} .-\mu, x_{2} .-\mu, \ldots, x_{c} .-\mu\right)$ is obtained from the vector $\left(x_{1}^{\prime}-\mu, x_{2}^{\prime}\right.$. $\left.\mu \ldots, x_{c}^{\prime}-\mu\right)$ by a single progressive transfer $\delta$.

Assume the progressive transfer is from an individual $(i, j)$ to $(k, j)$ who is in the same responsibility group. A progressive transfer between $x_{i j}-\mu_{j}$ and $x_{k j}-\mu_{j}$ is equivalent to a progressive transfer between $x_{i j}$ and $x_{k j}$. Thus, by ex post Pigou-Dalton compensation, $W(X)>W\left(X^{\prime}\right)$. Similarly, if the progressive transfer is from $(i, j)$ to $(i, s)$ who is in the same circumstance group, we have $W(X)>W\left(X^{\prime}\right)$ by liberal Pigou-Dalton reward.

Now, assume the progressive transfer is from an individual $(i, j)$ to $(k, s)$. Let $Y$ and $X^{\prime \prime}$ be income distributions such that $y_{k s}=x_{i s}$ and $x_{k s}=y_{i s}$ with $Y$ and $X$ coinciding everywhere else, and $x_{k s}^{\prime}=x_{i s}^{\prime \prime}$ and $x_{k s}^{\prime}=x_{i s}^{\prime \prime}$ with $X^{\prime \prime}$ and $X^{\prime}$ coinciding everywhere else. By ex post compensation symmetry, we have 
$W(X)=W(Y)$ and $W\left(X^{\prime}\right)=W\left(X^{\prime \prime}\right)$. By liberal Pigou-Dalton reward, we have $W(Y)>W\left(X^{\prime \prime}\right)$. Thus, $W(X)>W\left(X^{\prime}\right)$.

Proof of Theorem 4.2. Suppose that market incomes are additively separable with summary vector $\mu$ in $\mathbb{R}^{r}$. Let $W$ be a social welfare function that satisfies all axioms.

By monotonicity, continuity, ex ante aggregation and ex ante compensation symmetry, there exist a strictly increasing, continuous, symmetric function $\hat{f}: \mathbb{R}^{c} \rightarrow \mathbb{R}$ and a strictly increasing, continuous function $\hat{\hat{g}}: \mathbb{R}^{r} \rightarrow \mathbb{R}$ such that, for each $X$ in $R^{c \times r}, W(X)=\hat{f}\left(\hat{\hat{g}}\left(x_{1}.\right), \ldots, \hat{\hat{g}}\left(x_{c}.\right)\right)$.

Next, let us define a new function $\hat{g}: \mathbb{R}^{r} \rightarrow \mathbb{R}$ such that $\hat{\hat{g}}(y)=\hat{g}(y-\mu)$ for any vector $y$ in $\mathbb{R}^{r}$. Note that such a function can be defined since $\mu$ is the same for every vector $y$. The function $\hat{g}$ inherits strict increasingness and continuity from $\hat{\hat{g}}$.

Let $y, z$ be two vectors in $\mathbb{R}^{r}$ and $\lambda$ a real number. By translation invariance, $\hat{g}(y-\mu) \geq \hat{g}(z-\mu)$ if and only if $\hat{g}\left(y+\lambda 1_{r}-\mu\right) \geq \hat{g}\left(z+\lambda 1_{r}-\mu\right)$. That is, $\hat{g}$ is a translatable function. Hence, there exists a strictly increasing function $\psi: \mathbb{R} \rightarrow \mathbb{R}$ and a unit-translatable function $g: \mathbb{R}^{r} \rightarrow \mathbb{R}$ such that $\hat{g}=\psi \circ g$. Now let the function $f: \mathbb{R}^{c} \rightarrow \mathbb{R}$ be such that, for each $\left(s_{1}, \ldots, s_{c}\right)$ in $\mathbb{R}^{c}$, we have $\hat{f}\left(s_{1}, \ldots, s_{c}\right)=f\left(\psi^{-1}\left(s_{1}\right), \ldots, \psi^{-1}\left(s_{c}\right)\right)$. That is, we have $\hat{f}\left(\hat{g}\left(x_{1}\right.\right.$. $\left.\mu), \ldots, \hat{g}\left(x_{c} \cdot-\mu\right)\right)=f\left(g\left(x_{1}-\mu\right), \ldots, g\left(x_{c}-\mu\right)\right)$. Hence, $W(X)=f\left(g\left(x_{1}--\right.\right.$ $\left.\mu), \ldots, g\left(x_{c}-\mu\right)\right)$. The function $f$ inherits strict increasingness, continuity and symmetry from $\hat{f}$. It is translatable due to translation invariance and the fact that $g$ is unit-translatable. The function $g$ inherits strict increasingness and continuity from $\hat{g}$. It is Schur-concave due to liberal Pigou-Dalton reward and liberal symmetry.

Finally, we show that $f$ is Schur-concave. Let $X, X^{\prime}$ in $\mathbb{R}^{c \times r}$ be such that the vector $\left(g\left(x_{1}^{\prime}-\mu\right), \ldots, g\left(x_{c}^{\prime}-\mu\right)\right)$ is obtained from the vector $\left(g\left(x_{1}\right.\right.$. $\left.\mu), \ldots, g\left(x_{c}-\mu\right)\right)$ by a single progressive transfer. That is, there exist $i, k$ in $C$ and a positive real number $\delta$ such that $g\left(x_{i} .-\mu\right)-\delta=g\left(x_{i}^{\prime}-\mu\right) \geq$ $g\left(x_{k}^{\prime}-\mu\right)=g\left(x_{k}-\mu\right)+\delta$ with $X$ and $X^{\prime}$ coinciding everywhere else. By continuity of $g$, there exist real numbers $\tau, \tau^{\prime}$ such that $g\left(\tau 1_{r}-\mu\right)=g\left(x_{i}-\mu\right)$ 
and $g\left(\tau^{\prime} 1_{r}-\mu\right)=g\left(x_{k} .-\mu\right)$. Note that $\tau>\tau^{\prime}$ since $g\left(x_{i .}-\mu\right)>g\left(x_{k}^{\prime}-\mu\right)$. Now let $T$ be a $c \times r$ matrix in which the $i$ th row is $\tau 1_{r}$ and the $k$ th row is $\tau^{\prime} 1_{r}$ with $T$ and $X$ coinciding everywhere else. Let $T^{\prime}$ be a $c \times r$ matrix in which the $i$ th row is $(\tau-\delta) 1_{r}$ and the $k$ th row is $\left(\tau^{\prime}+\delta\right) 1_{r}$ with $T^{\prime}$ and $X^{\prime}$ coinciding everywhere else. By ex ante Pigou-Dalton compensation, we have $W\left(T^{\prime}\right)>W(T)$. By construction, we have $W\left(T^{\prime}\right)=W\left(X^{\prime}\right)$ and $W(T)=W(X)$. We therefore have $W\left(X^{\prime}\right)>W(X)$. This shows that $f$ is an inequality averse function. Schur-concavity of $f$ follows from Lemma 4.2 and symmetry of $f$.

Proof of Theorem 4.3. Suppose that $W$ satisfies all axioms.

Let $X$ and $X^{\prime}$ in $\mathbb{R}^{c \times r}$ be such that $\sum_{j \in R} x_{i j} \geq \sum_{j \in R} x_{i j}^{\prime}$ for each $i$ in $C$. Let $\delta_{i}$ be a real number such that $\delta_{i}=\left(\sum_{j \in R} x_{i j}-\sum_{j \in R} x_{i j}^{\prime}\right) / r$. Let us construct a new income distribution $Y$ such that $y_{i j}=x_{i j}-\delta_{i}$ for each $(i, j)$ in $C \times R$. Note that we have $\sum_{j \in R} y_{i j}=\sum_{j \in R} x_{i j}^{\prime}$ for each $i$ in $C$. Thus, by utilitarian reward, we have $W(Y)=W\left(X^{\prime}\right)$. By monotonicity, we have $W(X) \geq W(Y)$. Thus, we have $W(X) \geq W\left(X^{\prime}\right)$ with equality holding if every $\delta_{i}=0$, that is, if $\sum_{j \in R} x_{i j}=\sum_{j \in R} x_{i j}^{\prime}$. This shows that $W(X) \geq W\left(X^{\prime}\right)$ whenever $\sum_{j \in R} x_{i j} \geq$ $\sum_{j \in R} x_{i j}^{\prime}$ for each $i$ in $C$ with equality holding if $\sum_{j \in R} x_{i j}=\sum_{j \in R} x_{i j}^{\prime}$ for each $i$ in $C$. Thus, there exists a strictly increasing function $f: R^{c} \rightarrow \mathbb{R}$ such that $W(X)=f\left(\sum_{j \in R} x_{1 j}, \ldots, \sum_{j \in R} x_{c j}\right)$. The function $f$ is continuous by continuity, translatable by translation invariance and symmetric by ex ante compensation symmetry.

Next, we show that $f$ is Schur-concave. Let $X, X^{\prime}$ in $\mathbb{R}^{c \times r}$ be such that there exist $i, k$ in $C$ and a positive real number $\delta$ such that $\left(\sum_{j \in R} x_{i j}\right)-\delta=\sum_{j \in R} x_{i j}^{\prime} \geq$ $\sum_{j \in R} x_{k j}^{\prime}=\left(\sum_{j \in R} x_{k j}\right)+\delta$. Let $Y$ and $Y^{\prime}$ in $\mathbb{R}^{c \times r}$ be such that, for each $(i, j)$ in $C \times R$, we have $y_{i j}=\sum_{j \in R} x_{i j} / r$ and $y_{k j}=\sum_{j \in R} x_{k j} / r$ and $y_{i j}^{\prime}=\sum_{j \in R} x_{i j}^{\prime} / r$ and $y_{k j}^{\prime}=\sum_{j \in R} x_{k j}^{\prime} / r$. By utilitarian reward, $W(Y)=W(X)$ and $W\left(Y^{\prime}\right)=W\left(X^{\prime}\right)$. By ex ante Pigou-Dalton compensation, $W\left(Y^{\prime}\right)>W(Y)$. Hence, $W\left(X^{\prime}\right)>W(X)$. This shows that $f$ is an inequality averse function. Schur-concavity of $f$ follows from Lemma 4.2 and symmetry of $f$. 
Proof of Theorem 4.4. Suppose that $W$ satisfies all axioms. By monotonicity, continuity and ex post aggregation there exist a strictly increasing and continuous function $\hat{f}: \mathbb{R}^{r} \rightarrow \mathbb{R}$, and, for each $j$ in $R$, a strictly increasing and continuous function $g_{i}: \mathbb{R}^{c} \rightarrow \mathbb{R}$ such that, for each $X$ in $\mathbb{R}^{c \times r}$, we have $W(X)=\hat{f}\left(g_{1}\left(x_{1}\right), \ldots, g_{r}\left(x_{c} \cdot\right)\right)$.

First, we show that $g_{j}=g_{s}$ for all $j, s$ in $R$. Take $y, z$ in $\mathbb{R}^{c}$. By continuity of $g_{j}$ and $g_{s}$, there exist real numbers $\delta_{1}, \delta_{2}$ such that $g_{j}(y)=g_{j}\left(\delta_{1} 1_{c}\right)$ and $g_{s}(z)=$ $g_{s}\left(\delta_{2} 1_{c}\right)$. Let $Y$ and $Z$ be income distributions such that $y_{\cdot j}=y, y_{\cdot s}=z$ and $z_{\cdot j}=\delta_{1} 1_{c}, z_{\cdot s}=\delta_{2} 1_{c}$ with $Y$ and $Z$ coinciding everywhere else. By definition, we have $W(Y)=W(Z)$. Next, let $Z^{\prime}$ be the income distribution obtained from $Z$ only by permuting the $j$ th and $s$ th columns of $Z$. By uniform utilitarian reward, $W(Z)=W\left(Z^{\prime}\right)$. Hence, $W\left(Z^{\prime}\right)=W(Y)$. Since this holds for any $y$ and $z$ in $\mathbb{R}^{c}$ and $j, s$ in $R$, it follows that we must have $\hat{g}_{j}=\hat{g}_{s}$ for all $j, s$ in $R$.

Using the reasoning used in the proof of Theorem 4.2, we can conclude that there exists a unit-translatable $g$ such that $W(X)=f\left(g\left(x_{1}.\right), \ldots, g\left(x_{c}.\right)\right)$ for each $X$ in $\mathbb{R}^{c \times r}$.

Next, let $X^{\prime}$ in $\mathbb{R}^{c \times r}$ be such that $\sum_{j \in R} g\left(x_{\cdot j}\right) \geq \sum_{j \in R} g\left(x_{. j}^{\prime}\right)$. Let $Y$ and $Y^{\prime}$ in $\mathbb{R}^{c \times r}$ be such that, for each $j$ in $R$, we have $g\left(y_{\cdot j}\right)=\sum_{j \in R} g\left(x_{\cdot j}\right) / r$ and $g\left(y_{\cdot j}^{\prime}\right)=\sum_{j \in R} g\left(x_{\cdot j}^{\prime}\right) / r$. By uniform utilitarian reward and unit-translatability of $g$, we have $W(X)=W(Y)$ and $W\left(X^{\prime}\right)=W\left(Y^{\prime}\right)$. Moreover, $W(Y) \geq W\left(Y^{\prime}\right)$ with equality holding if $\sum_{j \in R} g\left(x_{\cdot j}\right)=\sum_{j \in R} g\left(x_{\cdot j}^{\prime}\right)$ since $f$ is strictly increasing. Thus, we have $W(Y) \geq W\left(Y^{\prime}\right)$ if $\sum_{j \in R} g\left(x_{\cdot j}\right) \geq \sum_{j \in R} g\left(x_{\cdot j}^{\prime}\right)$ with equality holding if $\sum_{j \in R} g\left(x_{\cdot j}\right)=\sum_{j \in R} g\left(x_{\cdot j}^{\prime}\right)$. Thus, there exists a function $\phi: \mathbb{R} \rightarrow \mathbb{R}$ such that $W(X)=\phi\left(\sum_{j \in R} g\left(x_{\cdot j}\right)\right)$. The function $g$ is symmetric due to ex post compensation symmetry and Schur-concave by symmetry, ex post Pigou-Dalton compensation and Lemma 4.2.

Proof of Proposition 4.4.

1. Let $W: \mathbb{R}^{c \times r} \rightarrow \mathbb{R}$ be a social welfare function that belongs to the class characterized in Theorem 4.1, and $X$ an income distribution in $\mathbb{R}^{c \times r}$. 
Since $f$ is Schur-concave, for all $i, k$ in $C$, we must have $\left(x_{i}^{*}-\mu\right)=$ $\left(x_{k}^{*}-\mu\right)$. That is, we must have $x_{i}^{*}=\left(\mu_{1}+\alpha(X), \ldots, \mu_{r}+\alpha(X)\right)$ where $\alpha(X)=\frac{1}{c r}\left(\sum_{i \in C} \sum_{j \in R} x_{i j}-c \sum_{i \in R} \mu_{i}\right)$.

Now, assume that $W$ is a social welfare function that belongs to the class characterized in Theorem 4.2, and $X$ is an income distribution in $\mathbb{R}^{c \times r}$.

Since $g$ is Schur-concave, for each $i$ in $C$ and $j, s$ in $R$, we must have $x_{i j}^{*}-\mu_{j}=x_{i s}^{*}-\mu_{s}$. Moreover, since $g$ is unit-translatable and $f$ is Schur-concave, we must have $\left(x_{i \cdot}^{*}-\mu\right)=\left(x_{k}^{*}-\mu\right)$. That is, $x_{i}^{*}=\left(\mu_{1}+\right.$ $\left.\alpha(X), \ldots, \mu_{r}+\alpha(X)\right)$ where $\alpha(X)=\frac{1}{c r}\left(\sum_{i \in C} \sum_{j \in R} x_{i j}-c \sum_{i \in R} \mu_{i}\right)$.

2. (a) Let $W: \mathbb{R}^{c \times r} \rightarrow \mathbb{R}$ be a social welfare function that belongs to the class characterized in Theorem 4.3. Let $X$ be an income distribution in $\mathbb{R}^{c \times r}$.

Since $f$ is Schur-concave, for all $i, k$ in $C$, we have $\sum_{j \in R} x_{i j}^{*}=$ $\sum_{j \in R} x_{k j}^{*}$.

(b) Let $W: \mathbb{R}^{c \times r} \rightarrow \mathbb{R}$ be a social welfare function that belongs to the class characterized in Theorem 4.4. Let $X$ be an income distribution in $\mathbb{R}^{c \times r}$. Let $g: \mathbb{R}^{c} \rightarrow \mathbb{R}$ such that $W(X)=f\left(\sum_{j=1}^{r} g\left(x_{\cdot j}\right)\right)$. Since $g$ is Schur-concave, for each $j$ in $R$, we have $x_{k j}^{*}=\frac{1}{c} \sum_{i \in C} x_{i j}$.

Proof of Proposition 4.5. Take any $X$ in $\mathbb{R}^{c \times r}$. Recall that $\hat{X}$ is an income distribution such that the total income in $\hat{X}$ is optimally distributed according to $W$ and $\hat{X}$ has the same welfare as $X$.

1. Let $W$ be a social welfare function that belongs to the class characterized in Theorem 4.1 (or 4.2) such that $f$ is unit-translatable and $f(0, \ldots, 0)=0$. Let $\alpha(X)=\left(\sum_{i \in C} \sum_{j \in R} x_{i j}-c \sum_{i \in R} \mu_{i}\right) / c r$ and $\alpha(\hat{X})=\left(\sum_{i \in C} \sum_{j \in R} \hat{x}_{i j}-\right.$ $\left.c \sum_{i \in R} \mu_{i}\right) / c r$. 
We have

$$
\begin{aligned}
\sum_{i \in C} \sum_{j \in R} \hat{x}_{i j} & =c\left(\sum_{j \in R} \mu_{j}+\alpha(\hat{X}) r\right) \\
& =c \sum_{j \in R} \mu_{j}+\alpha(\hat{X}) c r
\end{aligned}
$$

Similarly, we have $\sum_{i \in C} \sum_{j \in R} x_{i j}=c \sum_{j \in R} \mu_{j}+\alpha(X) c r$. Thus,

$$
\begin{aligned}
I(X) & =\frac{1}{c r}\left(\sum_{i \in C} \sum_{j \in R} x_{i j}-\sum_{i \in C} \sum_{j \in R} \hat{x}_{i j}\right) \\
& =\frac{1}{c r}(\operatorname{cr}(\alpha(X)-\alpha(\hat{X}))) \\
& =\alpha(X)-\alpha(\hat{X}) .
\end{aligned}
$$

By Proposition 4.4, for each $i$ in $C$, we have $x_{i}^{*}=\mu+\alpha(X) 1_{r}$. That is, $W\left(X^{*}\right)=f\left(\alpha(X) 1_{r}\right)=\alpha(X)$. Similarly, $\hat{x}_{i}=\mu+\alpha(\hat{X}) 1_{r}$ and $W(\hat{X})=$ $f\left(\alpha(\hat{X}) 1_{r}\right)=\alpha(\hat{X})$. Moreover, $W(X)=W(\hat{X})$ by construction. That is, $W\left(X^{*}\right)-W(X)=\alpha(X)-\alpha(\hat{X})$. Thus, $I(X)=W\left(X^{*}\right)-W(X)$.

2. Let $W$ be a social welfare function that belongs to the class characterized in Theorem 4.3. Let the function $f$ in (4.3) be unit-translatable with $f(0, \ldots, 0)=0$. We have $W\left(X^{*}\right)=f\left(\frac{1}{c} \sum_{i \in C} \sum_{j \in R} x_{i j}, \ldots, \frac{1}{c} \sum_{i \in C} \sum_{j \in R} x_{i j}\right)$. Since $f$ is unit-translatable and $f(0, \ldots, 0)=0, W\left(X^{*}\right)=\frac{1}{c} \sum_{i \in C} \sum_{j \in R} x_{i j}$. Similarly, we have $W(\hat{X})=\frac{1}{c} \sum_{i \in C} \sum_{j \in R} \hat{x}_{i j}$. Combining the two yields $W\left(X^{*}\right)-W(X)=\frac{1}{c} \sum_{i \in C} \sum_{j \in R} x_{i j}-\frac{1}{c} \sum_{i \in C} \sum_{j \in R} \hat{x}_{i j}$. Thus, we conclude $I(X)=\frac{1}{r}\left(W\left(X^{*}\right)-W(X)\right)$.

Assume next that $W$ is a social welfare function that belongs to the class characterized in Theorem 4.4 such that $f$ is unit-translatable and $f(0, \ldots, 0)=0$ and $g(0, \ldots, 0)=0$. By Proposition 4.4, we know that $W\left(X^{*}\right)=\frac{1}{c} \sum_{j \in R} \sum_{i \in C} x_{i j}$. Thus, $I(X)=\frac{1}{r}\left(W\left(X^{*}\right)-W(X)\right)$. 


\section{5}

\section{FAIR SHARING OF AN INTERNATIONAL RIVER}

\subsection{Introduction}

This paper studies the problem of sharing water from an international river. The river in question is linear and picks up volume along its course. Water inflow at the territory of a downstream country cannot be consumed by a country upstream from it. The aim of this paper is to develop a methodology to evaluate allocations that consist of a schedule of water consumption and a monetary compensation scheme. We consider a monetary compensation scheme along with the water allocation since some upstream countries might be required to let some of the water within their territory pass to downstream countries in order to reach an efficient consumption plan. Monetary compensations are needed to convince upstream countries to give up water.

Sharing river water has often been a source of conflict between riparian countries mostly due to lack of well-defined property rights over rivers (Kilgour and Dinar, 1995). Several principles of international law based on different conceptions of property rights have been proposed to resolve such conflicts. This paper focuses on three of those principles. The principle of absolute territorial sovereignty (ATS) states that a country has absolute sovereignty over the part of the river that is within its borders. Unlimited territorial integrity (UTI) states that one country cannot alter the quantity or quality of water available to another. 
The territorial integration of all basin states (TIBS) considers the entire river a single unit, and allows each country an unlimited use of it. ${ }^{1}$

Even though these principles are intuitive, they are difficult to formulate in applications. Moreover, allocations proposed by UTI and TIBS are not feasible due to the one directionality of the water flow. This paper first proposes a way to formalize the principles. To do so, we take a reference vector $r$ that defines the property rights over the river. That is, $r_{i}$ shows the amount of river water $i$ has a right to consume without having to compensate any other country. Our main axiom, Pigou-Dalton for $r$, says that, given that each country consumes its reference level of water, equalizing monetary compensations received by countries is an improvement. This axiom is based on the idea that property rights remove the need for compensations. In Section 5.3, we argue that the axiom provides a reasonable way to formalize ATS, UTI and TIBS via the choice of the reference vector. We present a theorem which shows that anonymity and Pigou-Dalton for $r$ imply that TIBS must be chosen over ATS and UTI (Theorem 5.1).

Next, we show that a ranking that satisfies Pigou-Dalton for $r$, Pareto, anonymity and an independence axiom applies the Lorenz dominance criterion to equivalent income vectors. The equivalent income of a country is the amount of the hypothetical monetary compensation that, if combined with the reference level of water consumption, would give the country the same utility as its initial situation. The Hammond equity version of Pigou-Dalton for $r$ combined with weak Pareto, on the other hand, characterizes the class of egalitarian equivalent orderings that apply the maximin criterion to vectors of equivalent income.

The practice of using reference vectors in the construction of (social) orderings can be found in the literature on fair allocations, but has not been utilized by the literature on river sharing. The contribution of this paper is in showing that the idea of a reference vector can be very fruitful when applied to the issue of river sharing. Moreover, we contribute to the debate on which principle of international law to use in practice by recommending TIBS over the other two.

\footnotetext{
${ }^{1}$ See Kilgour and Dinar (1995) for a more comprehensive list of such principles.
} 
Most of the recent axiomatic studies (Ambec and Sprumont, 2002; Béal et al., 2012; Van den Brink et al., 2012) model the problem as a cooperative game where axioms are imposed on the distribution of welfare to the countries. Van den Brink et al. (2013) argue that the axioms should be imposed directly on the allocation of welfare derived from water use since this allows a close link between the axioms and actual water allocation. Ansink and Weikard (2013) take the argument one step further and impose axioms directly on the allocation of water without using tools of cooperative game theory. This paper also imposes axioms directly on allocations of water without using a coalitions approach. However, unlike Van den Brink et al. (2013) and Ansink and Weikard (2013), we use orderings instead of allocation rules. This approach provides a tool for addressing issues of second-best allocation (see the conclusion).

\subsection{Preliminaries}

A group of $n$ countries collected in a set $N$ are located along a linear river. We name the countries based on their location: Country 1 is the source country, Country 2 is the one downstream from 1 and so on. The river flows in one direction only. It picks up volume along its course starting with $e_{1}$ at the beginning of 1's position, followed by $e_{2}$ at the beginning of 2's position and so on. Each $e_{i}$ is positive.

Each country $i$ has a benefit function $b_{i}: \mathbb{R}_{+} \rightarrow \mathbb{R}$ that represents the benefits $i$ derives from the consumption of water. Each $b_{i}$ is strictly increasing (that is, each country is non-satiable) and strictly concave. ${ }^{2}$ The set of all admissible benefit functions is $B$. A profile of benefit functions is denoted by $b=\left(b_{1}, \ldots, b_{n}\right)$.

The amount of water consumed by $i$ is denoted by $w_{i}$ and the net monetary compensation $i$ receives is denoted by $t_{i}$. The utility of $i$ at $\left(w_{i}, t_{i}\right)$ is given by

\footnotetext{
${ }^{2}$ It is not restrictive to assume non-satiable agents. Assume $b_{i}$ is not strictly increasing and it has a satiation point $y_{i}$. If $e_{i}>y_{i}$, then we can redefine $e_{i+1}=e_{i+1}+e_{i}-y_{i}$. So the problem can be rewritten as $e_{i}^{\prime}=y_{i}$ and $e_{i+1}^{\prime}=e_{i+1}+e_{i}-y_{i}$ and so forth.
} 
$u_{i}\left(w_{i}, t_{i}\right)=b_{i}\left(w_{i}\right)+t_{i}$. Hence, it is possible to use monetary compensations to convince countries to agree on a certain allocation of water use.

An allocation $a$ is a pair $(w, t)=\left(w_{1}, \ldots, w_{n} ; t_{1}, \ldots, t_{n}\right)$. The set of all allocations is $A=\mathbb{R}_{+}^{n} \times \mathbb{R}^{n}$. We use a complete and transitive ranking $R$ on $A$ to evaluate allocations in terms of fairness and goodness. For every profile of benefit functions $b$ in $B^{n}, R$ determines an ordering $R(b)$ over $A$. The strict and indifference counterparts are denoted by $P$ and $I$. Throughout the paper, we use $a R a^{\prime}$ instead of $a R(b) a^{\prime}$ when this raises no confusion. Note that we do not restrict the domain of $R$ to the set of feasible allocations. This is because unlimited territorial integrity (UTI) and territorial integration of all basin states (TIBS) propose unfeasible allocations as the optimal, and our solution for the unfeasibility problem requires the ranking $R$ to work on the full domain.

Our first axiom is Pareto. Pareto requires $R$ to be indifferent between two allocations $a$ and $a^{\prime}$ if each country is indifferent between them. Moreover, if at least one country strictly prefers $a$ to $a^{\prime}$ with no other country that strictly prefers $a^{\prime}$ to $a$, then Pareto demands that the first be strictly preferred by $R$.

Pareto. For each profile of benefit functions $b$ in $B^{n}$ and all allocations $(w, t)$ and $\left(w^{\prime}, t^{\prime}\right)$ in $A$, if $u_{i}\left(w_{i}, t_{i}\right)=u_{i}\left(w_{i}^{\prime}, t_{i}^{\prime}\right)$ for each $i$ in $N$, then $a I(b) a^{\prime}$. Moreover, if $u_{i}\left(w_{i}, t_{i}\right) \geq u_{i}\left(w_{i}^{\prime}, t_{i}^{\prime}\right)$ for each $i$ in $N$ and $u_{j}\left(w_{j}, t_{j}\right)>u_{j}\left(w_{j}^{\prime}, t_{j}^{\prime}\right)$ for some $j$ in $N$, then $a P(b) a^{\prime}$.

Next, we define anonymity. Anonymity says that, if each country has the same benefit function, $R$ must be indifferent between two allocations if one is obtained from the other by a permutation of the bundles of countries. Given an allocation $a$ in $A$ and a permutation $\rho$ on $N$, the permuted allocation is denoted by $a_{\rho}=\left(w_{\rho}, t_{\rho}\right)=\left(w_{\rho(1)}, \ldots, w_{\rho(n)} ; t_{\rho(1)}, \ldots, t_{\rho(n)}\right)$.

Anonymity. For each allocation $a$ in $A$, each permutation $\rho$ on $N$ and each profile of benefit functions $b$ in $B^{n}$ such that each country $i$ has the same benefit function, we have $a I(b) a_{\rho}$.

Note that anonymity says that names and locations of the countries do not matter. It is therefore different from the anonymity axioms which require only 
the names not to matter. Moreover, it is restricted to a limited number of cases, i.e., it only applies if every country has the same benefit function. This version of the axiom is plausible in our context since the location, and hence the inflow of a country, is determined mostly by historical events and nature. Thus, a fair ranking should not take those into account in social judgments.

\subsection{Formalization of the principles}

The lack of well-defined property rights over an international river leads to international water disputes. Several principles of international law have been proposed to prevent and solve such conflicts. However, they are often difficult to formalize and apply. We argue that Pigou-Dalton for $r$ defined below provides a reasonable formalization of absolute territorial sovereignty (ATS), unlimited territorial integrity (UTI) and territorial integration of all basin states (TIBS).

Let the vector $r=\left(r_{1}, \ldots, r_{n}\right)$ in $\mathbb{R}_{+}^{n}$ be the reference vector that defines property rights over the river. That is, $r_{i}$ is the amount of river water that country $i$ has a right to consume. Pigou-Dalton for $r$ says that a transfer of money from a richer country to a poorer one such that the one that starts out with less monetary compensation does not end up with more than the other is an improvement at allocations where each country already consumes their reference level.

Pigou-Dalton for $r$. For each profile of benefit functions $b$ in $B^{n}$, all allocations $(r, t)$ and $\left(r, t^{\prime}\right)$ in $A$, if there exist two countries $i$ and $j$ such that $t_{i} \geq t_{j}$ and a positive real number $\delta$ such that $t_{i}^{\prime}=t_{i}+\delta$ and $t_{j}^{\prime}=t_{j}-\delta$ with $t$ and $t^{\prime}$ coinciding everywhere else, then $(r, t) P(b)\left(r, t^{\prime}\right)$.

Pigou-Dalton for $r$ is based on the idea that a country that consumes the amount of water they are entitled to does not need to compensate another.

Recall that ATS considers a country entitled to the part of the river within its borders. Thus, setting each $r_{i}$ equal to $e_{i}$ in the definition of Pigou-Dalton for $r$ provides a formalization of the principle. The principle clearly favours countries with a higher inflow. 
The second principle, UTI, on the other hand, can be interpreted as considering each country entitled to the welfare level they would achieve if they could consume all the water available up to their position. ${ }^{3}$ Setting each $r_{i}$ equal to $\sum_{j \leq i} e_{j}$ provides a reasonable formalization of the principle. The principle clearly favours downstream countries.

Finally, recall that TIBS considers each riparian country entitled to a reasonable and equitable share in the river water. One can thus interpret the principle as sharing the total flow in the river equally among countries (Van den Brink et al., 2012). Setting each $r_{i}$ equal to $\sum_{i \in N} e_{i} / n$ provides a reasonable formalization of the principle. We can also set $r_{i}$ equal to $\sum_{i \in N} e_{i}$ since it considers the entire river as a single unit and states that all countries are allowed an unlimited use of it (Soffer et al., 1999).

An important difference between TIBS and the other two principles is that the former sets the same reference level for all countries. The following theorem shows that this makes the principle the only principle among the three compatible with Pareto and anonymity. ${ }^{4}$

Theorem 5.1. A ranking $R$ on A satisfies Pareto, anonymity and Pigou-Dalton for $r$ only if $r_{i}=r_{j}$ for all countries $i$ and $j$ in $N$.

Pareto is a standard axiom of efficiency. The interpretation of the impossibility result of Theorem 5.1 depends on whether one considers the other two desirable. We consider Pigou-Dalton for $r$ to be desirable since it provides a reasonable formalization of the principles. Anonymity, on the other hand, is a fairness axiom which guarantees that irrelevant characteristics do not matter. Thus, we argue that Theorem 5.1 suggests that TIBS should be chosen over the other two principles.

In light of Theorem 5.1, in the sequel, we assume that each country has the same reference level. We nevertheless use the same notation, $r$, to denote this reference vector as this raises no confusion.

\footnotetext{
${ }^{3}$ This is also the interpretation of Ambec and Sprumont (2002) and Ambec and Ehlers (2008).

${ }^{4}$ Assuming the same reference level for each country, a ranking that satisfies all axioms in Theorem 5.1 is the generalized Lorenz preorder defined in the next section.
} 


\subsection{Two proposals to rank allocations}

\subsubsection{Generalized Lorenz preorder}

Given the assumption that the reference level is the same for all countries, we suggest that in comparisons of allocations $a$ and $a^{\prime}$ where every country is given their reference level, the social ranking must be independent of the benefit function profile. Indeed, in these cases, each country $i$ 's ranking of $a_{i}$ and $a_{i}^{\prime}$ is independent of $b_{i}$, so why would the social ranking depend on those? Independence captures this idea.

Independence. For each profile of benefit functions $b$ and $b^{\prime}$ in $B^{n}$ and all allocations $(r, t)$ and $\left(r, t^{\prime}\right)$ in $A$, we have $(r, t) R(b)\left(r, t^{\prime}\right)$ if and only if $(r, t) R\left(b^{\prime}\right)\left(r, t^{\prime}\right)$.

Theorem 5.2 below shows that a ranking that satisfies Pareto, anonymity, independence and Pigou-Dalton for $r$ must be inequality averse with respect to equivalent incomes of individual countries. The equivalent income of a country $i$ at an allocation $a$ is the amount of the hypothetical monetary compensation that, if combined with the reference level of water consumption, would give the country the same utility $i$ has at $a .^{5}$ That is, given an allocation $a=(w, t)$ in $A$, for each $i$ in $N$, the equivalent income of $i$, denoted by $d_{i}(a)$, is such that $b_{i}\left(w_{i}\right)+t_{i}=b_{i}\left(r_{i}\right)+d_{i}(a)$. Note that $d_{i}$ represents country $i$ 's preferences. Figure 5.1 shows the calculation of equivalent incomes.

Now, set $d(a)=\left(d_{1}(a), \ldots, d_{n}(a)\right)$. Let $d_{[] .]}(a)$ be a rearrangement of the elements of $d(a)$ that reorders elements of $d(a)$ in a non-decreasing way. That is, $d_{[1]}(a) \leq d_{[2]}(a) \leq \ldots \leq d_{[n]}(a)$. The generalized Lorenz preorder with reference $r$, denoted $R_{L}^{r}$, is such that, for each $b$ in $B^{n}$ and all allocations $a$ and $a^{\prime}$ in $A$,

$$
a R_{L}^{r}(b) a^{\prime} \Longleftrightarrow \sum_{i=1}^{k} d_{[i]}(a) \geq \sum_{i=1}^{k} d_{[i]}\left(a^{\prime}\right) \text { for each } k \text { in }\{1, \ldots, n\} .
$$

\footnotetext{
${ }^{5}$ For uses and discussions of the concept of equivalent income, see Pazner and Schmeidler (1978) in the context of fair allocations, Willig (1981) in the context of ranking income distributions, Moulin (1987) in sharing the cost of a public good and Fleurbaey et al. (2013) and references therein for an application to health.
} 


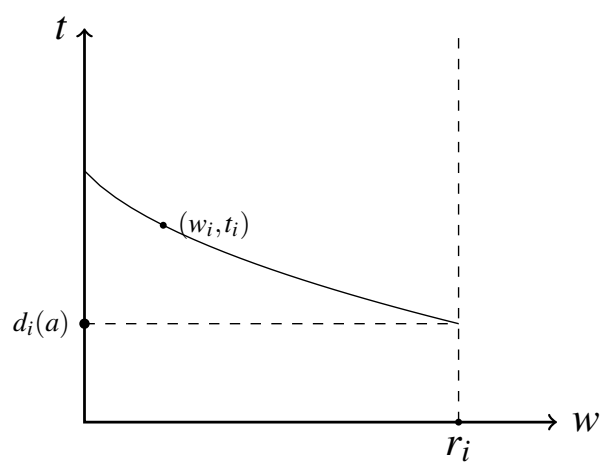

Figure 5.1 Calculation of $d_{i}$ s. The intersection of $i$ 's indifference curve at $\left(w_{i}, t_{i}\right)$ with the line $w=r_{i}$ is $d_{i}(a)$.

Given $d(a)$ and $d\left(a^{\prime}\right)$, the generalized Lorenz preorder prefers the more equally distributed one. For instance, for $n=3$ and $a$ and $a^{\prime}$ such that $d(a)=$ $(1,15,8), d\left(a^{\prime}\right)=(4,15,5)$, we have $a^{\prime} R_{L}^{r} a$ since $a^{\prime}$ is obtained from $a$ via a transfer of 3 units from country 3 to country 1, making the distribution more equal.

Theorem 5.2 shows that any ranking that satisfies Pareto, anonymity, independence and Pigou-Dalton for $r$ respects the generalized Lorenz preorder. ${ }^{6}$

Theorem 5.2. If a ranking $R$ on A satisfies Pareto, anonymity, independence and Pigou-Dalton for $r$, then $a R_{L}^{r}(b) a^{\prime}$ implies $a R(b) a^{\prime}$ and $a P_{L}^{r}(b) a^{\prime}$ implies $a P(b) a^{\prime}$ for each profile of benefit functions $b$ in $B^{n}$.

\subsubsection{Egalitarian equivalent ordering}

In this section, we first define weak Pareto and a stronger version of PigouDalton for $r{ }^{7}$

\footnotetext{
${ }^{6}$ It has been shown before that axioms recommending Pigou-Dalton transfers combined with anonymity and Pareto lead to characterizations of Lorenz preorders. Willig (1981) is the first to use reference vectors and prove a similar result in an income distribution context where the household endowments and prices are given.

${ }^{7}$ Recall that the reference level is assumed to be the same for each country.
} 
Weak Pareto. For each profile of benefit functions $b$ in $B^{n}$ and all allocations $a$ and $a^{\prime}$ in $A$, if $u_{i}\left(w_{i}, t_{i}\right)>u_{i}\left(w_{i}^{\prime}, t_{i}^{\prime}\right)$ for each country $i$ in $N$, then $a P(b) a^{\prime}$.

Hammond equity for $r$. For each profile of benefit functions $b$ in $B^{n}$, all allocations $(r, t)$ and $\left(r, t^{\prime}\right)$ in $A$, if there exist two countries $i$ and $j$ such that $t_{i}^{\prime} \geq t_{i} \geq t_{j} \geq t_{j}^{\prime}$ with the first or third inequality strict and with $(r, t)$ and $\left(r, t^{\prime}\right)$ coinciding everywhere else, then $(r, t) R(b)\left(r, t^{\prime}\right)$.

The egalitarian equivalent ordering with reference $r$, denoted by $R_{E}^{r}$ is such that for each $b$ in $B^{n}$ and all allocations $a$ and $a^{\prime}$ in $A$,

$$
a R_{E}^{r}(b) a^{\prime} \Leftrightarrow d_{[1]}(a) \geq d_{[1]}\left(a^{\prime}\right)
$$

The ordering $R_{E}^{r}$ also favors more equal distributions of $d_{i} \mathrm{~s}$. The main difference between the two relations is that $R_{E}^{r}$ only focuses on the minimum of $d(a)$ and is not concerned with what happens in other parts of the distribution. In the example above, $R_{E}^{r}$ also prefers $a^{\prime}$ to $a$.

Theorem 5.3 below shows that any ranking that satisfies weak Pareto and Hammond equity for $r$ is either the egalitarian equivalent ordering or a refinement of it. ${ }^{8}$

Theorem 5.3. If a ranking $R$ on A satisfies weak Pareto and Hammond equity for $r$, then $a P_{E}^{r}(b) a^{\prime}$ implies $a P(b) a^{\prime}$ for each profile of benefit functions $b$ in $B^{n}$.

\subsection{Conclusion}

Most of the recent axiomatic studies on river sharing model the problem as a cooperative game, where axioms are imposed on the distribution of welfare to the countries and solution concepts (i.e., allocation rules) are proposed. This paper does not use a cooperative game theory approach since this is not

\footnotetext{
${ }^{8}$ It has been shown before that Pigou-Dalton axioms replaced with the stronger Hammond equity axioms and combined with weak Pareto lead to characterizations of the egalitarian equivalent ordering in various contexts (Bosmans and Ooghe (2013); Fleurbaey and Maniquet, 2011; Miyagishima et al., 2014; Tungodden, 2000).
} 
necessary to propose rankings. Nevertheless, allocation rules can be derived from the rankings characterized here simply by taking the optimal allocation chosen by each ranking.

Additionally, using a ranking approach makes our analysis applicable to second best problems. For instance, in situations where the core of the cooperative game ${ }^{9}$ induced by the river sharing problem is not a singleton, the rankings proposed here can be used to choose from the set of core allocations, hence enabling us to design acceptable and relatively fair allocations. This becomes especially important in cases of international rivers where we need to design allocations acceptable to all countries in order to achieve practical solutions.

\footnotetext{
${ }^{9}$ For a cooperative game derived from the river sharing problem, see Ambec and Sprumont (2002).
} 


\section{Appendix 5.A}

Proof of Theorem 5.1. Let $R$ satisfy the axioms and $r$ be the reference vector. Suppose, for a contradiction, that there exist $k, m$ in $N$ such that $r_{k}<r_{m}$.

Let $b$ in $B^{n}$ be such that $b_{i}=b_{j}$ for all countries $i, j$ in $N$. Let $\rho$ be the permutation on $N$ such that $\rho(k)=m, \rho(m)=k$ and $\rho(i)=i$ for each $i \neq k, m$. Consider the following three allocations (also shown in the table below): $a=\left(r_{1}, \ldots, r_{n}, t 1_{n}\right), a_{\rho}$, and $a^{\prime}=\left(r_{1}, \ldots, r_{n}, t, \ldots, t_{k}^{\prime}, t_{m}^{\prime}, \ldots, t\right)$ where $t_{k}^{\prime}, t_{m}^{\prime}$ are such that $b\left(r_{m}\right)+t=b\left(r_{k}\right)+t_{k}^{\prime}$ and $b\left(r_{k}\right)+t=b\left(r_{m}\right)+t_{m}^{\prime}$.

\begin{tabular}{|l|c|c|c|}
\hline & $\left(w_{k}, t_{k}\right)$ & $\left(w_{m}, t_{m}\right)$ & $\left(w_{i}, t_{i}\right)$ for $i \neq k, m$ \\
\hline$a$ & $\left(r_{k}, t\right)$ & $\left(r_{m}, t\right)$ & $\left(r_{i}, t\right)$ \\
\hline$a_{\rho}$ & $\left(r_{m}, t\right)$ & $\left(r_{k}, t\right)$ & $\left(r_{i}, t\right)$ \\
\hline$a^{\prime}$ & $\left(r_{k}, t_{k}^{\prime}\right)$ & $\left(r_{m}, t_{m}^{\prime}\right)$ & $\left(r_{i}, t\right)$ \\
\hline
\end{tabular}

Note that each country is indifferent between their bundle at $a$ and $a_{\rho}$. Thus, $a_{\rho} I(b) a^{\prime}$ by Pareto.

Since $r_{k}<r_{m}$ and $b$ is strictly increasing, we must have $t_{m}^{\prime}<t<t_{k}^{\prime}$. Moreover, by construction $t_{k}^{\prime}+t_{m}^{\prime}=2 t$. Thus, we have $a P(b) a^{\prime}$ by Pigou-Dalton for $r$. Finally, by anonymity, we have $a I(b) a_{\rho}$, a contradiction.

Proof of Theorem 5.2. Let $R$ satisfy the axioms. Let $b$ in $B^{n}$ be a profile of benefit functions and $a=(w, t)$ and $a^{\prime}=\left(w^{\prime}, t^{\prime}\right)$ allocations such that $a R_{L}^{r}(b) a^{\prime}$. We will show that $a R(b) a^{\prime}$.

First, let $\bar{b}$ in $B^{n}$ be a profile where each country has the same benefit function. Let $a_{d}=(r, d(a))$ and $a_{d}^{\prime}=\left(r, d\left(a^{\prime}\right)\right)$ be such that $d_{1}(a) \leq \ldots \leq d_{n}(a)$ and $d_{1}\left(a^{\prime}\right) \leq \ldots \leq d_{n}\left(a^{\prime}\right)$. Note that this can be done without loss of generality due to anonymity and the fact that $r_{i}=r_{j}$ for all $i, j$ in $N$.

Next, let $\hat{a}=(r, \hat{t})$ be an allocation such that $\hat{t}_{i}=d_{i}\left(a_{d}^{\prime}\right)$ for each $i \in$ $\{1, \ldots, n-1\}$ and $\hat{t}_{n}=d_{n}\left(a_{d}^{\prime}\right)+\sum_{i \in N} d_{i}\left(a_{d}\right)-\sum_{i \in N} d_{i}\left(a_{d}^{\prime}\right) .{ }^{10}$ Note that we have $\sum_{i \in N} d_{i}\left(a_{d}\right)=\sum_{i \in N} \hat{t}_{i}$ by construction.

The following are true.

\footnotetext{
${ }^{10}$ This formulation is inspired by Shorrocks (1983, Theorem 2).
} 
1. By construction, $\sum_{i \in N} d_{i}\left(a_{d}\right)=\sum_{i \in N} \hat{t}_{i}$. Moreover, $a R_{L}^{r}(b) a^{\prime}$ implies $a_{d} R_{L}^{r}(\bar{b}) \hat{a}$. That is, we have either $d_{i}\left(a_{d}\right)=\hat{t}_{i}$ for each $i$ in $N$ or that $d\left(a_{d}\right)$ can be obtained from $\hat{t}$ by a finite sequence of Pigou-Dalton transfers. Thus, by reflexivity and Pigou-Dalton for $r$, we have $a_{d} R(\bar{b}) \hat{a}$ :

2. By construction, we have $\hat{t} \geq d\left(a_{d}^{\prime}\right)$ with strict inequality holding if $\sum_{i \in N} d_{i}\left(a_{d}\right)>\sum_{i \in N} d_{i}\left(a_{d}^{\prime}\right)$. Thus, by Pareto, we have $\hat{a} R(\bar{b}) a_{d}^{\prime}$.

So, we have $a_{d} R(\bar{b}) \hat{a} R(\bar{b}) a_{d}^{\prime}$. Thus, by transitivity, $a_{d} R(\bar{b}) a_{d}^{\prime}$. By independence, $a_{d} R(\bar{b}) a_{d}^{\prime}$ implies $a_{d} R(b) a_{d}^{\prime}$. By Pareto, $a_{d} I(b) a$ and $a_{d}^{\prime} I(b) a^{\prime}$. We therefore obtain $a R(b) a^{\prime}$ by transitivity.

Now, assume $a P_{L}^{r}(b) a^{\prime}$. This means $a_{d} P_{L}^{r}(\bar{b}) a_{d}^{\prime}$ by definition. That is, $\sum_{i=1}^{k} d_{i}\left(a_{d}\right) \geq \sum_{i=1}^{k} d_{i}\left(a_{d}^{\prime}\right)$ for each $k$ in $\{1, \ldots, n\}$ with some $m$ in $\{1, \ldots, n\}$ for which the inequality is strict. Let $m$ also denote the minimum $m$ such that this inequality holds strictly.

If $\sum_{i \in N} d_{i}\left(a_{d}\right)=\sum_{i \in N} d_{i}\left(a_{d}^{\prime}\right)$, then we can conclude that $d\left(a_{d}\right)$ can be reached from $d\left(a_{d}^{\prime}\right)$ by a finite sequence of Pigou-Dalton transfers since we know that $d\left(a_{d}\right) \neq d\left(a_{d}^{\prime}\right)$. Thus, $a_{d} P(\bar{b}) a_{d}^{\prime}$ by Pareto and Pigou-Dalton for $r$ (and transitivity if necessary).

If $\sum_{i \in N} d_{i}\left(a_{d}\right)>\sum_{i \in N} d_{i}\left(a_{d}^{\prime}\right)$ and $d_{i}\left(a_{d}\right) \geq d_{i}\left(a_{d}^{\prime}\right)$ for each $i \in\{m+1, m+$ $2, \ldots, n\}$, then $a_{d} P(\bar{b}) a_{d}^{\prime}$ follows from Pareto.

Now, assume $\sum_{i \in N} d_{i}\left(a_{d}\right)>\sum_{i \in N} d_{i}\left(a_{d}^{\prime}\right)$. Assume also that the set $N_{1}=\{i \in$ $\left.N: d_{i}\left(a_{d}^{\prime}\right)>d_{i}\left(a_{d}\right)\right\}$ is non-empty. Let $N_{2}=\left\{i \in N: d_{i}\left(a_{d}\right) \geq d_{i}\left(a_{d}^{\prime}\right)\right\}$. The fact that $a_{d} P_{L}^{r}(\bar{b}) a_{d}^{\prime}$ yields,

$$
\sum_{i \in N_{2}}\left(d_{i}\left(a_{d}\right)-d_{i}\left(a_{d}^{\prime}\right)\right)>\sum_{i \in N_{1}}\left(d_{i}\left(a_{d}^{\prime}\right)-d_{i}\left(a_{d}\right)\right)
$$

Let $\tilde{a}=(r, \tilde{t})$ be an allocation such that $\tilde{t}_{i}=d_{i}\left(a_{d}\right)$ for each $i$ in $N_{2}$ and $\sum_{i \in N_{1}}\left(d_{i}\left(a_{d}^{\prime}\right)-d_{i}\left(a_{d}\right)\right)$ is allocated, via Pigou-Dalton transfers, to agents in $N_{1}$ in a way such that $d_{i}\left(a_{d}\right) \geq \tilde{t}_{i}$ for each $i$ in $N_{1}$. Note that equation (5.2) guarantees that this can be done.

We therefore have $\tilde{a} P(\bar{b}) a_{d}^{\prime}$ by Pigou-Dalton for $r$. By Pareto, $a_{d} P(\bar{b}) \tilde{a}$. Thus, by transitivity $a_{d} P(\bar{b}) a_{d}^{\prime}$. 
Applying independence and Pareto as above, we obtain $a P(b) a^{\prime}$.

Proof of Theorem 5.3. Let $R$ satisfy the axioms. Let $b$ be a profile of benefit functions and $a=(w, t), a^{\prime}=\left(w^{\prime}, t^{\prime}\right)$ allocations in $A$ such that $a P_{E}^{r}(b) a^{\prime}$. It suffices to show that $a P(b) a^{\prime}$.

Let $\delta=\left(d_{[1]}(a)-d_{[1]}\left(a^{\prime}\right)\right) / 10 n$. Let $\hat{a}, \hat{a}^{\prime}$ be allocations such that $\hat{a}=$ $\left(r, d(a)-\delta 1_{n}\right)$ and $\hat{a}^{\prime}=\left(r, d\left(\hat{a}^{\prime}\right)+\delta 1_{n}\right)$ in $A$. By weak Pareto, $a P(b) \hat{a}$ and $\hat{a}^{\prime} P(b) a^{\prime}$.

Next, we show that $\hat{a} P(b) \hat{a}^{\prime}$. First note that $d_{[1]}(\hat{a})>d_{[1]}\left(\hat{a}^{\prime}\right)$. Let $\tilde{a}=(r, \tilde{t})$ be such that $d_{[1]}\left(\hat{a}^{\prime}\right) \leq \tilde{t}_{[1]} \leq \tilde{t}_{[2]} \leq \ldots \leq \tilde{t}_{[n]}<d_{[2]}\left(\hat{a}^{\prime}\right)$ and $\tilde{t}_{[n]}<d_{[1]}(\hat{a})$. By weak Pareto, $\hat{a} P(b) \tilde{a}$. By Hammond equity for $r, \tilde{a} R(b) \hat{a}^{\prime}$. Thus, we have $a P(b) \hat{a} P(b) \tilde{a} R(b) \hat{a}^{\prime} P(b) a^{\prime}$. That is, $a P(b) a^{\prime}$. 



\section{BIBLIOGRAPHY}

Alesina, A. and Angeletos, G.-M. (2005). Fairness and redistribution. American Economic Review, pages 960-980.

Almås, I., Cappelen, A. W., Lind, J. T., Sørensen, E. Ø., and Tungodden, B. (2011). Measuring unfair (in)equality. Journal of Public Economics, 95(7):488-499.

Ambec, S. and Ehlers, L. (2008). Sharing a river among satiable agents. Games and Economic Behavior, 64(1):35-50.

Ambec, S. and Sprumont, Y. (2002). Sharing a river. Journal of Economic Theory, 107(2):453-462.

Ansink, E. and Weikard, H.-P. (2013). Composition properties in the river claims problem. Technical report, Tinbergen Institute.

Arneson, R. (1990). Liberalism, distributive subjectivism, and equal opportunity for welfare. Philosophy \& public affairs, 19(2):158-194.

Arneson, R. J. (1989). Equality and equal opportunity for welfare. Philosophical Studies, 56(1):77-93.

Arneson, R. J. (2015). Equality of opportunity. In Zalta, E. N., editor, The Stanford Encyclopedia of Philosophy. Summer 2015 edition.

Arnsperger, C. (1994). Envy-freeness and distributive justice. Journal of Economic Surveys, 8(2):155-186.

Atkinson, A. B. (1970). On the measurement of inequality. Journal of Economic Theory, 2(3):244-263.

Atkinson, A. B. (2001). The strange disappearance of welfare economics. Kyklos, 54(2-3):193-206.

Atkinson, A. B. and Bourguignon, F. (1982). The comparison of multidimensioned distributions of economic status. The Review of Economic Studies, pages 183-201. 
Barrett, S. (1994). Conflict and cooperation in managing international water resources, volume 94 . World Bank Publications.

Béal, S., Rémila, E., and Solal, P. (2012). The sequential equal surplus division for sharing a river. Technical report, MPRA Paper 37346, University Library of Munich, Germany.

Bénabou, R. and Tirole, J. (2006). Belief in a just world and redistributive politics. Quaterly journal of economics, 121(2):699-746.

Bosmans, K., Decancq, K., and Ooghe, E. (2015). What do normative indices of multidimensional inequality really measure? Forthcoming in Journal of Public Economics.

Bosmans, K. and Ooghe, E. (2013). A characterization of maximin. Economic Theory Bulletin, 1(2):151-156.

Bossert, W. (1995). Redistribution mechanisms based on individual characteristics. Mathematical Social Sciences, 29(1):1-17.

Bossert, W. and Fleurbaey, M. (1996). Redistribution and compensation. Social Choice and Welfare, 13(3):343-355.

Bourguignon, F. (1979). Decomposable income inequality measures. Econometrica, 47(4):901-920.

Bourguignon, F., Ferreira, F. H., and Menendez, M. (2007). Inequality of opportunity in Brazil. Review of Income and Wealth, 53(4):585-618.

Cappelen, A. W., Hole, A. D., Sørensen, E. Ø., and Tungodden, B. (2007). The pluralism of fairness ideals: An experimental approach. The American Economic Review, 97(3):818-827.

Cappelen, A. W. and Tungodden, B. (2010). Fairness and the proportionality principle. NHH, Department of Economics Working paper.

Chakravarty, S. R. (2009). Inequality, Polarization and Poverty: Advances in Distributional Analysis. Springer, Heidelberg.

Chaudhuri, A. (1986). Some implications of an intensity measure of envy. Social Choice and Welfare, 3(4):255-270.

Checchi, D. and Peragine, V. (2010). Inequality of opportunity in Italy. The Journal of Economic Inequality, 8(4):429-450.

Cohen, G. A. (1989). On the currency of egalitarian justice. Ethics, 99(4):906944. 
Cowell, F. (2011). Measuring inequality. Oxford University Press.

Cowell, F. and Ebert, U. (2004). Complaints and inequality. Social Choice and Welfare, 23(1):71-89.

Cowell, F. A. (1980). On the structure of additive inequality measures. The Review of Economic Studies, 47(3):521-531.

Cowell, F. A. (1985). Measures of distributional change: An axiomatic approach. Review of Economic Studies, 52(1):135-151.

Dardanoni, V. (1995). On multidimensional inequality measurement. Research on Economic Inequality, 6:201-207.

Dasgupta, P., Sen, A., and Starrett, D. (1973). Notes on the measurement of inequality. Journal of Economic Theory, 6(2):180-187.

Devooght, K. (2008). To each the same and to each his own: A proposal to measure responsibility-sensitive income inequality. Economica, 75(298):280295.

Diamantaras, D. and Thomson, W. (1990). A refinement and extension of the no-envy concept. Economics Letters, 33(3):217-222.

Dworkin, R. (1981a). What is equality? Part 1: Equality of welfare. Philosophy and Public Affairs, 10(4):185-246.

Dworkin, R. (1981b). What is equality? Part 2: Equality of resources. Philosophy and Public Affairs, 10(4):283-345.

Ebert, U. (2010). The decomposition of inequality reconsidered: Weakly decomposable measures. Mathematical Social Sciences, 60(2):94-103.

Feldman, A. and Kirman, A. (1974). Fairness and envy. The American Economic Review, 64(6):995-1005.

Ferreira, F. H. and Gignoux, J. (2011). The measurement of inequality of opportunity: Theory and an application to Latin America. Review of Income and Wealth, 57(4):622-657.

Ferreira, F. H. and Peragine, V. (2015). Equality of opportunity: Theory and evidence. ECINEQ Working Paper Series, 359.

Fleurbaey, M. (1994). On fair compensation. Theory and Decision, 36(3):277307. 
Fleurbaey, M. (1995). The requisites of equal opportunity. In Barnett, W. A., Moulin, H., Salles, M., and Schofield, N. J., editors, Social Choice, Welfare, and Ethics. Cambridge University Press, Cambridge.

Fleurbaey, M. (2008). Fairness, Responsibility, and Welfare. Oxford University Press.

Fleurbaey, M., Luchini, S., Muller, C., and Schokkaert, E. (2013). Equivalent income and fair evaluation of health care. Health Economics, 22(6):711-729.

Fleurbaey, M. and Maniquet, F. (2004). Compensation and responsibility. In Arrow, K. J., Sen, A., and Suzumura, K., editors, Handbook of Social Choice and Welfare, volume 2. Amsterdam: North-Holland.

Fleurbaey, M. and Maniquet, F. (2011). A Theory of Fairness and Social Welfare. Cambridge University Press.

Fleurbaey, M. and Peragine, V. (2013). Ex ante versus ex post equality of opportunity. Economica, 80(317):118-130.

Fleurbaey, M., Tungodden, B., and Chang, H. F. (2003). Any non-welfarist method of policy assessment violates the Pareto principle: A comment. Journal of Political Economy, 111(6):1382-1385.

Foley, D. K. (1967). Resource allocation and the public sector. Yale Economic Essays, 7(1):45-98.

Kaplow, L. (2005). Why measure inequality? The Journal of Economic Inequality, 3(1):65-79.

Kaplow, L. and Shavell, S. (2001). Any non-welfarist method of policy assessment violates the Pareto principle. Journal of Political Economy, 109(2):281286.

Kaplow, L. and Shavell, S. (2004). Any non-welfarist method of policy assessment violates the Pareto principle: reply. Journal of Political Economy, 112(1):249-251.

Kilgour, D. M. and Dinar, A. (1995). Are stable agreements for sharing international river waters now possible? Policy Research Working Paper 1474, The World Bank.

Kolm, S.-C. (1969). The optimal production of social justice. In Julius, M. and Henri, G., editors, Public Economics: An Analysis of Public Production and Consumption and Their Relations to the Private Sectors. Macmillan, London. 
Kolm, S.-C. (1972). Justice et équité. Éd. du Centre National de la Recherche Scientifique.

Kolm, S.-C. (1977). Multidimensional egalitarianisms. The Quarterly Journal of Economics, 91(2):1-13.

Kranich, L. (1996). Equitable opportunities: an axiomatic approach. Journal of Economic Theory, 71(1):131-147.

Maasoumi, E. (1986). The measurement and decomposition of multidimensional inequality. Econometrica, 54:991-997.

Marrero, G. A. and Rodríguez, J. G. (2013). Inequality of opportunity and growth. Journal of Development Economics, 104:107-122.

Mill, J. S. (1865). Principles of Political Economy: with some of their Applications to Social Philosophy, volume 2. Longmans, Green.

Miyagishima, K., Bosmans, K., and Ooghe, E. (2014). A characterization of maximin: corrigendum. Economic Theory Bulletin, 2(2):1-2.

Moulin, H. (1987). Egalitarian-equivalent cost sharing of a public good. Econometrica, 55(4):963-976.

Musgrave, R. A. (1959). The Theory of Public Finance. New York: McGrawHill.

Nozick, R. (1974). Anarchy, State, and Utopia. Oxford: Blackwell.

Ok, E. A. and Kranich, L. (1998). The measurement of opportunity inequality: a cardinality-based approach. Social Choice and Welfare, 15(2):263-287.

Olkin, I. and Marshall, A. W. (1979). Inequalities: Theory of Majorization and Its Applications. Academic Press, New York.

Ooghe, E., Schokkaert, E., et al. (2007). Equality of opportunity versus equality of opportunity sets. Social Choice and Welfare, 28(2):209-230.

Pazner, E. A. and Schmeidler, D. (1978). Egalitarian equivalent allocations: A new concept of economic equity. The Quarterly Journal of Economics, 92(4):671-687.

Peragine, V. (2002). Opportunity egalitarianism and income inequality. Mathematical Social Sciences, 44(1):45-64.

Ramos, X. and Van de gaer, D. (2012). Empirical approaches to inequality of opportunity: Principles, measures, and evidence. Technical report, Discussion Paper series, Forschungsinstitut zur Zukunft der Arbeit. 
Rawls, J. (1971). A Theory of Justice. Harvard University Press, Cambridge, MA.

Rawls, J. (1982). Social unity and primary goods. In Sen, A. and Williams, B., editors, Utilitarianism and Beyond. Cambridge University Press.

Roemer, J. E. (1993). A pragmatic theory of responsibility for the egalitarian planner. Philosophy \& Public Affairs, 22(2):146-166.

Roemer, J. E. (1998a). Equality of Opportunity. Harvard University Press, Cambridge, MA.

Roemer, J. E. (1998b). Theories of Distributive Justice. Harvard University Press, Cambridge, MA.

Roemer, J. E. (2002). Equality of opportunity: A progress report. Social Choice and Welfare, 19(2):455-471.

Roemer, J. E. and Trannoy, A. (2013). Equality of opportunity. Technical report, Cowles Foundation for Research in Economics, Yale University.

Samuelson, P. A. (1947). Foundations of Economic Analysis. Harvard University Press, Cambridge, MA.

Savaglio, E. (2002). Multidimensional inequality: A survey. Technical Report 362, SSRN Working Paper Series.

Schokkaert, E. and Devooght, K. (2003). Responsibility-sensitive fair compensation in different cultures. Social Choice and Welfare, 21(2):207-242.

Sen, A. (1973). On Economic Inequality. Clarendon Press, Oxford.

Sen, A. (1992). Inequality Reexamined. Clarendon Press, Oxford.

Sen, A. (2011). The Idea of Justice. Harvard University Press, Cambridge, MA.

Shorrocks, A. F. (1980). The class of additively decomposable inequality measures. Econometrica, 48:613-625.

Shorrocks, A. F. (1983). Ranking income distributions. Economica, 50(197):317.

Shorrocks, A. F. (1984). Inequality decomposition by population subgroups. Econometrica, 52:1369-1385.

Soffer, A., Rosovsky, M., and Copaken, N. (1999). Rivers of Fire: The Conflict Over Water in the Middle East. Rowman \& Littlefield Publishers. 
Tadenuma, K. (2002). Efficiency first or equity first? two principles and rationality of social choice. Journal of Economic Theory, 104(2):462-472.

Temkin, L. S. (1986). Inequality. Philosophy \& Public Affairs, 15:99-121.

Temkin, L. S. (1993). Inequality. Oxford University Press.

The World Bank (2005). World Development Report 2006: Equity and Development. World Bank and Oxford University Press.

Thomson, W. (2010). Fair allocation rules. In Arrow, K., Sen, A., and Suzumura, K., editors, Handbook of Social Choice and Welfare, volume 2. NorthHolland, New York.

Tinbergen, J. (1946). Redelijke inkomensverdeling, 1953. NV Gulden Pers, Haarlem.

Tsui, K.-Y. (1995). Multidimensional generalizations of the relative and absolute inequality indices: the Atkinson-Kolm-Sen approach. Journal of Economic Theory, 67(1):251-265.

Tungodden, B. (2000). Egalitarianism: is leximin the only option? Economics and Philosophy, 16(02):229-245.

Van de gaer, D. (1993). Equality of Opportunity and Investment in Human Capital. Katholieke Universiteit Leuven, Faculteit der Economische en Toegepaste Economische Wetenschappen.

Van den Brink, R., Estévez-Fernández, A., van der Laan, G., and Moes, N. (2013). Independence of downstream and upstream benefits in river water allocation problems. Social Choice and Welfare, 43(1):1-22.

Van den Brink, R., Van der Laan, G., and Moes, N. (2012). Fair agreements for sharing international rivers with multiple springs and externalities. Journal of Environmental Economics and Management, 63(3):388-403.

Varian, H. R. (1974). Equity, envy, and efficiency. Journal of Economic Theory, 9(1):63-91.

Weinzierl, M. (2014). The promise of positive optimal taxation: normative diversity and a role for equal sacrifice. Journal of Public Economics, 118:128142 .

Weymark, J. (2006). The normative approach to the measurement of multidimensional inequality. In Farina, F. and Savaglio, E., editors, Inequality and Economic Integration. Routledge, London. 
Willig, R. D. (1981). Social welfare dominance. The American Economic Review, 71(2):200-204.

Young, H. P. (1987). Progressive taxation and the equal sacrifice principle. Journal of Public Economics, 32(2):203-214.

Young, H. P. (1990). Progressive taxation and equal sacrifice. The American Economic Review, 80(1):253-266. 


\section{NEDERLANDSE SAMENVATTING}

De vier hoofdstukken van deze dissertatie hebben betrekking op rechtvaardigheidsprincipes in een verscheidenheid van economische omstandigheden. In elk hoofdstuk is het hoofddoel rangschikkingen van sociale welvaartsfuncties te bepalen voor de evaluatie van distributies in termen van rechtvaardigheid en efficiëntie.

Rechtvaardigheid is een lastig concept. Wanneer men een eerlijke verdeling wil definiëren, moet men zich eerst afvragen wat de relevante uitkomstvariabele is (inkomen, welzijn, etc.) en wie de ontvangers van die uitkomstvariabele zijn. Hierna komen we bij een van de meest belangrijke vragen die we ons moeten stellen bij het definiëren van een eerlijke verdeling: "Welke individuele karakteristieken zijn ethisch relevant?". Met andere woorden, men moet zich afvragen welke persoonlijke karakteristieken ongelijkheid (bijvoorbeeld inkomensongelijkheid) tussen twee individuen kan rechtvaardigen. Wat ethisch relevant is hangt af van de specificaties van een situatie. Bijvoorbeeld, het aantal gewerkte uren kan als relevant worden beschouwd wanneer men een inkomensverdeling bestudeert, maar het aantal gewerkte uren zal waarschijnlijk niet relevant zijn in de context van stoelreserveringen in een bioscoop.

In hoofdstuk 2 is de uitkomst die we bestuderen een verzameling van $\mathrm{m}$ goederen, en de ontvangers zijn individuen. We karakteriseren rechtvaardigheid als afgunstvrijheid. Een allocatie is afgunstvrij als geen enkel individu de toebedeling van een ander prefereert boven zijn eigen toebedeling. Het criterium beschouwt voorkeuren als ethisch relevant.

Ook al is afgunstvrijheid een van de belangrijkste concepten in de literatuur betreffende verdelende rechtvaardigheid, het concept lost niet alle verdelingspro- 
blemen op. Dit is omdat de verzameling van afgunstvrije en efficiënte allocaties erg groot kan worden en zelfs leeg kan zijn. Voorgaande is het tweede onderwerp in hoofdstuk 2. We stellen een klasse van afgunstmaatstaven voor om allocaties te vergelijken. De klasse meet totale afgunst door het sommeren van individuele afgunst.

In hoofdstuk 3 bestuderen we inkomen waar de ontvangers een groep van $\mathrm{n}$ individuen zijn. Het basisprincipe van verdelende rechtvaardigheid in dit hoofdstuk is libertarisme. We definiëren een axioma, laissez-faire, om de bezwaren tegen herverdeling vanuit de hoek van libertarisme vast te leggen. Het axioma stelt dat de verdeling waarin elk individu zijn marktinkomen ontvangt beter is dan elke andere allocatie van dezelfde hoeveelheid van totaal inkomen. Om deze reden is libertarisme een criterium van verdelende rechtvaardigheid die marktinkomen beschouwt als de ethisch significante karakteristiek.

Twee justificaties voor libertarisme zijn individuele vrijheid en de efficiënte van de vrije markt. Dit hoofdstuk refereert naar de tweede justificatie. We tonen aan dat we nog steeds problemen tegenkomen in het bereiken van efficiënte zelfs als herverdeling compleet uitgesloten is.

In hoofdstuk 4 bestuderen we als relevante variabele inkomen, en de ontvangers verschillen met betrekking tot ethisch relevante karakteristieken (deze karakteristieken noemen we "verantwoordelijkheidskarakteristieken") en irrelevante karakteristieken (zogenaamde "omstandigheden"). Het concept van rechtvaardigheid is gelijkheid van kansen.

Gelijkheid van kansen bestaat uit twee hoofdprincipes. De eerste, het compensatieprincipe, stelt dat ongelijkheid vanwege omstandigheidsverschillen onrechtvaardig is. De tweede, het beloningsprincipe, geeft antwoord op de vraag hoe inkomen te verdelen tussen individuen welke alleen verschillen gebaseerd op hun "verantwoordelijkheidskarakteristieken". We focussen op twee interpretaties van het beloningsidee. De eerste interpretatie, "liberale beloning", stelt dat verschillen in marktinkomen tussen individuen moet worden gehandhaafd wanneer men inkomen tussen individuen verdeelt die dezelfde omstandigheden delen. De tweede interpretatie, "utilitaristische beloning", stelt 
dat rechtvaardigheid niet afhangt van de manier waarop inkomen wordt verdeeld tussen individuen.

In hoofdstuk 4, presenteren we welvaartsfuncties die "compensatie" en "liberale beloning" combineren, alsmede "compensatie" en "utilitaristische beloning". We presenteren ook de optimale verdelingen die gesuggereerd worden door deze welvaartsfuncties. In het tweede deel van het hoofdstuk, presenteren we ongelijkheidsmaten die ongelijkheid van kansen meten als het verschil tussen de eigenlijke verdeling en de eerlijke verdeling.

In hoofdstuk 5 bestuderen we internationale rivieren, en de ontvangers zijn soevereine staten die grenzen aan de rivier. Het delen van water uit internationale rivieren is vaak een bron van conflict tussen landen, voornamelijk doordat eigendomsrechten betreffende rivieren niet duidelijk bepaald zijn. Meerdere internationale principes van internationaal recht zijn voorgesteld om dit probleem op te lossen. Wij focussen op drie principes die de meeste aandacht van beleidsmakers en onderzoekers hebben gekregen. Ten eerste, het principe van absolute territoriale soevereiniteit (ATS), stelt dat een land absolute soevereiniteit heeft over het deel van een rivier binnen zijn grenzen. Met andere woorden, het principe stelt dat grenzen ethisch relevant zijn. Ten tweede, ongelimiteerde territoriale integriteit (UTI), stelt dat een land niet de kwantiteit en kwaliteit van water dat vloeit naar een ander land kan aanpassen. Het principe beschouwt de hoeveelheid water beschikbaar tot de grenzen van een land als ethisch relevant. Ten derde, territoriale integratie van alle landen grenzend aan een rivier (TIBS), stelt dat de hele rivier als een gehele entiteit beschouwd dient te worden en dat landen er een ongelimiteerd gebruik van mogen maken. Met andere woorden, alle landen zijn gelijk in termen van relevante karakteristieken.

Ook al zijn deze principes intuïtief, ze zijn desalniettemin lastig te formuleren in concrete toepassingen. Bovendien is er een voortdurend debat welke principes te gebruiken in praktische toepassingen. Deze twee vragen zijn het onderwerp van hoofdstuk 5. We stellen als eerste een manier voor om deze principe te formaliseren. We beargumenteren dan dat TIBS de voorkeur geniet boven ATS en UTI. 
Territoriale integriteit van alle landen grenzend aan een rivier als primair criterium nemend van verdelende rechtvaardigheid, stellen we twee rankings voor om allocaties van rivier water te vergelijken. 


\section{VALORIZATION}

\section{What, why and to whom?}

The current dissertation provides insights on criteria of distributive justice in a variety of economic environments. Distributive justice concerns the fair distribution of resources, including but not limited to income, goods and services, wealth, education, health care and opportunities. The four main chapters of this dissertation focus on the distribution of a group of commodities, the distribution of income, the distribution of opportunities for income in a society, and the distribution of water from an international river among riparian countries, respectively.

The relevance of this dissertation is therefore best explained by focusing on the social and economic relevance of the results presented in individual chapters.

The second chapter, "An axiomatic approach to the measurement of envy", provides a class of functions to measure envy in a society. As noted in the introduction and concluding remarks of the chapter, the envy measures proposed in the chapter can be used as multidimensional inequality measures in the (realistic) case of individuals who have possibly different preferences over the bundle of goods in question.

Naturally, there exists a wide variety of inequality measures that are based on different philosophical ideas, and that are designed to be used in different contexts. The literature is far too wide to provide a review here, yet suffice it to say, for our purposes here, that we can roughly divide inequality measures into two groups: unidimensional inequality measures and multidimensional inequality measures. The former are measures that focus on distributions of 
only one commodity such as income. However, there are many situations in which there are several dimensions to inequality and these dimensions cannot be reduced to a single index in a meaningful manner. For example, public authorities may be interested in the distributions of housing, health, education, food, etc. in the population and not so much with the distribution of income per se. Another case of interest is the case where the government is concerned both with income and with non-monetary variables. In such situations, unidimensional inequality measures prove inadequate to compare inequality within and between populations. The acknowledgement of this fact has lead to a wide literature on multidimensional inequality measurement beginning with the seminal articles by Kolm (1977) and Atkinson and Bourguignon (1982). ${ }^{11}$ And, as noted above, it is that literature that this chapter belongs to.

At this point, it is important to note the relevance of inequality measurement. Inequality is important for both normative and practical reasons. Social justice is central in considerations of inequality in a society. "That more just societies should register lower numbers on the inequality scale evidently accords with an intuitive appreciation of the term inequality" (Cowell, 2011, p. 11). Justice arguments are often made in connection with all dimensions of social life such as income, wealth, political power, taxation, labor markets, education, health care and military service. For instance, in considering a particular policy proposal say for reducing the amount given in student grants - the inequality implication of the policy (that is whether the policy leads to more or less inequality) is often taken to be an argument for or against the policy. A primary motivation for inequality measurement is therefore to guide policy. However, we need to be able to measure inequality in order to be able to assess inequality implications of policies. Thus, as noted by Kaplow (2005), measuring inequality seems appropriate as an input to policymaking. As such, the results of this chapter are of interest to policymakers as well as empirical researchers.

The third chapter, "Laissez-faire versus Pareto", contributes to discussions of libertarianism by showing the difficulty of combining libertarianism with

\footnotetext{
${ }^{11}$ See Savaglio (2002) for a survey.
} 
Pareto efficiency. As such, the academic community is the target audience of this chapter.

The fourth chapter, "Measurement of equality of opportunity: a normative approach", proposes social welfare functions and inequality measures to compare income distributions in terms of equality of opportunity. Equality of opportunity measures distinguish between inequalities arising from the exercise of individual responsibility and inequalities due to predetermined circumstances.

The theory of equality of opportunity differs from the classical theories of distributive justice in that perfect equality where each individual is given the same outcome (e.g., the same income for everyone) is not promoted as the ideal. Instead, a central role for personal responsibility is incorporated into the definition of distributive justice. It is argued that the outcome (e.g., income) of an individual is determined by his circumstances, which are characteristics that cannot be attributed to individual responsibility (e.g., gender), and responsibility characteristics which the individual can be held accountable for (e.g., effort). Inequalities due to circumstances (e.g., wage difference due to gender) are considered unacceptable, while inequalities due to responsibility characteristics (e.g., wage difference due to a difference in the number of hours worked) may be acceptable.

Such a distinction between equality of opportunity as an ideal and equality of outcomes as an ideal is of interest to economists for at least four reasons. First, a society in which people are not discriminated against on the basis of race, ethnicity, religion, sex and sexual orientation is widely upheld as desirable in itself Arneson (2015). Second, we know from social and political debate, surveys Schokkaert and Devooght (2003) and economic experiments Cappelen et al. (2007) that most people have a conception of fairness similar to that adopted by the theory of equality of opportunity. That is, they consider some inequality of outcomes fair. Third, there is evidence showing that there may be a link between perceptions of fairness and individual attitudes towards redistribution which in turn affect actual levels of redistribution, and hence investment and output generated (Alesina and Angeletos, 2005; Bénabou and Tirole, 2006). Finally, as argued by The World Bank (2005), equality of opportunity can be 
instrumental for economic growth. Thus, equality of opportunity has normative and practical significance. And as in the case of inequality measurement, the primary motivation for the measurement of equality of opportunity is to guide policy. As also in the case of inequality measurement, we must first be able to measure equality of opportunity in order to make empirical use of the concept. As such, the measures provided in this chapter are of interest to policymakers as well as empirical researchers.

The fifth chapter, "Fair sharing of an international river", contributes to the debate on sharing water from international rivers. Proposed here is a methodology to compare international river water allocations in terms of fairness and efficiency.

Water resources are called international if they are shared by several countries. Examples include rivers and lakes that border two or more countries and rivers that flow from one country into another. In all these cases, one country's use of the shared water resource affects the quantity or quality available to another country (Barrett, 1994).

The problem of river water sharing is of considerable practical importance given the fact that 148 rivers in the world flow through two countries, 30 through three, 9 through four, and 13 through five or more (Barrett, 1994).

Sharing water from international rivers has often been a source of conflict between riparian countries mostly because property rights over rivers are not well defined. Examples of disputes listed by Kilgour and Dinar (1995, p. 1) include the proposal for out-of-basin diversion of the Mekong River (Thailand and Laos); the operation of the Farraka Barrage diversion of the Ganges (India and Bangladesh); the proposed desalination plant near Morales Dam on the Colorado River (Mexico and U.S.A.); and the dispute over the 1959 Nile water agreement (Egypt, Sudan, and now Ethiopia). Several international principles of international law were proposed to solve this problem. We focus on three principles that attracted most attention from policymakers and researchers: absolute territorial sovereignty, unlimited territorial integrity and territorial integration of all basin states. Even though these principles are intuitive, they are difficult to formulate in applications. Moreover, there is an ongoing debate on which one 
to use in practical applications. It is these two questions that this chapter tackles. First, we propose a way to formalize the principles. Second, we argue that territorial integration of all basin states must be chosen over absolute territorial sovereignty and unlimited territorial integrity. Taking territorial integration of all basin states as the primary criterion of distributive justice, we propose a ranking that could be used to assess distributions of water among riparian countries. Furthermore, the ranking proposed in the chapter can easily be used to propose an implementable scheme for the allocation of water from a given river. The target audience of this chapter, in addition to the scientific community, is therefore, again, policymakers.

\section{Future directions}

All chapters of this dissertation are prepared for publication in international academic journals. In this section, we briefly discuss theoretical and applied research that the chapters of this thesis can lead to.

For each chapter, the context within which the model is defined can be changed into more realistic (and hence, complicated) contexts. For instance, in case of chapter two, a possible extension would be to propose envy measures in a production model where individuals possess unequal productive skills in addition to unequal preferences. Or one can modify our measures so as to compare envy in societies with different population sizes, which is a particularly necessary practice if one wishes to compare inequality levels between two countries. With regard to applications, one needs information on individual preferences in order to use our envy measures in applications. These could be derived from surveys. Once one has information on preferences, our measures are very easy to apply since they require the use of simple functions applied to pairwise comparisons of individual bundles.

In case of chapter four, a natural first extension of this paper would be to study the empirical applications of our measures. The classes of welfare functions and inequality measures presented in the chapter are large in the sense that many possibilities are available for use in empirical research. For instance, 
one could apply our measures to see to what extent the tax system in a country, or a region, equalizes opportunities for income acquisition. Some examples of questions to ask are "Does socio-economic status of one's parents affect one's chances in life?", "How about gender, race, sexual orientation?" or, on a more international level, "How should international aid be distributed based on country characteristics?" Our measures are readily applicable to such questions. A particular advantage our measures possess is that they allow for different ideological positions as to how exercise of responsibility is rewarded.

Chapter four considers comparisons of income distributions with a fixed set of circumstance and responsibility characteristics. A second natural extension would be to develop measures for comparisons of income distributions with different profiles of individual characteristics.

A third possible extension would be to focus on multidimensional inequality of opportunity. As discussed above, there are good reasons to do so. For instance, in the question of distributing international aid, international organisations might be willing to provide in-kind transfers such as medication, medical equipments and housing along with monetary transfers. One needs multidimensional measures of equality of opportunity to determine the fair distribution of aid in this case.

In case of chapter five, a first natural extension would be to develop rankings that allow for different property rights over the river in question. Technically, that could be achieved by relaxing the anonymity assumption in the chapter. As for applications, our rankings are easily applicable provided that one has information over countries' preferences over water consumption. 


\section{ShORT CURRICULUM VitAE}

Z. Emel Öztürk was born on May 27, 1986 in Ortaköy, Çorum, Turkey. In 2008, she obtained a BSc degree in Mathematics and Economics from Istanbul Bilgi University and the University of London (International Programmes). In 2011, she obtained a MA degree in Economics from Bilkent University, under the supervision of Semih Koray.

Thereafter, in 2011, Emel started her doctoral studies at Maastricht University Department of Economics, under the supervision of Jean-Jacques Herings and Kristof Bosmans. The results of her research during her $\mathrm{PhD}$ studies are presented in this dissertation. 
